RUMINAL DEGRADATION OF PROTEIN AND CARBOHYDRATE USING A BATCH CULTURE SYSTEM, AND RESPONSE TO ROUGHAGE

REMOVAL, RUMEN MODIFIER INCLUSION AND

POSTRUMINAL AMINO ACID SUPPLY

IN FEEDLOT CATTLE.

A Dissertation presented to the Faculty of the Graduate School

University of Missouri-Columbia

In Partial Fulfillment

of the Requirements of the Degree

Doctorate of Philosophy

by

MARIANA MEDEIROS MASIERO

Dr. Monty S. Kerley, Dissertation Supervisor

December 2017 
The undersigned, appointed by the Dean of the Graduate School, have examined the dissertation entitled

\section{RUMINAL DEGRADATION OF PROTEIN AND CARBOHYDRATE USING A BATCH CULTURE SYSTEM, AND RESPONSE TO ROUGHAGE REMOVAL, RUMEN MODIFIER INCLUSION AND POSTRUMINAL AMINO ACID SUPPLY IN FEEDLOT CATTLE}

Presented by Mariana Medeiros Masiero

A candidate for the degree of Doctorate of Philosophy And hereby certify that in their opinion it is worthy of acceptance

\begin{tabular}{c}
\hline Dr. Monty S. Kerley \\
\hline Dr. Allison M. Meyer \\
\hline
\end{tabular}

Dr. Bryon R. Wiegand

Dr. Harley D. Naumann 


\section{DEDICATION}

To my parents Tânia Mara M. Masiero and Paulo José Masiero, my sister Ana

Paula M. Masiero and brother Matheus M. Masiero,

who I truly love and admire,

supported me my entire life,

and I know are very proud of what I have accomplished 


\section{ACKNOWLEDGEMENTS}

I would like to thank my advisor, Dr. Monty S. Kerley for giving me the opportunity to pursue my Doctorate degree at the University of Missouri, and also for his support, teaching, guidance and patience throughout the years.

I also would like to thank my thesis committee, Dr. Meyer, Dr. Wiegand and Dr. Naumann for their guidance, advice, and support.

Special thank you to my fellow graduate students I have had the privilege to work with. Blake McDonald, Cooper Martin, Jacquelyn Prestegard, Nicholas Minton, Dexter Tomczak, Nicholas Mertz, Dylan Hamlin, Katlyn Niederecker, Jill Larson and Robson Barducci, Natalie Duncan and Emma Stephenson, thank you for helping and being very good friends.

A very special thank you to Dr Kenny, my good friend Ann, for her assistance in the laboratory and anything else I needed. I also would like to give thanks to Dr. Kim for his guidance and assistance in the laboratory. Additionally, I will always be appreciative for the support, time and efforts from Kenneth Ladyman and beef farm staff. A special thank is extended to Mary Smith, Kathy Craighead and Gloria Johnson, your help was much appreciated.

I would like to thank all ASRC faculty, staff and graduate students who made University of Missouri a very special place to work.

A special thank you to Dr. Ledoux and George Rottinghaus for supporting the Brazilian students and making us part of their families on special holydays and barbecues. 
Great friends made my life easier and wonderful in Columbia. I would like to thank, all the Brazilians for being my family in USA.

Special thank you to Dr. Hosotani, for being by my side on this journey. Gui, you made everything easier and special.

Finally, I would like to thank my family, particularly my parents Tânia and Paulo, my sister Ana Paula, and my brother Matheus for their love, care, and support throughout my life. 


\section{TABLE OF CONTENTS}

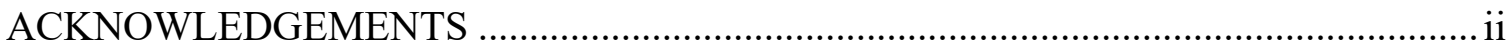

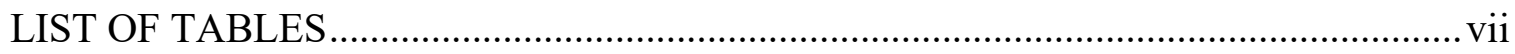

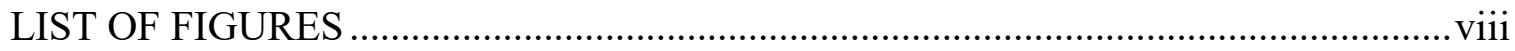

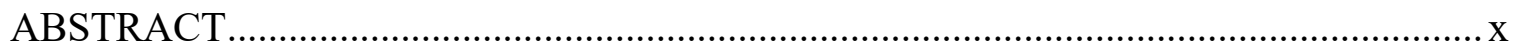

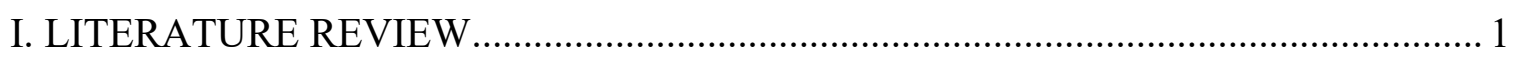

FACTORS AFFECTING RUMINAL FERMENTATION ............................. 1

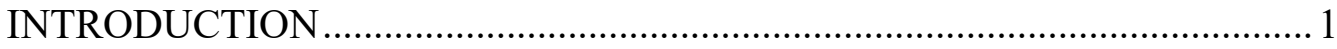

Gas production in the rumen ......................................................... 2

Animal........................................................................................... 4

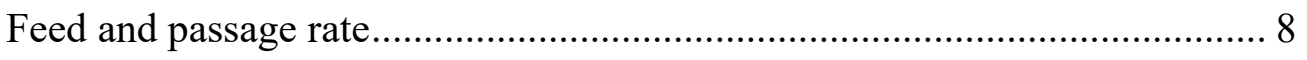

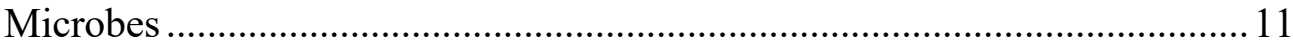

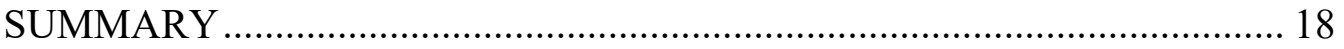

II. RUMINAL NITROGEN, STARCH AND NEUTRAL DETERGENT FIBER

DEGRADATION CHARACTERISTICS USING A BATCH CULTURE SYSTEM.....19

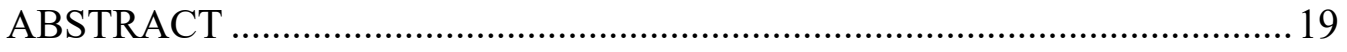

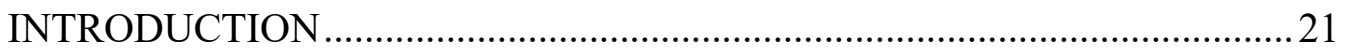

MATERIAL AND METHODS ......................................................... 22

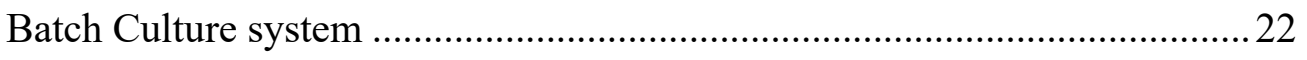




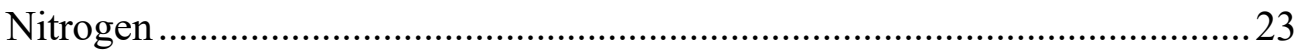

Starch

Neutral Detergent Fiber.............................................................................2 26

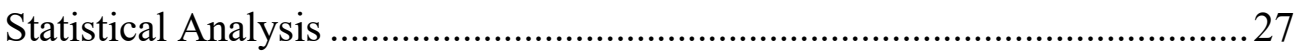

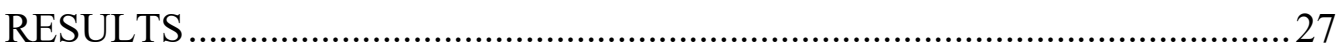

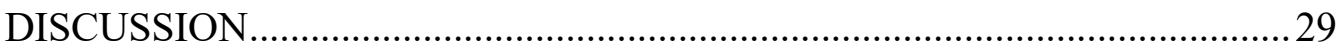

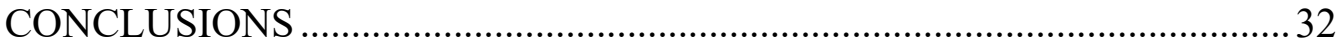

III. EFFECTS OF ROUGHAGE REMOVAL, RUMINAL MODIFIER INCLUSION AND POST-RUMINAL AMINO ACID SUPPLY ON GROWTH PERFORMANCE AND CARCASS CHARACTERISTICS IN BEEF STEERS ……………………….......44

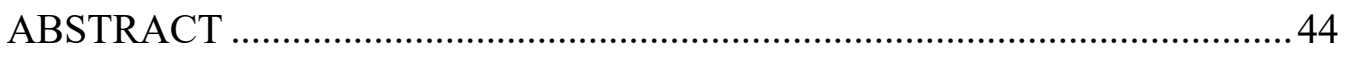

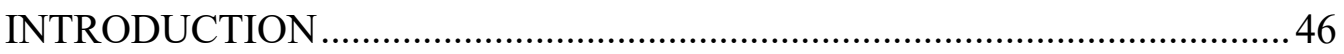

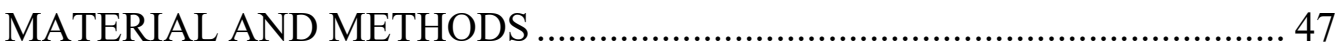

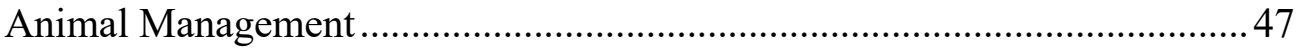

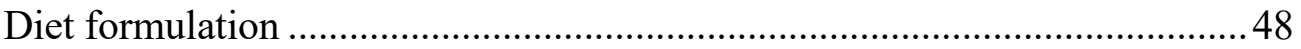

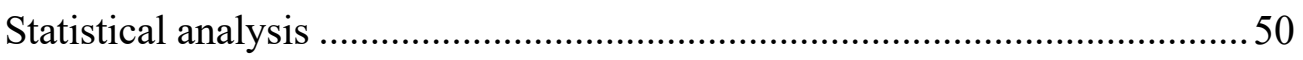

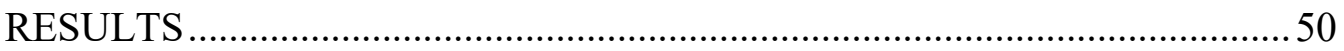

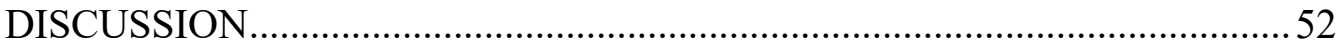

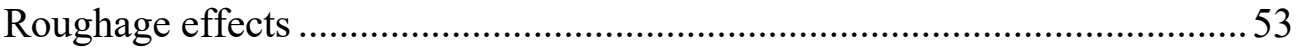

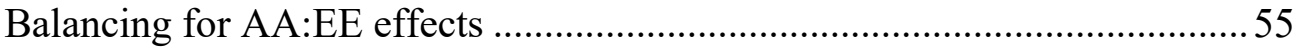


Roughage X ruminal modifiers effects ..................................................5

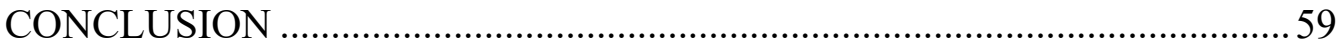

IV. . EFFECT OF ROUGHAGE REMOVAL AND RUMINAL MODIFIERS ON

RUMINAL FERMENTATION IN BEEF STEERS .................................................64

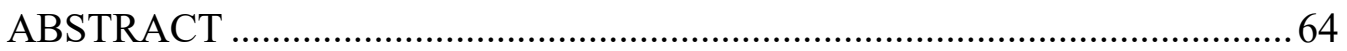

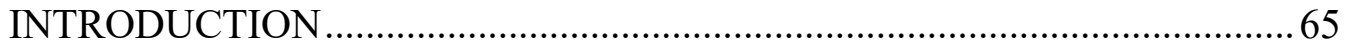

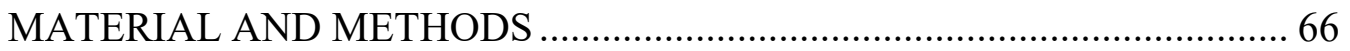

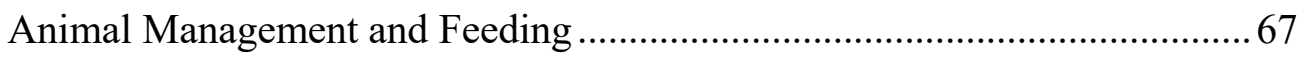

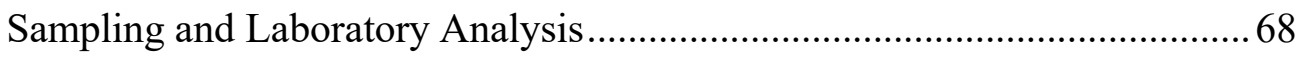

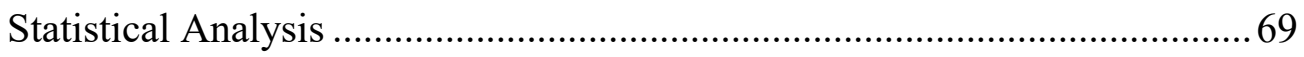

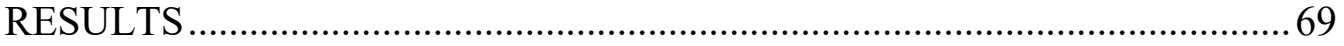

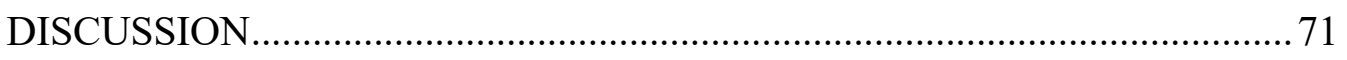

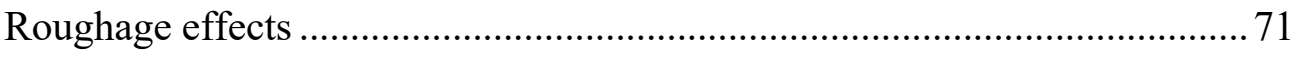

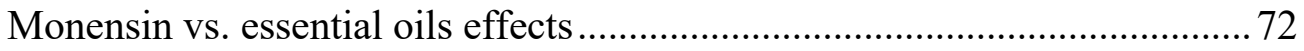

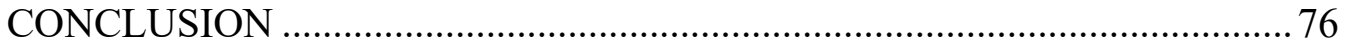

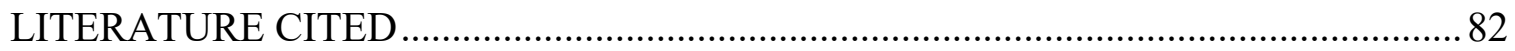

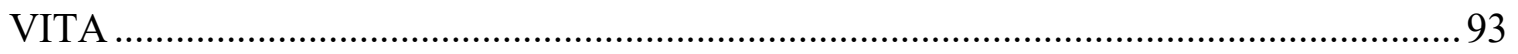




\section{LIST OF TABLES}

Table

2.1. Nutrient analysis of feedstuff used on batch culture experiments.

33

2.2. Ruminal degradable, undegradable and extent of digestion of starch using a batch culture system. 34

2.3. Ruminal degradable, undegradable and extent of digestion of nitrogen measured using a batch culture system. 37

2.4. Ruminal degradable, undegradable and extent of digestion of NDF using a batch culture system.

2.5. Degradation rate percent of variance source from different feedstuff using a batch culture system.

3.1. Dietary ingredients and composition for receiving and transitioning diets. 60

3.2. Dietary ingredient composition and nutrient analysis of treatments.

3.3. Effects of roughage removal, ruminal modifier inclusion and post ruminal amino acid supply on growth performance and feed efficiency during period one

3.4. Effects of roughage removal, ruminal modifier inclusion and post ruminal amino acid supply on carcass characteristics.

4.1. Dietary ingredient composition and nutrient analysis 77

4.2. Effect of roughage removal and ruminal modifier inclusion on daily intake..... 78

4.3. Effect of roughage removal and ruminal modifier inclusion on daily ruminal fermentation. .79 


\section{LIST OF FIGURES}

Figure

2.1. Starch ruminal degradation assuming $4 \% \cdot \mathrm{h}^{-1} \mathrm{Kp}$ using a batch culture system........35

2.2. Starch ruminal degradation rate using a batch culture system. ............................... 36

2.3. Nitrogen ruminal degradation assuming $4 \% \cdot \mathrm{h}^{-1} \mathrm{Kp}$ using a batch culture system.... 38

2.4. Nitrogen ruminal degradation rate using a batch culture system. ............................ 39

2.5. NDF ruminal degradation assuming $4 \% \cdot \mathrm{h}^{-1} \mathrm{Kp}$ using a batch culture system. ........ 41

2.6. NDF ruminal degradation assuming $4 \% \cdot \mathrm{h}^{-1} \mathrm{Kp}$ using a batch culture system. ........ 42

4.1. Effect of roughage removal and ruminal modifier inclusion on ruminal $\mathrm{pH}$ after

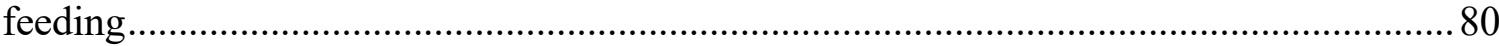

4.2. Effect of roughage removal and ruminal modifier inclusion on ruminal ammonia $\mathrm{N}$

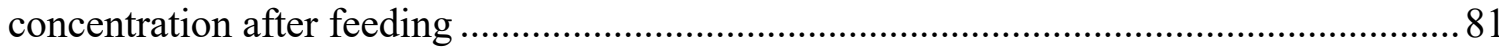




\title{
RUMINAL DEGRADATION OF PROTEIN AND CARBOHYDRATE USING A BATCH CULTURE SYSTEM, AND RESPONSES TO ROUGHAGE REMOVAL, RUMEN MODIFIERS INCLUSION AND POSTRUMINAL AMINO ACID SUPPLY IN FEEDLOT CATTLE.
}

\author{
Mariana Medeiros Masiero
}

Dr. Monty S. Kerley, Dissertation Supervisor

\begin{abstract}
Three main studies were conducted to characterize protein and carbohydrate ruminal degradation using a batch culture system, demonstrate and responses to roughage removal, rumen modifiers inclusion and postruminal amino acid supply in feedlot cattle. The objective of the first study was to characterize rumen N, starch, and NDF degradation rate $\left(k_{d}\right)$, and further calculate ruminal degradable, undegradable and extent of digestion of those nutrients using a batch culture system. Nitrogen $k_{d}$ experiments (48h incubation) used soybean meal (SBM), AminoPlus (AP, Ag Processing Inc, Omaha, $\mathrm{NE}$ ), corn dry distiller's grain solubles (DDGS), porcine blood meal (BM), cottonseed meal (CSM) and fish meal (FM), and ammonia release was used as an indicator of $\mathrm{N}$ degradation. Starch experiments (72-h incubation) used ground corn (GC), steam flaked
\end{abstract}


corn (SFC), barley grain (BG) and wheat middlings (WM), and $k_{d}$ was determined by DM disappearance and starch analysis. Neutral detergent fiber experiments (72-h incubation) used alfalfa fresh (AF), alfalfa hay (AH), tall fescue fresh (FF) tall fescue hay (FH) and soybean hulls (SH), and $k_{d}$ was determined by DM disappearance and NDF analysis. Ruminal degradable protein decreased and undegradable protein increased between SBM, AP, FM, CSM, DDGS and BM for each respective feed $(P<0.01)$. AminoPlus and SBM did not differ $(P=0.27)$ on extent of digestion. Linear response contrasts were different $(P<0.05)$ among all feeds except between CSM compared to AP and FM, and BM compared to DDGS. Ruminal degradable starch was greater, and undegradable was lesser, for BG and WM compared to GC, and SFC did not differ from other feeds $(P=0.055)$. Quadratic response contrasts were different among all feeds $(P<$ $0.01)$ except for GC compared to SFC and WM compared to BG $(P>0.05)$. Ruminal degradable NDF was greater, and undegradable was lesser, for AF, FF and SH compared to $\mathrm{AH}$ and $\mathrm{FH}(P<0.01)$. Quadratic response contrasts were different among all feeds $(P$ $<0.05)$ except for AH compared to $\mathrm{AF}$ and $\mathrm{FH}$, and $\mathrm{AF}$ compared to $\mathrm{FH}(P>0.05)$. Variance was mostly due to hour differences $(93.3,99.6$ and $89.2 \%$ for N, starch and NDF, respectively). In conclusion, this study provides estimates of protein and carbohydrate ruminal degradation of feedstuff for use in diet formulation models. Ruminal degradation results observed in this study agree with published data and have been proved to be reproducible, resulting in a viable, and less complex method, to determine ruminal digestion characteristics of feedstuff. The objective of the second study was to determine the effects of roughage removal, ruminal modifiers, and diets balanced to meet effective energy and predicted AA requirement on beef steer growth 
performance. Crossbred steers $(\mathrm{n}=150 ; 284 \pm 23 \mathrm{~kg} \mathrm{BW})$ were fed 5 diets. Four diets were balanced to meet effective energy and predicted AA requirement with a traditional feedlot diet used as Control. Two diets contained roughage, with monensin (R-MO) or essential oils (R-EO). Two diets replaced roughage with corn; no-roughage with monensin (NR-MO) or essential oil (NR-EO). Steers fed roughage diets had greater BW $(P<0.01)$ compared to no-roughage, and final BW was greater $(P=0.004)$ for R-MO than Control. Average daily gain was greater $(P<0.01)$ for steers fed roughage diets compared to no-roughage. Steers fed balanced diet $(\mathrm{R}-\mathrm{MO})$ had greater ADG $(P<0.01)$ than Control. Dry matter intake was greater $(P<0.01)$ for steers fed roughage compared to no-roughage diets. Steers fed R-MO had greater ADG $(P=0.03)$ than Control. Steers fed no-roughage diets were more feed efficient $(P<0.01)$ compared to roughage diets. Hot carcass weight and marbling score were greater $(P<0.01)$ for steers fed roughage compared to no-roughage, and $\mathrm{HCW}$ was greater $(P=0.017)$ for R-MO than Control. Ribeye area was greater $(P=0.02)$ for steers fed R-EO and other treatments did not differ among each other. Steers fed R-MO had lesser ribeye area $\cdot \mathrm{cwt}^{-1}$ compared to all other diets $(P<0.05)$. Steers fed R-MO had greater yield grade $(P=0.03)$ compared to all other diets. In conclusion, roughage removal improved feed efficiency but gain and carcass weight were not optimized. Balancing diets to meet effective energy and predicted AA requirement increased ADG for overall period, and increased carcass weight. Overall steers performance was not affected by ruminal modifiers, monensin or essential oils. The objective of the third study was to determine the effect of roughage removal and ruminal modifiers on ruminal fermentation characteristics in beef steers fed no-roughage diets. Three steers (initial BW $977 \pm 24.5 \mathrm{~kg}$ ) were used in a $3 \times 3$ Latin 
square. Roughage diet was formulated to meet effective energy and predicted absorbable AA requirement with monensin (R-MO) to achieve an ADG $1.82 \mathrm{~kg} \cdot \mathrm{d}^{-1}$ for growing steers (BW $272 \mathrm{~kg}$ ). No-roughage diets had fescue hay replaced with whole corn. Some ingredient levels in No-roughage diets were adjusted to meet nutrient requirements, and contained monensin (NR-MO) or essential oils (NR-EO). Dry matter intake was controlled at 1.87, 1.48, and 1.52\% BW for R-MO, NR-MO and NR-EO, respectively. Daily average ruminal $\mathrm{pH}$ (mean, minimum and maximum), ammonia $\mathrm{N}$ and VFA did not differ among diets. Ruminal $\mathrm{pH}$ was greater $(P<0.04)$ for R-MO and lesser for NR$\mathrm{MO}$ in the initial hours after feeding and did not differ among diets between 8 and $10 \mathrm{~h}$ $(P>0.05)$. Average hourly $\mathrm{pH}$ across diets ranged from 6.37 to 5.74 . Ammonia $\mathrm{N}$ was greater for NR-MO and NR-EO than R-MO during 2 and $10 \mathrm{~h}$ after feeding. In conclusion, roughage removal and replacement of monensin by essential oils had no effect on VFA profile, daily average ammonia $\mathrm{N}$ concentration and $\mathrm{pH}$ (daily average, minimum and maximum). 


\section{CHAPTER I}

\section{LITERATURE REVIEW}

\section{FACTORS AFFECTING RUMINAL FERMENTATION}

\section{INTRODUCTION}

Ruminant animals culture a diverse and complex microbial population in the rumen with members of 3 domains of life, Eubacteria (bacteria), Archaea (methanogens), and Eukarya (protozoa and fungi). The host maintains these microbes by supplying substrate, by adding buffers and removing products of fermentation such as acids and gases, by flushing out microbial products and indigested feed residues and by maintaining conditions such as $\mathrm{pH}$, temperature, and moisture appropriate to microbial survival and growth (Nagaraja, 2012). When feeds are degraded by microbes in the rumen anaerobic environment, it results in the production of not completely oxidized products such as VFA, carbon dioxide, methane, microbial cells, and lesser amounts of ethanol, lactate and succinate because they are used by other microorganisms as substrates (Russell, 2002). Gas production kinetics can be affected by intervention at 3 levels: animal, feed and microbial. These 3 levels are not independent thus animal, feed and microbial interactions are important in rumen fermentation. Different populations of rumen microbes may use several different metabolic pathways for digestion (Van Soest, 
1994). Variation in these pathways will result in variations in VFA profile produced leading to variation in gas production.

\section{Gas production in the rumen}

Rumen microbes ferment feed consumed by the host to obtain energy for maintenance and growth. This energy is mainly derived from the fermentation of carbohydrate, particularly starch and cell walls, which are first broken down into hexoses and pentoses, from which the main end-products are acetate, propionate and butyrate (VFA), $\mathrm{CO}_{2}$ and $\mathrm{CH} 4$ (Wolin, 1975), but which can also supply essential carbon skeletons for the synthesis of microbial biomass (Beever, 1993). During microbial fermentation in the rumen, approximately 75 to $85 \%$ of feed energy is converted to VFAs with the remaining lost as heat and gases (Sutton, 1979). Carbon dioxide and methane are the principal gases produced in the rumen accounting for about $65 \%$ and $27 \%$ respectively. Another gaseous end-product of fermentation is $\mathrm{H}_{2}$ which only occurs at about $0.2 \%$ since the methanogens use it to reduce $\mathrm{CO}_{2}$ to methane. Nitrogen comprises about $7 \%$ of the gas profile with traces of $\mathrm{H}_{2} \mathrm{~S}$ and $\mathrm{CO}$ and low transit quantities of $\mathrm{O}_{2}$ (Dehority, 2003). Based on in vitro studies the stochiometric reactions of fermentation of cell-wall hexoses were described by Hungate (1966).

$$
\begin{array}{ll}
1 \text { mol Hexose }+2 \mathrm{H}_{2} \mathrm{O} & \rightarrow 2 \text { Acetate }+2 \mathrm{CO}_{2}+4 \mathrm{H}_{2} \\
1 \text { mol Hexose }+2 \mathrm{H}_{2} & \rightarrow 2 \text { Propionate }+2 \mathrm{H}_{2} \mathrm{O} \\
1 \text { mol Hexose } & \rightarrow 1 \text { Butyrate }+2 \mathrm{CO}_{2}+2 \mathrm{H}_{2} \\
\mathrm{CO}_{2}+4 \mathrm{H}_{2} & \rightarrow \mathrm{CH}_{4}+2 \mathrm{H}_{2} \mathrm{O}
\end{array}
$$


The only VFA that requires the uptake of $\mathrm{H}_{2}$ is propionic acid (Van Soest, 1994). Remaining $\mathrm{H}_{2}$ produced in the rumen is usually converted to methane by methanogens. The production of propionic acid differs from other VFA because it does not involve the generation of $\mathrm{CO}_{2}$. Hence, the comparison of gas production among feeds should also consider VFA production more specifically acetate:propionate ratio (Stefanon et al., 1996; Groot et al., 1998). The Embden-Meyerhof-Parnas pathway is the most used by ruminal microbes to oxidize sugars to pyruvate. High energy compounds such as ATP and NADH are formed in this process. The following equation represents the oxidation of one molecule of glucose (Miller, 1994; Russell and Wallace, 1997):

$$
\text { Glucose }+2 \mathrm{NAD}^{+}+2 \mathrm{ADP}+2 \mathrm{Pi} \rightarrow 2 \text { Pyruvate }+2 \mathrm{NADH}+2 \mathrm{H}^{+}+2 \mathrm{ATP}+2 \mathrm{H}_{2} \mathrm{O}
$$

Pyruvate is further broken down in the Krebs cycle resulting in an additional ATP molecule and 5 redox equivalents including $\mathrm{NADH}$ and $\mathrm{FADH}_{2}$. Since anaerobic organisms lack a respiration chain, pyruvate acts as an electron sink, being further reduced to provide the regeneration of $\mathrm{NAD}^{+}$and other cofactors, as well as the general removal of excess electrons, thereby yielding ATP. The oxidation of one molecule of glucose results in a net gain of 2 ATP in anaerobic fermentation compared to 30 ATP molecules in aerobic respiration (McDonald et al., 2010). Adenosine triphosphate is also generated ( 3 molecules) when lactate is metabolized to acetate and propionate. Every 3 molecules of lactate on average will produce 2 molecules of propionate and one molecule of acetate (Piveteau, 1999). The oxidation of NADH to $\mathrm{NAD}^{+}$results in significant amounts of $\mathrm{H}^{+}$and electrons. Methane production is the main sink of $\mathrm{H}_{2}$ and methanogens use $\mathrm{H}_{2}$ for growth, leading to methane production and removal of $\mathrm{H}_{2}$ from 
the rumen environment (Ellis et al., 2008). Increases in propionate production are likely associated with a decrease in methane production because propionate formation serves as an electron acceptor. Acetate and butyrate production are associated with increases in methane production duet to the net formation of $\mathrm{H}_{2}$. In the rumen, there are other reducing equivalent processes such as sulfate and nitrate reduction, biohydrogenation of unsaturated fatty acids and synthesis of microbial cells (National Academies of Sciences and Medicine, 2016). Volatile fatty acids are the main energy source for ruminants and it can provide approximately 60 to $75 \%$ of total energy requirement (Sutton, 1979). Since microbes utilize most of the glucose from the feed and generates VFA, gluconeogenesis is relatively more important in ruminants than other species. Propionate is the only VFA that makes a net contribution to glucose synthesis, about 27 to $54 \%$ of the glucose in the ruminant is formed from propionate (Lindsay, 1970). After absorption, 80 to $90 \%$ of propionate is converted to phosphoenolpyruvate via methylmalonyl-CoA, succinate and oxaloacetate in the liver (Fahey and Berger, 1988; Kristensen and Harmon, 2004). Most of the acetate absorbed from the rumen reaches the liver unchanged, and a small amount is converted to ketone bodies. Butyrate, different than other VFAs, is extensively metabolized by the rumen epithelium, and the rest is oxidized for energy production. (National Academies of Sciences and Medicine, 2016).

\section{Animal}

\section{Salivation}

Saliva has important roles in digestive function when added to feed during mastication and rumination. Among its functions include, lubricates feed which facilitates passage though the gastrointestinal tract, buffers VFA production and provides water and 
nutrients such as recycled nitrogen to microbial fermentation (Church, 1988). Saliva is mainly composed of bicarbonate (113 to $125 \mathrm{meq} / \mathrm{L}$ ), sodium (161 to $166 \mathrm{meq} / \mathrm{L}$ ), postassium (6 to $4 \mathrm{meq} / \mathrm{L}$ ), phosphate (6 to $180 \mathrm{meq} / \mathrm{L}$ ) and other inorganic compounds (Bailey and Balch, 1961; Cook et al., 1995), with a DM content of 1.0 to $1.4 \mathrm{~g} / 100 \mathrm{~mL}$ (McDougall, 1948) and pH of 8.3 to 8.5 (Bailey and Balch, 1961). Saliva secretion rate is greater during eating and rumination, 2 to 4 times compared to resting (resting rate: 30 to $70 \mathrm{~mL} / \mathrm{min}$ ) in beef cattle (Bailey and Balch, 1961; Yarns et al., 1965) and 1.3 to 2 times greater (resting rate: 70 to $151 \mathrm{~mL} / \mathrm{min}$ ) in dairy cattle (Cassida and Stokes, 1986; Maekawa et al., 2002). Saliva production is affected by the amount, as well as chemical and physical composition of feed consumed. When forage is consumed, about 3.40 to 7.23- $\mathrm{mL}$ of saliva is produced per gram of $\mathrm{DM}$, in contrast to 0.76 to $1.12-\mathrm{mL}$ when consuming concentrate-based diets (Bailey and Balch, 1961; Beauchemin et al., 2008). Within forages, there is about threefold difference when comparing silage and hay, and twofold difference when comparing hay and straw, but both differences are minor when forages were equalized in DM and NDF content (Bailey and Balch, 1961; Beauchemin et al., 2008). This difference of saliva production reported is due to rumination and eating time duration. Cows fed concentrate consume feed about 3 to 12 times faster than foragebased diets depending on the forage source (Beauchemin et al., 2008).

\section{Rumination}

Rumination is defined as the regurgitation, salivation, remastication and reswallowing of rumen ingesta (Ruckebusch, 1988). This process allows ruminants to consume feed quickly when available and later regurgitate and remasticate the feed, which decreases particle size providing more surface area necessary for microbial 
digestion and passage from the rumen. Particle size and cell wall content of the diet are the major factors influencing rumination on number of periods, duration and total time each day (National Academies of Sciences and Medicine, 2016). These periods can last from $30 \mathrm{~s}$ to more than 2-h, with 10 to 20 periods each day, to a maximum of about 8 to 9h/d for forage-fed cattle (Welch, 1982). Rumination is decreased when fed concentrate and finely ground forages, but is present even in feedlot cattle fed grain based diet. Mature cattle fed all concentrate diets ruminated for 2 to $2.5 \mathrm{~h} / \mathrm{d}$ when fed whole wheat or whole barley grain, and when fed whole corn grain, rumination last for $1.25 \mathrm{~h} / \mathrm{d}$ (Beauchemin et al., 1994). Particle size reduction occurs 15 to 55\% during eating (Beauchemin, 1991) and the rest occurs by rumination and microbial digestion. The contribution to the decrease in particle size is mainly due to rumination while microbial digestion contributes to less than 20\% (McLeod and Minson, 1988).

\section{Rumen environment}

The ruminal environment is described as anaerobic, temperatures closely regulated around $39^{\circ} \mathrm{C}, \mathrm{pH}$ between 5.8 and 6.8 , oxidation-reduction potential of -250 to $450 \mathrm{mv}$ and osmolality ranging from 280 to 300 mOsm (Van Soest, 1994; Marden et al., 2005; Kahn, 2010). Products of rumen fermentation such as acetate, propionate, lactate, and methane, are strongly affected by ruminal $\mathrm{pH}$, caused mainly by the effect of $\mathrm{pH}$ on the microbes (Lana et al., 1998). Fungi and ciliated protozoa are the most sensitive to $\mathrm{pH}$ changes among microbes and bacteria involved in fiber degradation, lactate utilization, and methane production are more susceptible to $\mathrm{pH}$ variation among bacteria (Nagaraja, 2012). Ruminal $\mathrm{pH}$ decreases after feeding, and later increases reaching values similar to before feeding due to VFA absorption, saliva and feed passage out of the rumen. The $\mathrm{pH}$ 
maximum, minimum and mainly duration of optimal $\mathrm{pH}$ will determine microbial population and activity (Nagaraja, 2012). Cerrato-Sanchez et al. (2008) reported no changes in digestibility values and concentrations of VFA and ammonia when $\mathrm{pH}$ was maintained at 5.6 for 4-h or fluctuated between $5.1(2 \mathrm{~h} / \mathrm{d})$ and $7.1(2 \mathrm{~h} / \mathrm{d})$, however NDF digestibility, total VFA production and acetate:propionate ratio were decreased when $\mathrm{pH}$ was maintained at 5.1 for 4 -h. In order to determine the effects of $\mathrm{pH}$ (4.9 to 7.0) on rumen fermentation using continuous culture system Calsamiglia et al. (2008) varied forage to concentrate ratio (60:40 vs. 10:90). Data demonstrated that OM and NDF digestibility, acetate and butyrate concentration were major affected by $\mathrm{pH}$, while total VFA and propionate concentrations were affected by the combined effects of $\mathrm{pH}$ and diet. Effects of ruminal $\mathrm{pH}$ on fiber degradation have been extensively reported in the literature. Fibrolytic bacteria growth and activity are affected when $\mathrm{pH}$ is less than 6.0. When $\mathrm{pH}$ decreases below optimum, bacteria growth is inhibited because of inability to regulate intracellular $\mathrm{pH}$, which could possibly decrease the fibrolytic population if passage rate out of the rumen is maintained, leading to a decrease in fiber digestion (Nagaraja, 2012). Another possible reason is a reduced binding capacity of fibrolytic bacteria to feed particles at low ruminal pH (Mourino et al., 2001). Methanogens are also sensitive to decreases in pH. Van Kessel and Russell (1996) demonstrated based on in vitro incubations that ruminal methanogens are unable to take up $\mathrm{H}_{2}$ when $\mathrm{pH}$ is below 5.5. Methanogens are present in different parts of the rumen, attached to feed particles and rumen epithelium, associated to ciliated protozoa and free in the fluid. Methanogens account for only 1 to $4 \%$ of the total microbial population, however they represent a major pathway in $\mathrm{H}_{2}$ utilization referred to as inter species $\mathrm{H}_{2}$ transfer. The $\mathrm{H}_{2}$ transfer 
among microbial species is essential to maintain partial pressure of $\mathrm{H}_{2}$ optimum, and prevent disruption of microbial enzymes normal function involved in oxidation-reduction reactions. Protozoa have a specialized organelle called hydrogenosomes and single organism could cause methane production, by methanogens inside or outside the protozoa, up to $3 \mathrm{nmol} /$ day, hence the protozoa defaunation would reduce methane production (Nagaraja, 2012). Defaunation studies have been demonstrated to decrease butyrate concentrations, increase propionate, leading to decrease in methane production (Ushida and Jouany, 1996; Eugène et al., 2004).

\section{Feed and passage rate}

Rumen fermentation can be altered by changing physical and chemical feed composition. One approach is changing ingredients in the diet to alter VFA and gas production patterns. A second approach is to increase passage rate from the rumen, which can alter microbial population and result in changes in VFA and gas production patterns.

Substrates for microbial fermentation provided by feed ingredients, which differ in chemical and digestible composition, are able to change energy utilized by microbes changing VFA and gas production patterns. As previously described in this review, proportions of VFA affect gas production because the formation of acetate and butyrate generates $\mathrm{CO}_{2}$ and $\mathrm{H}_{2}$ while propionate formation consumes $\mathrm{H}_{2}$ and do not produce $\mathrm{CO}_{2}$ (Hungate, 1966). Therefore, when propionate production is stimulated by any change in dietary digestible and chemical composition, fermentation product pattern is altered.

Although changes in diet composition such as amount of rumen degradable protein, fatty acids, structural and non-structural carbohydrates can result in changes in gas production kinetics, passage rate is another crucial factor to be considered. Passage 
rate influences gas production kinetics due to length of time the substrate is present in the rumen, and determines site and extent of digestion. Slower digesta passage out of the rumen results in greater extent of rumen fermentation depending on the potential feed digestibility whereas faster passage means lower extent and increases in microbial energy requirements because cells have to multiply more frequently to maintain rumen population.

Passage rate of feed particles for most beef cattle diets varies from 2 to $6 \% / \mathrm{h}$ (National Academies of Sciences and Medicine, 2016). Ruminants fed forage-based diets have their contents stratified in distinct phases: a liquid phase, a floating mat formed by larger particles which are retained in the dorsal rumen, and a pool of small particles immersed within the fluid phase located ventral to the floating mat (Vieira et al., 2008). Several factors contribute to escaping probability of digesta from the rumen. The larger particles retained in the floating mat have less chance of leaving the rumen. With the decrease in particle size by rumination and microbial degradation, gases from fermentation are released, and feed particles sink to the ventral sac of the rumen, which with ruminal contractions are more likely to be close to the reticulorumen orifice and pass to the omasum (Faichney, 1986; Sutherland, 1987; Faichney, 1993).

As energy density increases in the diets, which means more non-structural carbohydrates relative to structural carbohydrates, less methane is produced (Moe and Tyrrell, 1979). When cattle were fed ad libitum, variation in dry matter intake (DMI) has been shown to account for 52 to $64 \%$ of the variation in methane production (Boadi and Wittenberg, 2002; Pinares-Patiño et al., 2007; Hammond et al., 2009). The relationship between gas production and DMI is not a constant positive correlation (Knapp et al., 
2014). As DMI increases, available feed to be fermented also increases, leading to greater gas production, however when DMI is above maintenance, gas production decreases when expressed in relation to DMI, due to decrease in rumen digestibility and increase in passage rate (Blaxter and Clapperton, 1965; Moe and Tyrrell, 1979; Pinares-Patiño et al., 2009). This decrease in rumen digestibility will have greater impact on energy supply to the animal if the diet is composed mostly of structural carbohydrates in comparison to non-structural carbohydrates. Site and extent of digestion is different between NDF and starch therefore decrease in rumen digestibility due to increase passage rate will negatively impact total-tract NDF digestibility but not for starch, which has potential to be digested in the small intestine (Firkins et al., 2001; Huhtanen et al., 2009).

Fermentation product profile is highly influenced by type of carbohydrate present in the diet (Sutton et al., 2003; Bannink et al., 2006). Forage-based diets are high in structural carbohydrate such as cellulose, intermediate in soluble sugars and low in starch. Hence, the most active bacteria are cellulolytic which extensively digest cellulose and saccharolytic which ferment soluble carbohydrate leading to higher acetate production (Moe and Tyrrell, 1979). In contrast, concentrate-based diets are rich in nonstructural carbohydrate leading to a large amylolitic bacteria population which results in large amounts of propionate (Johnson and Johnson, 1995). Tropical grasses usually have greater content of NDF, more lignification and produce more methane in relation to intake than temperate grasses, however tropical legumes are less digestible and produce less methane in relation to intake compared to temperate legumes possibly due to greater content of tannins in tropical legumes (Pinares-Patiño et al., 2009; Archimède et al., 2011). 
Altering forage quality by using different management practices such as harvesting or grazing less mature forages, selection of genetic strains or species that have superior digestibility, and proper storage might affect the proportion of non- structural carbohydrate to NDF as well as NDF lignification resulting in dietary nutrient utilization improvement (Moss et al., 1994; Boadi et al., 2004).

Feed processing alters rates of fermentation and passage due to reduced particle size and increased nutrient availability (i.e., starch gelatinization). Processing of forage and grains has different consequences in rumen fermentation. When forage is processed and particle size is reduced, rumen NDF digestibility as well as acetate:propionate ratio is reduced due to increased passage rate (Van Nevel and Demeyer, 1996; Moss et al., 2000). Grain processing is a practice that can increase extent of digestion in the rumen and decrease amount passing to the intestines. Degradation rates of protein and carbohydrates increase when grains are processed through pelleting, flaking and extruding leading to decrease in acetate :propionate ratio (Van Nevel and Demeyer, 1996; Zinn et al., 2002).

\section{Microbes}

Ruminal microbial fermentation process has protein and energy inefficiencies that limit feed utilization by the host and overall production performance. To improve fermentation efficiency and feed utilization, manipulation of the ruminal microbial ecosystem has been practiced for a long time with the feed supplementation of antibiotics. Due to the reduced social acceptance use of antibiotics in animal feed, new technologies have been developed and tested such as probiotics or direct-fed microbial, exogenous enzymes, plant extract or products, prebiotic oligosaccharides, and essential oils. 


\section{Ionophore antibiotics}

Ionophores are included in growing and finishing beef cattle to improve feed efficiency and animal health. The mechanism of action is to bind to cations and facilitate their movement across membranes, resulting in disruption in ionic gradients and a decrease in intracellular $\mathrm{pH}$, leading to proton expel and depletion of ATP (National Academies of Sciences and Medicine, 2016). Gram-positive bacteria are susceptible to ionophores, which causes a change in bacteria population. As a result, VFA profile is modified and studies have shown that propionate increases, whereas acetate and butyrate decrease (Bergen and Bates, 1984). Ionophores decrease methane production by affecting ciliated protozoa, however it seems to be transitory for about 4 to 6 weeks because protozoa eventually adapt (Guan et al., 2006). A significant improvement in feed energy utilization with less production of methane is supported by an increased molar proportions of propionate while acetate and butyrate decreased with no change in total VFA production as ionophore (monensin) dose increased (Ellis et al., 2012).

\section{Probiotics or direct-fed microbial}

The beneficial effects of probiotics occur by altering gut microflora composition and/or activity (Krehbiel et al., 2003). The different types of probiotics used in cattle are bacterial or fungal. The most common bacterial probiotics are Lactobacilli and Enterococci (lactic acid producing bacteria). Nocek et al. (2002) supplemented dairy cows with Enterococcus, particularly E. faecium, and observed a prevention on ruminal $\mathrm{pH}$ decline. Lactic acid producing probiotics are believed to produce a tonic concentration of lactic acid in the rumen, which stimulates and maintains an active population of lactic acid utilizers, leading to elevated $\mathrm{pH}$ (Nocek et al., 2002; Nocek and 
Kautz, 2006; Oetzel et al., 2007). The yeast Saccharomyces cerevisiae and the mold Arpergillus oryzae are the most common fungal cultures used as feed additives in ruminants diets. Fungal cultures have an affect primarily on ruminal fungi and bacteria, mainly fibrolytic bacteria and lactate utilizers (Martin and Nisbet, 1992; Callaway and Martin, 1997). Increase in fiber digestibility was observed when fungal cultures were supplemented as part of in vitro, in situ and in vivo studies (Chaucheyras-Durand et al., 2008). The increase in ruminal $\mathrm{pH}$ by increasing lactic acid utilization also could play a role in increasing fiber digestion (Nisbet and Martin, 1991)

\section{Essential oils}

Plant extracts have been used for their antimicrobial activities and are one of the alternatives to antibiotic use in animals (Tedeschi et al., 2011). Compounds such as saponins, tannins, lignins, flavonoids, and essential oils are important to the plant as protection against bacterial, fungi, insect, and vertebrate attacks. When provided in low doses in the feed, these compounds have the potential to alter ruminal fermentation and more recently, studies have demonstrated potential host mediated effects (Oh et al., 2017). Essential oils are steam volatile or organic solvent extracts with odor, fragrances, flavor, antiseptic and preservative properties which are known to possess antimicrobial properties. These compounds are produced by different parts of the plant such as roots, stems, leaves, flowers, and seeds (Hart et al., 2008) and are characterized in 2 chemical groups, terpenoids (monoterpenoids and sesquiterpenoids) and phenylpropanoids (Calsamiglia et al., 2007). Capsaicin, thymol, and carvacrol are examples of terpenoids and anethol, eugenol and cinnamaldehyde are part of the phenylpropanoids group (Calsamiglia et al., 2007). Essential oils can vary in their composition depending on 
extraction methods and plant characteristics (species, maturity, and part of the plant used (Okoh et al., 2010)). Twelve plant extracts were tested by Busquet et al. (2006) using in vitro fermentation and showed to have antimethanogenic effects, reduced ammonia concentration and some had negative effects on fermentation. Cardozo et al. (2006) tested garlic oil, cinnamaldehyde, eugenol, capsaicin, cervacol and anethol (from garlic, cinnamon, clove bud, hot pepper, oregano and anise respectively) and found improvement in fermentation using in vitro and in some cases in vivo studies.

Among essential oil molecules, different modes of action have been described, which reduced selectivity against specific ruminal microbial populations. The cyclic hydrocarbons of these molecules interact hydrophobically with the lipid bilayer of bacterial cell membranes, causing changes in conformation, leading to expansions and fluidification of membranes (Calsamiglia et al., 2007). Due to the decreased stability of membranes, ion leakage occurs, causing increased energy expenditure by the cell, slowing down bacterial growth or even cell death (Calsamiglia et al., 2007). This mode of action is one of the causes for ruminal fermentation profile changes, because changing the bacterial population proportions in the rumen, likely causes a change in fermentation product proportions as well. A second mechanism was described by Ultee et al. (2002), which similarly to ionophore antibiotics, ions are carried through membranes by hydroxyl groups of phenol. Both modes of actions are most likely to affect gram-positive bacteria. Gram-negative bacteria are known to be more resistant to lipophilic substances because of their hydrophilic external membrane, however, molecules with low molecular weight like some essential oils, can slowly diffuse through the cell wall, when interacted with 
water, and affect the internal lipid bilayer membrane (Griffin et al., 1999; Dorman and Deans, 2000).

Ammonia is produced in the rumen from AA deamination by a group of grampositive bacteria called hyper ammonia producing bacteria (Russell et al., 1991). Essential oils have been shown to impact deamination activity of some hyper ammonia producing bacteria such as Clostridium sticklandii, Clostridium aminophilum, and Prevotella ruminicola, which potentially increase AA and peptide flow to small intestine, which likely cause an increase isn $\mathrm{N}$ retention (Wallace et al., 2002).

The phenolic molecule, eugenol (4-allyl-2-methoxyphenol), an active compound found in clove, has a wide-spectrum antimicrobial activity against gram-positive and gram-negative bacteria. Eugenol has been shown to bind to proteins, inactivate enzymes and cause cell lysis (Calsamiglia et al., 2007; Benchaar and Greathead, 2011). In vitro studies using eugenol and clove bud oils demonstrated improved utilization of energy and protein in the rumen. Busquet et al. (2006) tested clove bud oil using a batch culture system and observed reduced VFA and ammonia $\mathrm{N}$ concentration, quadratic effects on acetate and butyrate proportion and linear increases in propionate proportions. Using a different system and lower doses of clove bud oils $\left(2.2 \mathrm{mg} \cdot \mathrm{L}^{-1}\right)$, Busquet et al. (2005b) reported lesser acetate and branched chain VFA proportions and greater propionate and peptide $\mathrm{N}$ greater proportions.

Another phenolic molecule with antimicrobial activity is cinnamaldehyde (3fenil-2-propenal phenol) found in cinnamon oil. Cinnamaldehyde was tested with diets containing 50:50 forage to concentrate and were used in 2 different in vitro systems (Busquet et al., 2005a; Busquet et al., 2006). When increasing levels of cinnamaldehyde 
were provided to a batch culture system for $24-\mathrm{h}$, high doses (300 to $\left.3,000 \mathrm{mg} \cdot \mathrm{L}^{-1}\right)$ decreased total VFA production, increased propionate without affecting acetate and butyrate proportions, and decreased ammonia $\mathrm{N}$ concentrations (Busquet et al., 2006). Two levels of cinnamaldehyde and monensin as well as a control without rumen modifiers were tested on longer incubations using dual flow continuous culture by Busquet et al. (2005a). Low inclusion of cinnamaldehyde $\left(31.2 \mathrm{mg} \cdot \mathrm{L}^{-1}\right)$ decreased acetate to propionate ratio whereas high inclusion $\left(312 \mathrm{mg} \cdot \mathrm{L}^{-1}\right)$ increased proportions of propionate and butyrate, and decreased acetate. Cinnamaldehyde was also tested using rumen fluid from cattle fed a high concentrate diet (10:90 forage to concentrate). When fermentation was maintained at $\mathrm{pH} 7$, cinnamaldehyde increased acetate:propionate ratio and decreased total VFA production, whereas at $\mathrm{pH} 5.5$, total VFA increased, and ammonia $\mathrm{N}$ as well as acetate:propionate ratio decreased (Cardozo et al., 2005). This suggests that essential oils effects are $\mathrm{pH}$ dependent, and cinnamaldehyde may have more relevant effects on feedlot cattle fed high concentrate diets. These changes in ruminal fermentation were hypothesized by Cardozo et al. (2005) as a combination of microbial population susceptibility and greater hydrophobicity of the essential oil active molecules caused by increased proportion of undissociated molecules due to the lower $\mathrm{pH}$.

Another essential oil that has been used as feed additive in ruminants is capsaicin (8-methyl-N-vanillyl-6-nonenamide), a carotenoid that belongs to the tetraterpenoid group and is found in hot peppers. Capsicum inclusion using a short term in vitro culture at $\mathrm{pH} 5.5$ resulted in favorable ruminal fermentation for feedlot cattle (Cardozo et al., 2005), reducing ammonia $\mathrm{N}$ concentration, acetate proportion and acetate:propionate ratio, and increasing total VFA production and propionate proportions. When cannulated 
animals were fed a high concentrate diet, $1 \mathrm{~g}$ of capsicum extract, containing $15 \%$ the active ingredient capsaicin, did not change VFA production, decreased acetate proportion and concentration of large peptides, while increasing small peptides and AA without affecting ammonia $\mathrm{N}$ (Cardozo et al., 2006).

Most research using essential oils on ruminants has focused on its effects on ruminal microbial and fermentation changes, however, a recent review has noted the potential host-mediated effects of essential oils in ruminants. In theory, feed additives must be protected from microbial degradation in order to reach the lower gastrointestinal tract, and have the same effect as in non-ruminants. However, even when not protected, considerable amounts may bypass microbial degradation, especially with fast ruminal passage rate(Oh et al., 2017). Mammalian transient receptor potential channels, expressed in several tissues such as immune cells, intestine, neurons and pancreas, can be activated by essential oils such as eugenol, capsaicin and cinnamaldehyde and lead to a physiological response (Vennekens et al., 2008; Holzer, 2011). In non-ruminants, essential oils can mediate pro- or anti-inflammatory responses by changing inflammatory cytokines, white blood cells, and oxidative stress (Zeng et al., 2015). When essential oils (garlic oil, Curcuma, and Capsicum) where infused into the abomasum of dairy cows, Thelper cells (from adaptive immunity) increased and no effects were observed on intestinal microbial population (Oh et al., 2013). Also using dairy cows, rumen protected Capsicum alleviated acute phase immune responses from LPS challenge and decreased insulin secretion during a glucose tolerance test (Oh et al., 2017). 


\section{SUMMARY}

The fermentation pattern is a major determinant of feed utilization by ruminants.

Animal, feed and microbial interventions that would alter salivation, rumination, ruminal $\mathrm{pH}$ passage rate and microbial population can affect fermentation pattern. These interventions are not independent, therefore, understanding each one, and their dynamic interactions is crucial in order optimize microbial fermentation outputs and further ruminant production. 


\title{
CHAPTER II
}

\section{RUMINAL NITROGEN, STARCH AND NEUTRAL DETERGENT FIBER DEGRADATION CHARACTERISTICS USING A BATCH CULTURE SYSTEM.}

\begin{abstract}
The objective of this study was to characterize rumen N, starch, and NDF degradation rate $\left(k_{d}\right)$, and further calculate ruminal degradable, undegradable and extent of digestion of those nutrients using a batch culture system. We hypothesized feed ingredients would have different ruminal $k_{d}$, results would agree with published literature that used different methods, and our method would have high reproducibility. Nitrogen $k_{d}$ experiments (48-h incubation) used soybean meal (SBM), AminoPlus (AP, Ag Processing Inc, Omaha, NE), corn dry distiller's grain solubles (DDGS), porcine blood meal (BM), cottonseed meal (CSM) and fish meal (FM), and ammonia release was used as an indicator of $\mathrm{N}$ degradation. Extent of $\mathrm{N}$ digestion was measured using separate batch culture (72-h incubation) and degradation was determined by DM disappearance and $\mathrm{N}$ analysis. Starch experiments (72-h incubation) used ground corn (GC), steam flaked corn (SFC), barley grain (BG) and wheat middlings (WM), and $k_{d}$ was determined by DM disappearance and starch analysis. Neutral detergent fiber experiments (72-h incubation) used alfalfa fresh (AF), alfalfa hay (AH), tall fescue fresh (FF) tall fescue hay
\end{abstract}


(FH) and soybean hulls (SH), and $k_{d}$ was determined by DM disappearance and NDF analysis. A polynomial second order regression was used to determine $k_{d}$, and ruminal degradable nutrients were calculated assuming a $4 \% \cdot \mathrm{h}^{-1}$ dilution rate. Ruminal degradable, undegradable and extent of digestion of N, starch and NDF were analyzed by ANOVA, with experiment as experimental unit. Experiment and feed $k_{d}$ reproducibility were analyzed by ANOVA, with flask as experimental unit. Degradation rates and response differences were contrasted for linear and quadratic components. Ruminal degradable protein decreased and undegradable protein increased between SBM, AP, FM, CSM, DDGS and BM for each respective feed $(P<0.01)$. AminoPlus and SBM did not differ $(P=0.27)$ on extent of digestion. Linear response contrasts were different $(P<$ 0.05) among all feeds except between CSM compared to AP and FM, and BM compared to DDGS. Ruminal degradable starch was greater, and undegradable was lesser, for BG and WM compared to GC, and SFC did not differ from other feeds $(P=0.055)$. Quadratic response contrasts were different among all feeds $(P<0.01)$ except for $\mathrm{GC}$ compared to SFC and WM compared to BG $(P>0.05)$. Ruminal degradable NDF was greater, and undegradable was lesser, for $\mathrm{AF}, \mathrm{FF}$ and $\mathrm{SH}$ compared to $\mathrm{AH}$ and $\mathrm{FH}(P<$ $0.01)$. Quadratic response contrasts were different among all feeds $(P<0.05)$ except for $\mathrm{AH}$ compared to $\mathrm{AF}$ and $\mathrm{FH}$, and $\mathrm{AF}$ compared to $\mathrm{FH}(P>0.05)$. Variance was mostly due to hour differences $(93.3,99.6$ and $89.2 \%$ for N, starch and NDF, respectively). In conclusion, this study provides estimates of protein and carbohydrate ruminal degradation of feedstuff for use in diet formulation models. Ruminal degradation results observed in this study agree with published data and have been proved to be 
reproducible, resulting in a viable, and less complex method, to determine ruminal digestion characteristics of feedstuff.

\section{INTRODUCTION}

Balancing diets for ruminants, to meet microbial and host requirements, relies on estimates of feedstuff ruminal degradation. Feedstuff have different ruminal degradation rates $\left(k_{d}\right)$, which are a reflection of their physicochemical characteristics. Based on a continuous culture and in vivo growth experiment, Brooks et al. (2012) demonstrated the benefits of balancing diets for fermen carbohydrates, ruminal degradable peptides and ruminal degradable nitrogen by decreased lactate production and increased OM digestibility and MOEFF in a continuous culture system and increased ADG and G:F in feedlot steers fed no-roughage diets. Therefore, accurate estimates of protein and carbohydrate degradation of feedstuffs in the rumen are required. In vitro and in situ techniques are important tools to determine ruminal digestion characteristics of a feedstuff. Several researchers investigated $k_{d}$ of nutrients using different methods, resulting in variable values. The in situ method is the most commonly used, however this technique fails to determine $k_{d}$ of the soluble protein fraction which is variable (120 to $400 \% \cdot h^{-1}$ (Sniffen et al., 1992)). Batch culture systems are an alternative method that closely mimic the rumen environment. The objective of this study was to characterize

rumen $\mathrm{N}$, starch, and NDF $k_{d}$, and further calculate ruminal degradable, undegradable and extent of digestion of $\mathrm{N}$, starch and NDF using a batch culture system. We hypothesized 
different feedstuffs would have different ruminal $k_{d}$, results would agree with published literature that used different methods, and our method would have high reproducibility.

\section{MATERIAL AND METHODS}

\section{Batch Culture system}

Feed ingredients used on batch culture experiments were processed using the following procedure. Samples were dried in a forced air oven at $55^{\circ} \mathrm{C}$ for $72-\mathrm{h}$, and ground initially to pass through a 5-mm screen (Wiley Mill; Arthur H. Thomas Company, Phyladelphia, PA). Subsamples were ground again to pass through a 1-mm screen and then used on batch culture (Cyclotech grinder; Foss Tecator Cyclotec 1093 sample mill). Samples were analyzed ( 2.1) for DM, ash, nitrogen content (vario Macro Cube, Elementar Americas, Mt. Laurel, NJ), NDF and ADF (ANKOM Technology, Macedon, NY, (Goering and Van Soest, 1970).

The same 2 steers, previously fitted with ruminal fistulas, were used for all experiments. Steers were maintained together in a limestone packed dry lot with access to tall fescue hay (88\% DM, 8.32\% CP, 65.5\% NDF, 35.7\% ADF), ad libitum access to water and were supplemented every morning with dry distiller's grain solubles (DDGS; $\pm 2 \mathrm{~kg} \cdot$ steer $\left.^{-1} ; 83.4 \% \mathrm{DM}, 29.6 \% \mathrm{CP}, 31.9 \% \mathrm{NDF}, 8.97 \% \mathrm{ADF}\right)$. On ruminal fluid collection days, supplement was provided following collection. Collections occurred between $0830 \mathrm{~h}$ and $1100 \mathrm{~h}$. All in vitro experiments used ruminal fluid collected from 2 steers and collection was performed using a suction strainer modified from Raun and Burroughs (1962). The instrument was inserted in the ruminal fistula and samples were 
collected from the mid portion of the rumen. Ruminal fluid was transported from the farm to the laboratory in closed thermal controlled containers, mixed using a blender and filtered through 4 layers of cheese cloth. Ruminal fluid was inoculated into the flask, which contained feed and buffer mixed at $39^{\circ} \mathrm{C}$. Carbon dioxide was added, and the fermentation flask was closed with a stopper containing a one-way valve.

Buffers (Mould et al., 2005) were prepared 1-d before trial initiation, kept at $4^{\circ} \mathrm{C}$ and mixed 3-h prior to ruminal fluid collection. Primer was added $(0.0025 \mathrm{~g} / \mathrm{mL}$ of ruminal fluid) to the final buffer, and inoculum (buffer containing primer) was transferred to fermentation flasks, which were incubated at $39^{\circ} \mathrm{C}$ in a floor shaker (MAXQ 5000, Thermo Scientific, OH). Primer contained corn starch (71\%; Sigma-Aldrich, St. Louis, MO), cellulose (17\%; Sigma-Aldrich, St. Louis, MO), casein (4.2\%, Sigma-Aldrich, St. Louis, MO), isolated soy protein (4.2\%; MP Biomedicals, LLC., Solon, OH), citrus pectin (3\%; Biochemical Corporation, Cleveland, $\mathrm{OH})$ and urea ( $0.6 \%$; Acros Organics B.V.B.A. Morris, NJ).

\section{Nitrogen}

Nitrogen $k_{d}$ was estimated (48-h incubation) using a batch culture system. Feed sources used were soybean meal (SBM), AminoPlus (AP, Ag Processing Inc, Omaha, $\mathrm{NE}$ ), corn dry distiller's grain solubles (DDGS), porcine blood meal (BM), cottonseed meal (CSM) and fish meal (FM). Four flasks were sacrificed at each sampling time and ammonia release was used as an indicator of nitrogen degradation, which was measured at $0,2,4,8,16,24$ and $48 \mathrm{~h}$ post flask inoculation. At 0 -h, there were 5 flasks per feed, 3 containing feed, ruminal fluid and primed buffer, and the other 2 served as blank flasks with only feed and primed buffer, which was used to correct for feed present on ruminal 
fluid. Each 50-mL flask was inoculated with 30-mL of primed buffer, 10-mL of ruminal fluid and $0.31 \mathrm{~g}$ of feed. At sampling times, flask content was acidified using $6 \mathrm{M} \mathrm{HCl,} 2-$ $\mathrm{mL}$ were transferred to microcentrifuge tubes and immediately frozen for ammonia analysis. Ammonia samples were rapidly thawed using hot water, analyzed using the phenol-hypochlorite assay as described by Broderick and Kang (1980) and measured on a spectrophotometer (Evolution 201, Thermo Scientific, Waltham, MA).

Two degradation curves were generated for each feed (one per experiment). Soybean meal was used as a control in all experiments. Ammonia $\mathrm{N}$ release was used to calculate $\mathrm{N} \%$ degraded using the following equation.

$$
N \% \text { degraded }=\left\{g \mathrm{Nin} i-\left[g \mathrm{Nin}_{i}-\left(g \mathrm{NH}_{3} \mathrm{~N}_{i}-\text { mean blk } \mathrm{g} \mathrm{NH} \mathrm{H}_{3} \mathrm{~N}\right)\right] \times \mathrm{g} \mathrm{Nin^{-1 }}\right\} \times 100
$$

Where $i=\mathrm{h} ; g N$ in $=$ grams of nitrogen inoculated; $g \mathrm{NH}_{3} \mathrm{~N}=$ grams of ammonia $\mathrm{N}$ recovered; mean blk $\mathrm{g} \mathrm{NH}_{3} \mathrm{~N}=$ ammonia nitrogen measured on blank flasks (contained rumen fluid and primed buffer).

Using N \% degraded over time, a polynomial second order regression was used to determine nitrogen $k_{d}$.

Protein digestion extent was measured using a 72-h incubation batch culture system. Feed was incubated in filter bags (Ankom Technology, Macedon NY), and degradation was determined by DM disappearance and $\mathrm{N}$ analysis. Three $500-\mathrm{mL}$ flasks were incubated for each feed which contained 6 bags ( 1 blank and 5 with $0.5 \mathrm{~g}$ of feed per bag), $80-\mathrm{mL}$ of ruminal fluid, and $320-\mathrm{mL}$ of primed buffer. After measuring $\mathrm{N}$ DM disappearance, ruminally undegradable protein was calculated using the following equation. 


$$
R U P=\text { Indigestible }+\sum\left\{R D P_{i}-\left(R D P_{i} x k_{p}\right)-\left[\left(a x^{2}+b x+c\right) 100^{-1} x R D P_{i}\right]\right\}
$$

Where Indigestible $=$ indigestible feed after $72 \mathrm{~h}$ in vitro incubation; $i=\mathrm{h} ; k_{d}=$ degradation rate describes as " $a \mathrm{x}^{2}+b \mathrm{x}+c$ "; $k_{p}=$ ruminal passage rate of $4 \% \cdot \mathrm{h}^{-1}$.

\section{Starch}

Starch $k_{d}$ was estimated (72-h incubation) using a batch culture system. Feed sources used were ground corn (GC), steam flaked corn (SFC), barley grain (BG) and wheat middlings (WM). Three flasks were sacrificed at each sampling time and $k_{d}$ was determined by DM disappearance and starch analysis (Resistant Starch assay procedure, Megazyme, Wicklow, Ireland) which was measured at 0, 4, 8, 12, 16, 24, 36, 48 and 72-h post flask inoculation. At 0-h, there were 6 flasks, 3 containing feed, ruminal fluid and primed buffer, and the other 3 blank flasks with only feed and primed buffer, which was used to correct for feed present on ruminal fluid. Each 250-mL flask was inoculated with 120-mL of primed buffer, $30-\mathrm{mL}$ of ruminal fluid and $3 \mathrm{~g}$ of feed. At sampling times, flask content was transferred to centrifuge flasks and centrifuged at $1000 \mathrm{xg}$ for $10 \mathrm{~min}$. Sample supernatant was discarded, feed particles were transferred to aluminum pans and dried at $105^{\circ} \mathrm{C}$ for 48 -h. Dried feed samples were ground using a mortar and pestle and kept at room temperature until further starch analysis. Two degradation curves were generated for each feed (one per experiment). Ground corn was used as a control in all experiments. Percent starch degraded was calculated using the following equation.

Starch \% degraded $=\left\{\left[\left(\mathrm{g}\right.\right.\right.$ starch $_{\text {in }}-\mathrm{g}$ starch from ruminal fluid and primed buffer $)-(g$ starch remaining $\left.)] \times\left(g \text { starch in } n_{i}-g \text { starch from ruminal fluid and primed buffer }\right)^{-1}\right\} \times 100$ 
Where $i=\mathrm{h} ; g$ starch $i n=$ grams of starch inoculated.

A polynomial second order regression was used to determine starch $k_{d}$. Ruminally undegradable starch was calculated using the equation for RUP.

\section{Neutral Detergent Fiber}

Neutral detergent fiber $k_{d}$ was estimated (72-h incubation) using a batch culture system. Feed sources used were alfalfa fresh (AF), alfalfa hay (AH), tall fescue fresh (FF) tall fescue hay $(\mathrm{FH})$ and soybean hulls $(\mathrm{SH})$. Three flasks were sacrificed at each sampling time and $k_{d}$ was determined by DM disappearance and NDF analysis ((ANKOM Technology, Macedon, NY, (Goering and Van Soest, 1970)) which was measured at $0,4,8,12,16,24,36,48$ and 72 -h post flask inoculation. At 0 -h, there were 6 flasks, 3 containing feed, ruminal fluid and primed buffer, and the other 3 blank flasks with only feed and primed buffer, which were used to correct for feed present on ruminal fluid. Each $250-\mathrm{mL}$ flask was inoculated with $120-\mathrm{mL}$ of primed buffer, $30-\mathrm{mL}$ of ruminal fluid and $3 \mathrm{~g}$ of feed. At sampling times, flask content was transferred to centrifuge flasks and centrifuged at $1000 \mathrm{xg}$ for $10 \mathrm{~min}$. Sample supernatant was discarded, feed particles were transferred to aluminum pans and dried at $105^{\circ} \mathrm{C}$ for $48-\mathrm{h}$. Dried feed samples were ground using a mortar and pestle and kept at room temperature until further starch analysis. Two degradation curves were generated for each feed (one per experiment). Alfalfa fresh was used as a control in all experiments. Percent NDF degraded was calculated using the following equation.

$N D F \%$ degraded $=\left\{\left[\left(g N D\right.\right.\right.$ in $n_{i}-g N D F$ from ruminal fluid and primed buffer $)-(g$ $N D F$ remaining $\left.i)] \times\left(g N \text { N in }{ }_{i}-g \text { NDF from ruminal fluid and primed buffer }\right)^{-1}\right\} \times 100$ 
Where $i=\mathrm{h} ; g N D F$ in $=$ grams of NDF inoculated.

A polynomial second order regression was used to determine NDF $k_{d}$. Ruminally undegradable NDF was calculated using the equation for RUP.

\section{Statistical Analysis}

Data analyses were performed using SAS (SAS 9.4 Institute Inc., Cary, NC). Ruminal degradable, undegradable and extent data analyses were performed by ANOVA using GLM procedure, and when F-test was significant $(P \leq 0.05)$, means separation was performed using LSMEANS statement. Experiment and feed $k_{d}$ reproducibility were tested by ANOVA, flask was the experimental unit, and NESTED procedure was used. Degradation rates were tested for linear and quadratic responses using GLM procedure. Differences between linear and quadratic responses were contrasted for linear and quadratic components of each feed using GLM procedure.

\section{RESULTS}

Ruminal degradable protein decreased and undegradable protein increased between SBM, AP, FM, CSM, DDGS and BM for each respective feed $(P<0.01 ; 2.2)$. AminoPlus and SBM did not differ $(P=0.27)$ for extent of digestion and were greater than all other feeds $(P<0.01)$. Extent of digestion decreased between FM, DDGS, CSM and $\mathrm{BM}$ for each respective feed $(P>0.01)$. All nitrogen feed sources had a linear response for $k_{d}$ over a 48-h incubation $\left(P<0.05\right.$; Figure 2.4). AminoPlus nitrogen $k_{d}$ was the only feed with a quadratic effect $(P<0.05)$. Due to the short incubation time to reach 
$\mathrm{N}$ extent of digestion, most $\mathrm{N} k_{d}$ regressions were linear, however, we reported quadratic regressions for all feeds, because AP had a quadratic response, and other feeds increased coefficient of determination when linear regressions were changed to quadratic. Contrast of linear responses were different $(P<0.05)$ among all feeds except between CSM compared to AP and FM, and BM compared to DDGS. Contrasts of quadratic responses were different between AP, SBM and FM. Among 6 nitrogen feed sources, SBM had the fastest $k_{d}$, and DDGS, not different to BM had the slowest $k_{d}$.

Ruminal degradable starch was greater, and undegradable was lesser, for BG and WM compared to GC, and SFC did not differ from other feeds $(P=0.055 ; 2.1)$. Steam flaked corn and WM did not differ $(P=0.62)$ on extent of starch digestion, and were greater than $\mathrm{GC}(P=0.015)$, while $\mathrm{BG}$ was lesser than $\mathrm{SFC}(P=0.04)$ and did not differ from other feeds $(P>0.06)$. All starch feed sources had a linear and quadratic response for $k_{d}$ over a 16-h incubation for WM and BG, and 36-h for SFC and GC $(P<0.01$; Figure 2.2). Contrast of linear responses did not differ $(P>0.05)$ among all feeds. Contrast of quadratic responses were different among all feeds $(P<0.01)$ except for GC compared to SFC and WM compared to BG $(P>0.05)$. All 4 feeds had starch degradation greater than $90 \%$, however BG and WM had faster $k_{d}$ than GC and SFC.

Ruminal degradable NDF was greater, and undegradable was lesser, for AF, FF and SH compared to AH and FH $(P<0.01 ; 2.3)$. Tall fescue fresh and SH had greater $(P$ $<0.01$ ) extent of NDF digestion, followed by AF, which was greater than $\mathrm{AH}$ and $\mathrm{FH}$. All NDF feed sources had a linear and quadratic response for $k_{d}$ over a 72-h incubation $(P$ $<0.01$; Figure 2.6). Contrast of linear responses differed $(P<0.05)$ among all feeds except for $\mathrm{AF}$ compared to $\mathrm{AH}$. Contrast of quadratic responses were different among all 
feeds $(P<0.05)$ except for AH compared to $\mathrm{AF}$ and $\mathrm{FH}$, and $\mathrm{AF}$ compared to $\mathrm{FH}(P>$ $0.05)$.

Variance was primarily due to the differences among hours within each treatment (2.4). Variance among all nitrogen ingredients were $3.41,0,93.3$, and $3.28 \%$ from experiment, treatment, hour and error respectively. Hour accounted for more than $90 \%$ of variance for each feed except for BM, which had $21.88,74.55$ and $3.57 \%$ of variance from experiment, hour and error respectively. Starch ingredients had greater reproducibility with variances from all ingredients been, zero from experiment and treatment, and 99.55 and $0.45 \%$ from hour and error respectively. Alfalfa hay had the lowest reproducibility among NDF ingredients, with $20.2,78.5$ and $1.34 \%$ variance from experiment, hour and error respectively. All others NDF sources had at most 3.6\% variance due to error with zero percent from experiment.

\section{DISCUSSION}

Ability of diet formulation models to meet animal nutrient requirements depends on the accuracy of feed composition values used. More specifically, prediction of energy and protein (ammonia N, peptides and AA) supply to ruminal microbes and the host are highly dependent on ruminal $\mathrm{k}_{d}$. Protein and carbohydrate from feed sources have different ruminal $\mathrm{k}_{d}$, which reflects their physicochemical characteristics. Ruminal degradation can be measured using direct and indirect methods. Direct methods, which measure nutrient disappearance over time, are widely used to measure carbohydrates $\mathrm{k}_{d}$, however for protein, this method has issues with microbial contamination. The direct in 
situ method is widely used, however this technique fails to determine $k_{d}$ of the soluble protein fraction, which is variable (120 to $\left.400 \% \cdot \mathrm{h}^{-1}\right)$ (Sniffen et al., 1992) and not $100 \%$ degradable in all feeds as assumed in diet formulation models (Bach et al., 2008). Because ammonia is produced from microbial protein degradation, the issues mentioned before can be solved by measuring ammonia accumulation rate using a batch culture system.

The diet formulation model developed in our laboratory, uses a constant $\mathrm{k}_{d}$ for starch, NDF and protein of 5.1, 2.5, and $2.86 \% \cdot \mathrm{h}^{-1}$, which was determined by Brooks (2010) and tabular RDP and RUP values from NRC (2000). The Beef Cattle Nutrient Requirements most recent model (National Academies of Sciences and Medicine, 2016) categorizes carbohydrates into 5 fractions, such as sugars, starch, pectin, potentially fermented fiber, and unavailable fiber, and 3 protein fractions, such as, soluble protein, potentially degradable protein and unavailable protein. Ruminal degradable and undegradable protein are used to predict ruminal microbial requirements supply and to supplement microbial protein in meeting animal AA requirements. Tabular values used in both models are from various sources and different in vitro and in situ methods were used to determine it.

Even with a less complex method proposed by this study, because it does not separate protein and carbohydrates into fractions, rumen degradable and undegradable values predicted from measured $k_{d}$ and extent of ruminal digestion were simlar to literature reported values. AminoPlus RDP and RUP calculated in this experiment were 75 and $60 \%$ different from values reported by the manufacture, the same sample was used on both experiments, $k_{d}$ curves coefficient of determination were 0.92 and 0.96 , and 
had high reputability with zero and $5 \%$ variance due to experiment and repeatability error respectively, therefore, difference between ours and values reported by the company cannot be explained. Among other protein sources, calculated degradable portion were 2.7, 15.4, $0.65,49$, and $0.27 \%$ and undegradable portions were $6.6,17,0.2,12.6$ and $0.35 \%$ different from tabular values for SBM, CSM, DDGS, BM and FM respectively. Ranking for starch ruminal availability reported in the literature are the same as observed in this experiment but not with the same absolute value. Offner et al. (2003) measured starch $k_{d}$ using in situ method and reported rumen effective degradability (calculated using $4 \% \cdot \mathrm{h}^{-1}$ dilution rate) values of 74,83 and $89 \%$ for ground corn, steam flaked corn and barley grain respectively, which were similar to RDP calculated in this experiment. Batajoo and Shaver (1998), also using an in situ method reported barley, corn and wheat middlings as $80.5,56.5$ and $88.4 \%$ ruminally available starch respectively $\left(7 \% \mathrm{k}_{p}\right)$. Variations among laboratories could be due to multiple factors such as, methods used, inherent differences in feed samples (i.e., feed processing method, nutrient profile, particle size), animal and diet variation. Differences in NDF digestibility among NDF feed sources are mostly due to maturity. When different maturity stages of alfalfa hay were tested using in situ method, authors reported 64.7, 51.7 and 41.5\% NDF digestibility for early vegetative, late bud and full bloom respectively (Llamas-Lamas and Combs, 1990).

Variance was primarily due to the differences among hours within each treatment. Which means that $k_{d}$ experiments were highly reproducible for all ingredients. The less reproducible ingredients were $\mathrm{BM}$ and, $\mathrm{AH}$. Therefore, this study indicates that using a batch culture system with indirect and direct measurements to determine $k_{d}$ of $\mathrm{N}$, starch 
and NDF are viable methods, with values similar to those reported in the literature as well as reproducible.

\section{CONCLUSIONS}

In conclusion, this study provides estimates of protein and carbohydrate ruminal degradation of feedstuff for use in diet formulation models. Ruminal degradation results observed in this study agrees with published data and have been proven to be reproducible, resulting in a viable, and less complex method, to determine ruminal digestion characteristics of feedstuff. 
Table 2.1. Nutrient analysis of feedstuff used on batch culture experiments.

\begin{tabular}{|c|c|c|c|c|c|c|}
\hline \multirow[b]{2}{*}{ Feedstuff } & \multicolumn{6}{|c|}{ Nutrient analysis } \\
\hline & DM, \% & $\begin{array}{c}\text { Ash, } \\
\% \text { DM }\end{array}$ & $\begin{array}{l}\text { NDF, } \\
\% \text { DM }\end{array}$ & $\begin{array}{c}\text { ADF, } \\
\% \mathrm{DM}\end{array}$ & $\begin{array}{c}\text { CP, } \\
\% \mathrm{DM}\end{array}$ & $\begin{array}{l}\text { Insolubl } \\
\text { e starch, } \\
\% \mathrm{DM}^{1}\end{array}$ \\
\hline \multicolumn{7}{|l|}{ Nitrogen source } \\
\hline Soybean meal & 85.32 & 7.15 & 17.41 & 4.71 & 40.98 & - \\
\hline AminoPlus $^{2}$ & 86.88 & 8.25 & 14.19 & 5.48 & 49.01 & - \\
\hline Cottonseed meal & 90.83 & 8.54 & 31.97 & 14.48 & 46.04 & - \\
\hline Dry distiller's grain solubles & 83.43 & 5.53 & 32.33 & 8.32 & 29.96 & - \\
\hline Porcine blood meal & 89.69 & 1.99 & - & - & 92.19 & - \\
\hline Fish meal & 93.02 & 24.76 & 17.44 & 2.87 & 66.00 & - \\
\hline \multicolumn{7}{|l|}{ Starch source } \\
\hline Ground corn & 86.85 & 3.36 & 8.44 & 1.08 & 11.45 & 62.17 \\
\hline Steamed flaked corn & 90.29 & 1.82 & 12.03 & 3.20 & 9.24 & 58.03 \\
\hline Wheat middlings & 91.35 & 5.47 & 36.76 & 10.65 & 17.07 & 23.88 \\
\hline Barley grain & 90.26 & 3.18 & 18.03 & 4.87 & 10.04 & 44.63 \\
\hline \multicolumn{7}{|l|}{ Fiber source } \\
\hline Alfalfa fresh & 28.22 & 10.39 & 45.09 & 32.04 & 21.41 & - \\
\hline Alfalfa hay & 88.56 & 9.12 & 54.46 & 38.68 & 18.20 & - \\
\hline Tall fescue fresh & 22.92 & 10.34 & 60.08 & 32.49 & 12.88 & - \\
\hline Tall fescue hay & 88.81 & 8.62 & 65.55 & 35.66 & 9.26 & - \\
\hline Soybean hulls & 91.03 & 5.49 & 65.02 & 47.39 & 10.99 & - \\
\hline
\end{tabular}


Table 2.2. Ruminal degradable, undegradable and extent of digestion of starch using a batch culture system.

\begin{tabular}{lcccccc}
\multicolumn{7}{c}{ Ingredients } \\
\hline Item & $\begin{array}{c}\text { Ground } \\
\text { corn }\end{array}$ & $\begin{array}{l}\text { Steam } \\
\text { flaked } \\
\text { corn }\end{array}$ & $\begin{array}{c}\text { Wheat } \\
\text { middlings }\end{array}$ & $\begin{array}{c}\text { Barley } \\
\text { grain }\end{array}$ & SEM & $P$-value \\
\hline $\begin{array}{c}\text { Measured, } \% \\
\text { Degradable }\end{array}$ & $76.44^{\mathrm{b}}$ & $82.17^{\mathrm{ab}}$ & $84.09^{\mathrm{a}}$ & $86.70^{\mathrm{a}}$ & 1.76 & 0.055 \\
Undegradable & $23.56^{\mathrm{a}}$ & $17.83^{\mathrm{ab}}$ & $15.91^{\mathrm{b}}$ & $13.30^{\mathrm{b}}$ & 1.76 & 0.055 \\
Extent & $97.03^{\mathrm{c}}$ & $99.15^{\mathrm{a}}$ & $98.95^{\mathrm{ab}}$ & $98.03^{\mathrm{bc}}$ & 0.27 & 0.015 \\
\hline
\end{tabular}

$\overline{\mathrm{a}, \mathrm{b}, \mathrm{c}, \mathrm{d}, \mathrm{e}}$ least square means within a row with different superscript $\operatorname{differ}(P<0.05)$. 


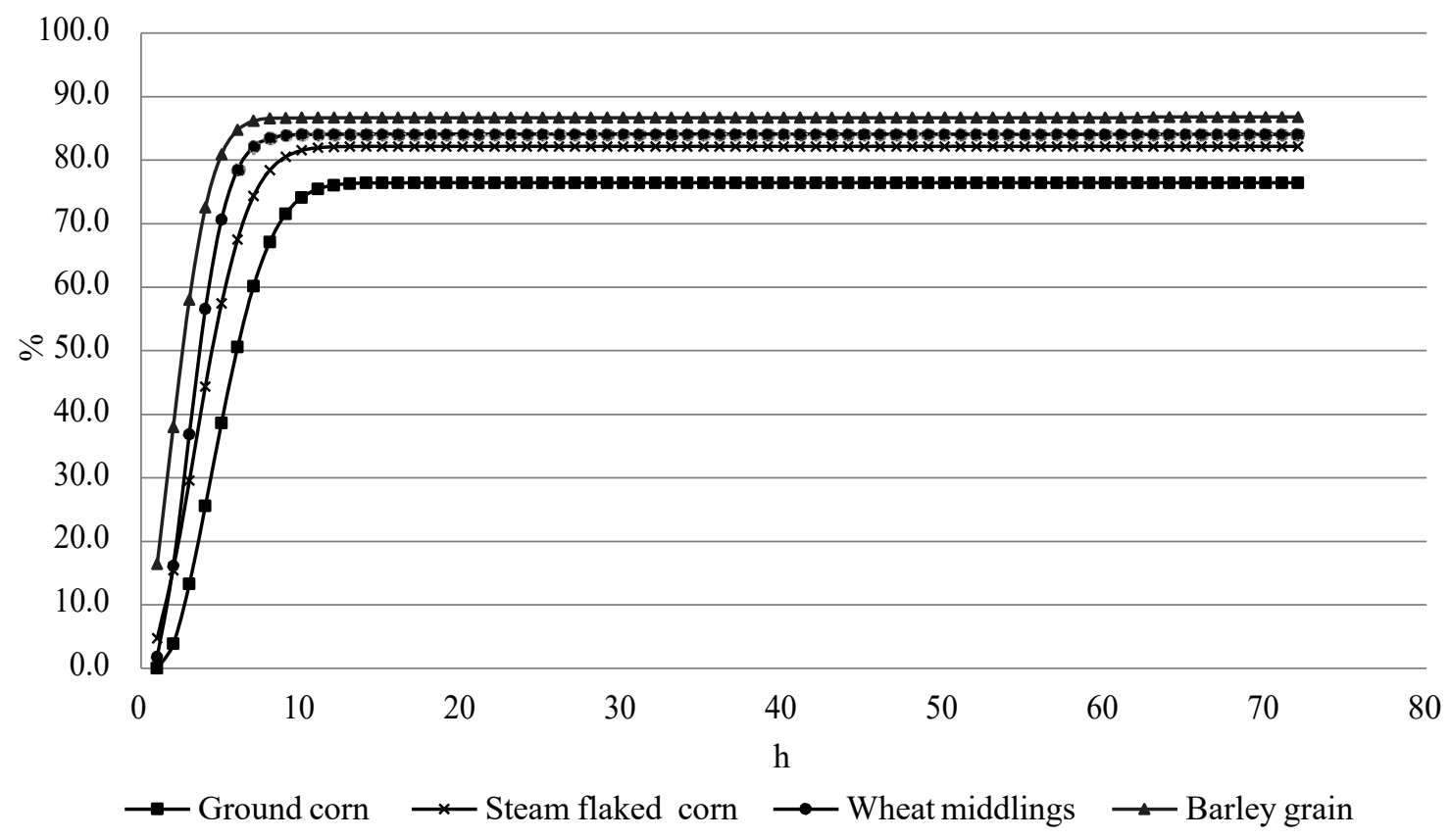

Figure 2.1. Starch ruminal degradation assuming $4 \% \cdot \mathrm{h}^{-1} \mathrm{Kp}$ using a batch culture system. 


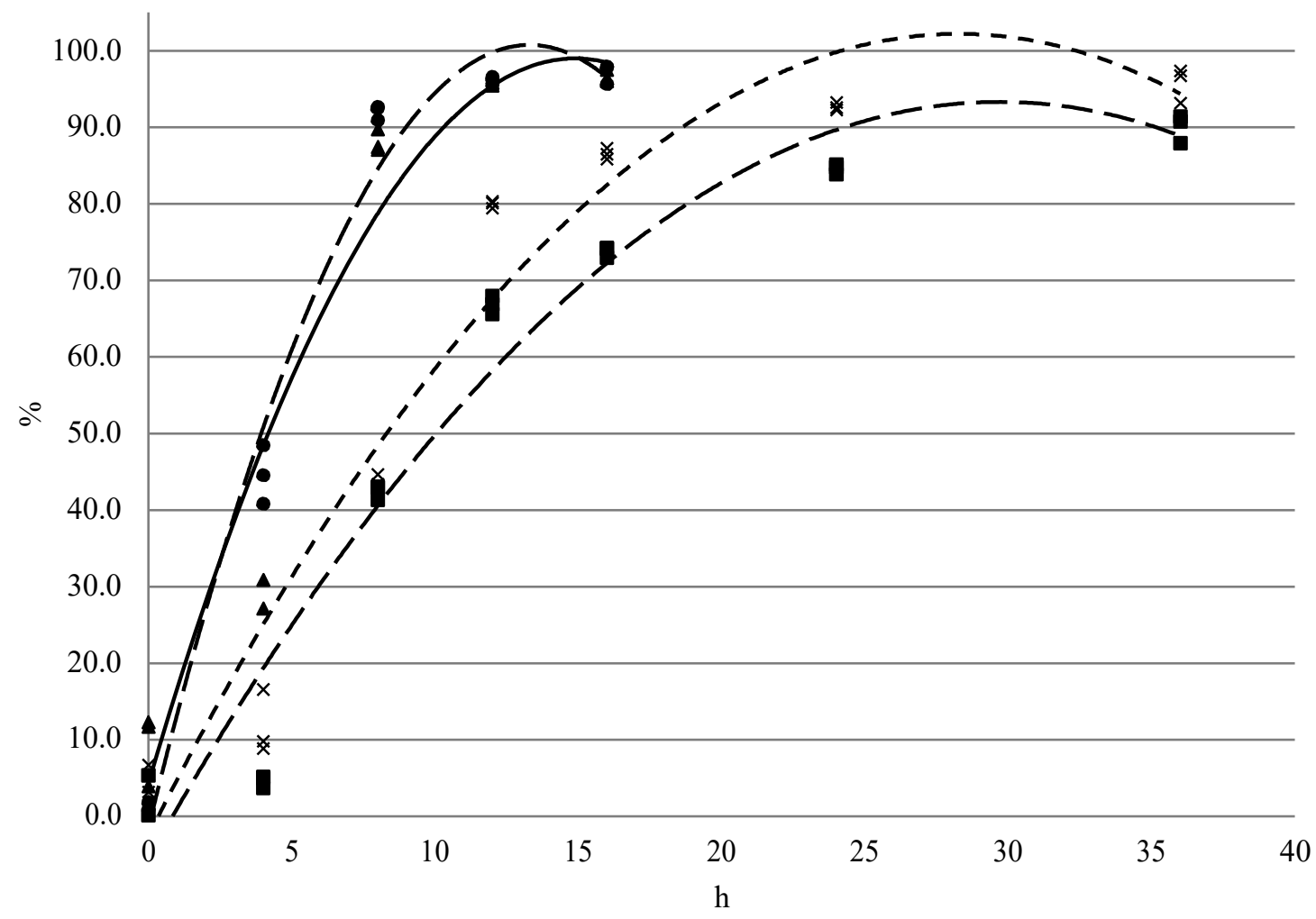

- Ground corn

$\times \quad$ Steam flaked corn

\begin{tabular}{lcc}
\hline Treatments & Linear & Quadratic \\
\hline Ground corn & $* *$ & $* *$ \\
Steam flaked corn & $* *$ & $* *$ \\
Wheat middlings & $* *$ & $* *$ \\
Barley grain & $* *$ & $* *$ \\
\hline
\end{tabular}

- Wheat middlings

\begin{tabular}{cccc}
\hline \multicolumn{2}{c}{ Treatments } & Linear & Quadratic \\
\hline Ground corn & Steam flaked corn & NS & NS \\
Ground corn & Wheat middlings & NS & $* *$ \\
Ground corn & Barley grain & NS & $* *$ \\
Steam flaked corn & Wheat middlings & NS & $* *$ \\
Steam flaked corn & Barley grain & NS & $* *$ \\
Wheat middlings & Barley grain & NS & NS \\
\hline
\end{tabular}

- - Poly. (Ground corn) $\quad y=-0.112 x^{2}+6.6526 x-5.4902$ $\mathrm{R}^{2}=0.9527$

\footnotetext{
- - Poly. (Steam flaked $y=-0.131 x^{2}+7.4062 x-2.4719$ corn) $\quad \mathrm{R}^{2}=0.9448$
- Poly. (Wheat middlings)$$
\mathrm{R}^{2}=0.978
$$$$
y=-0.5789 x^{2}+15.387 x-1.4918
$$

Poly. (Barley grain)

$$
\mathrm{R}^{2}=0.9407
$$$$
y=-0.4271 x^{2}+12.714 x+4.3802
$$

Figure 2.2. Starch ruminal degradation rate using a batch culture system. 
Table 2.3. Ruminal degradable, undegradable and extent of digestion of nitrogen measured using a batch culture system.

\begin{tabular}{|c|c|c|c|c|c|c|c|c|}
\hline \multicolumn{9}{|c|}{ Ingredients $^{2}$} \\
\hline Item, \% & SBM & AP & CSM & DDGS & $\mathrm{BM}$ & $\mathrm{FM}$ & SEM & $P$-value \\
\hline \multicolumn{9}{|l|}{ Measured } \\
\hline Degradable & $68.54^{\mathrm{a}}$ & $61.62^{\mathrm{b}}$ & $49.39^{c}$ & $32.21^{\mathrm{d}}$ & $15.30^{\mathrm{e}}$ & $54.81^{\mathrm{bc}}$ & 2.34 & $<0.01$ \\
\hline Undegradable & $31.46^{\mathrm{e}}$ & $38.39^{\mathrm{d}}$ & $50.61^{\mathrm{c}}$ & $67.80^{\mathrm{b}}$ & $84.71^{\mathrm{a}}$ & $45.20^{\mathrm{cd}}$ & 2.34 & $<0.01$ \\
\hline Extent & $98.29^{\mathrm{a}}$ & $96.22^{\mathrm{a}}$ & $71.72^{\mathrm{d}}$ & $79.04^{c}$ & $32.68^{\mathrm{e}}$ & $85.09^{b}$ & 1.31 & $<0.01$ \\
\hline \multicolumn{9}{|c|}{ Literature reported $^{l}$} \\
\hline Degradable & 70.42 & 28.00 & 57.19 & 32.00 & 25.23 & 54.96 & - & - \\
\hline Undegradable & 29.45 & 72.00 & 42.70 & 67.93 & 74.64 & 45.04 & - & - \\
\hline Extent & - & - & - & - & - & - & - & - \\
\hline
\end{tabular}




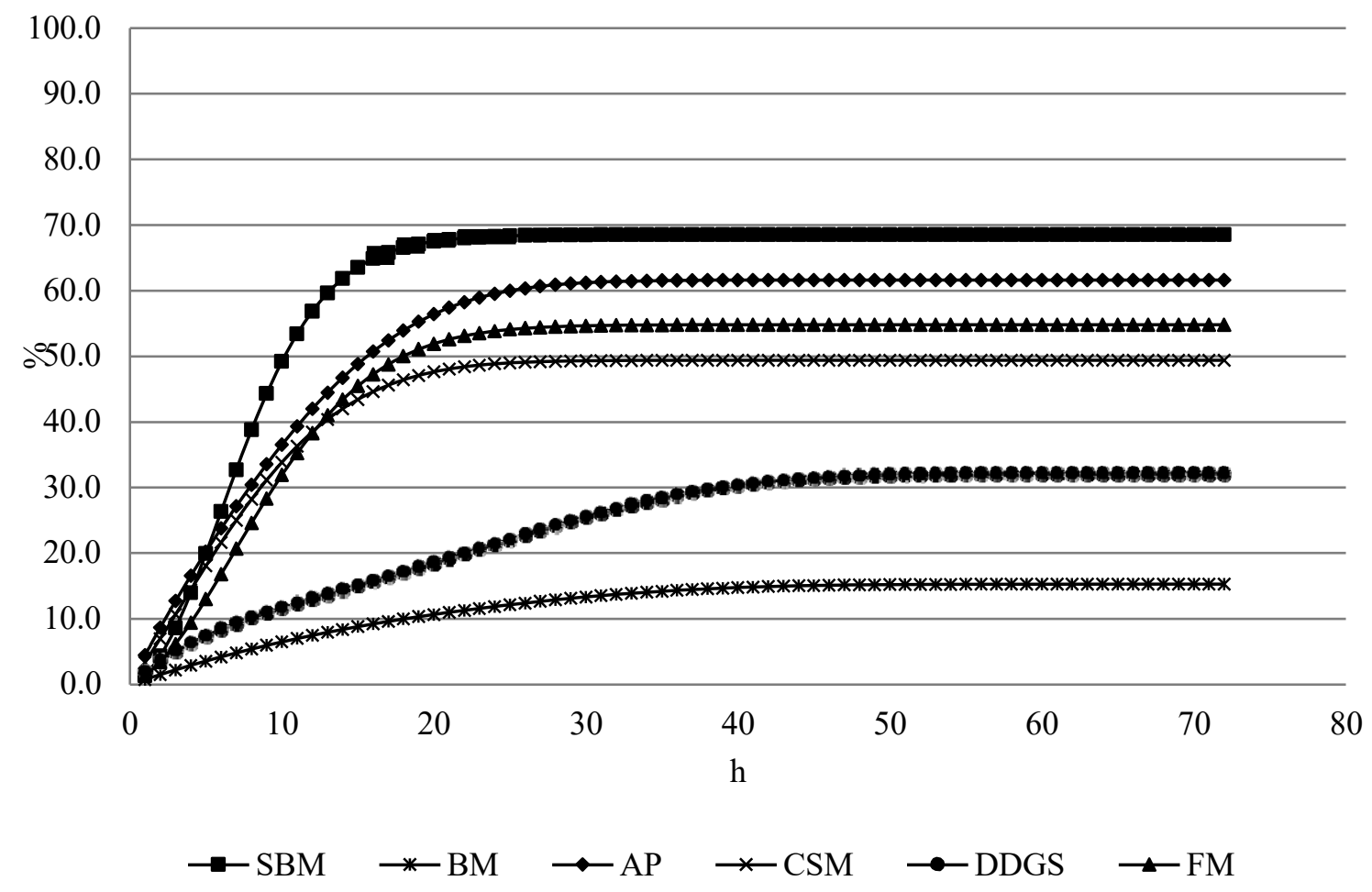

Soybean meal, SBM; AminoPlus, AP, Cottonseed meal, CSM, Dry distiller's grain solubles, DDGS; Porcine blood meal, BM; Cottonseed meal, CSM, Fish meal, FM

Figure 2.3. Nitrogen ruminal degradation assuming $4 \% \cdot \mathrm{h}^{-1} \mathrm{Kp}$ using a batch culture system. 


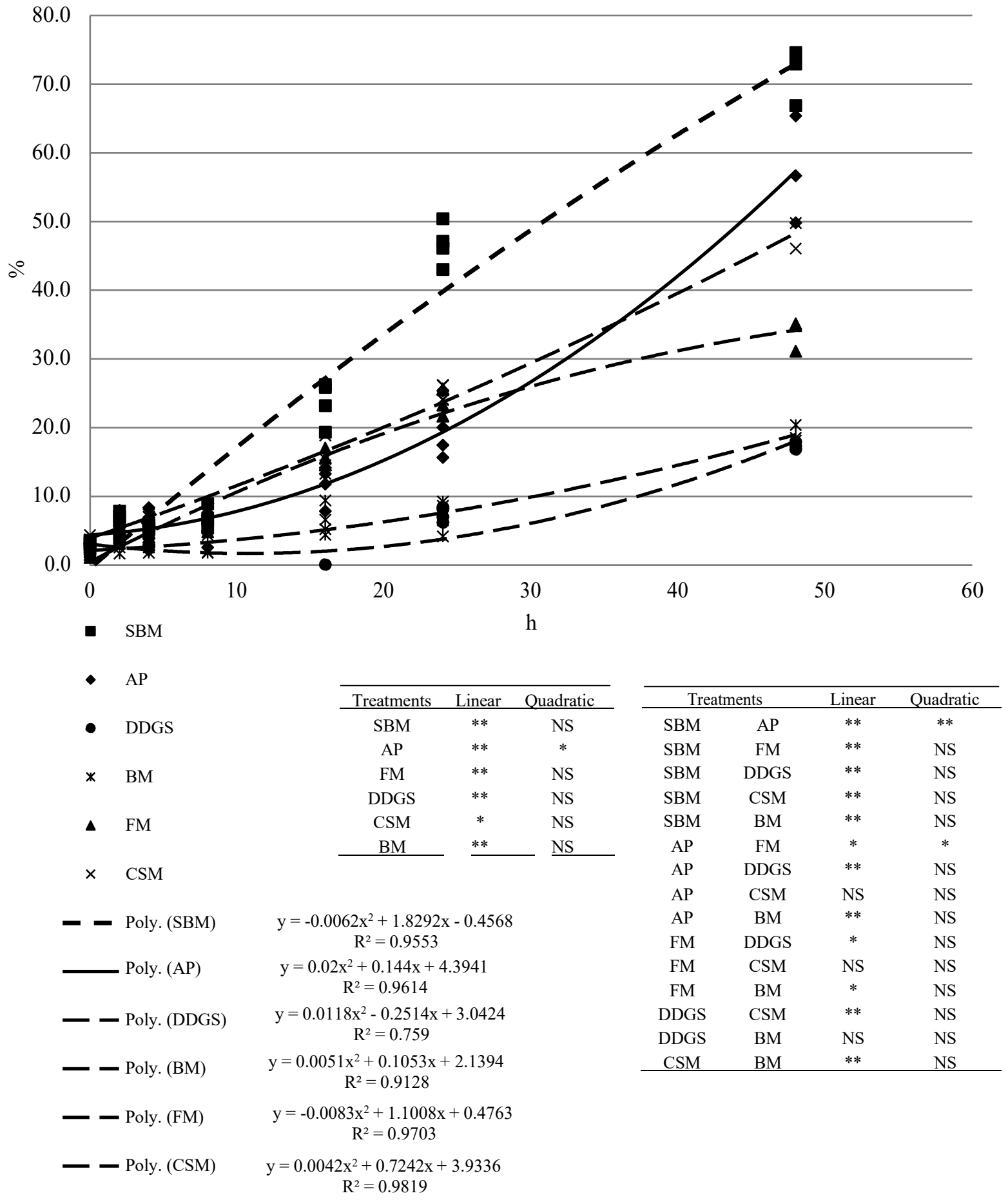

Soybean meal, SBM; AminoPlus, AP, Cottonseed meal, CSM, Dry distiller's grain solubles, DDGS; Porcine blood meal, BM; Cottonseed meal, CSM, Fish meal, FM

Figure 2.4. Nitrogen ruminal degradation rate using a batch culture system. 
Table 2.4. Ruminal degradable, undegradable and extent of digestion of NDF using a batch culture system.

\begin{tabular}{|c|c|c|c|c|c|c|c|}
\hline \multicolumn{8}{|c|}{ Ingredients } \\
\hline Item & $\begin{array}{c}\text { Alfalfa } \\
\text { fresh }\end{array}$ & $\begin{array}{c}\text { Alfalfa } \\
\text { hay }\end{array}$ & $\begin{array}{c}\text { Tall } \\
\text { fescue } \\
\text { fresh }\end{array}$ & $\begin{array}{c}\text { Tall } \\
\text { fescue } \\
\text { hay }\end{array}$ & $\begin{array}{c}\text { Soybean } \\
\text { hulls }\end{array}$ & SEM & $P$-value \\
\hline \multicolumn{8}{|l|}{ Measured, \% } \\
\hline Degradable & $46.37^{\mathrm{a}}$ & $32.19^{b}$ & $58.06^{\mathrm{a}}$ & $24.95^{\mathrm{b}}$ & $48.79^{\mathrm{a}}$ & 4.17 & $<0.01$ \\
\hline Undegradable & $53.63^{b}$ & $67.81^{\mathrm{a}}$ & $41.94^{\mathrm{b}}$ & $75.04^{\mathrm{a}}$ & $51.21^{\mathrm{b}}$ & 4.17 & $<0.01$ \\
\hline Extent & $54.27^{\mathrm{b}}$ & $41.25^{\mathrm{c}}$ & $68.47^{\mathrm{a}}$ & $41.22^{\mathrm{c}}$ & $65.05^{\mathrm{a}}$ & 3.94 & $<0.01$ \\
\hline
\end{tabular}

a, b, c, d, e least square means within a row with different superscript differ $(P<0.05)$. 


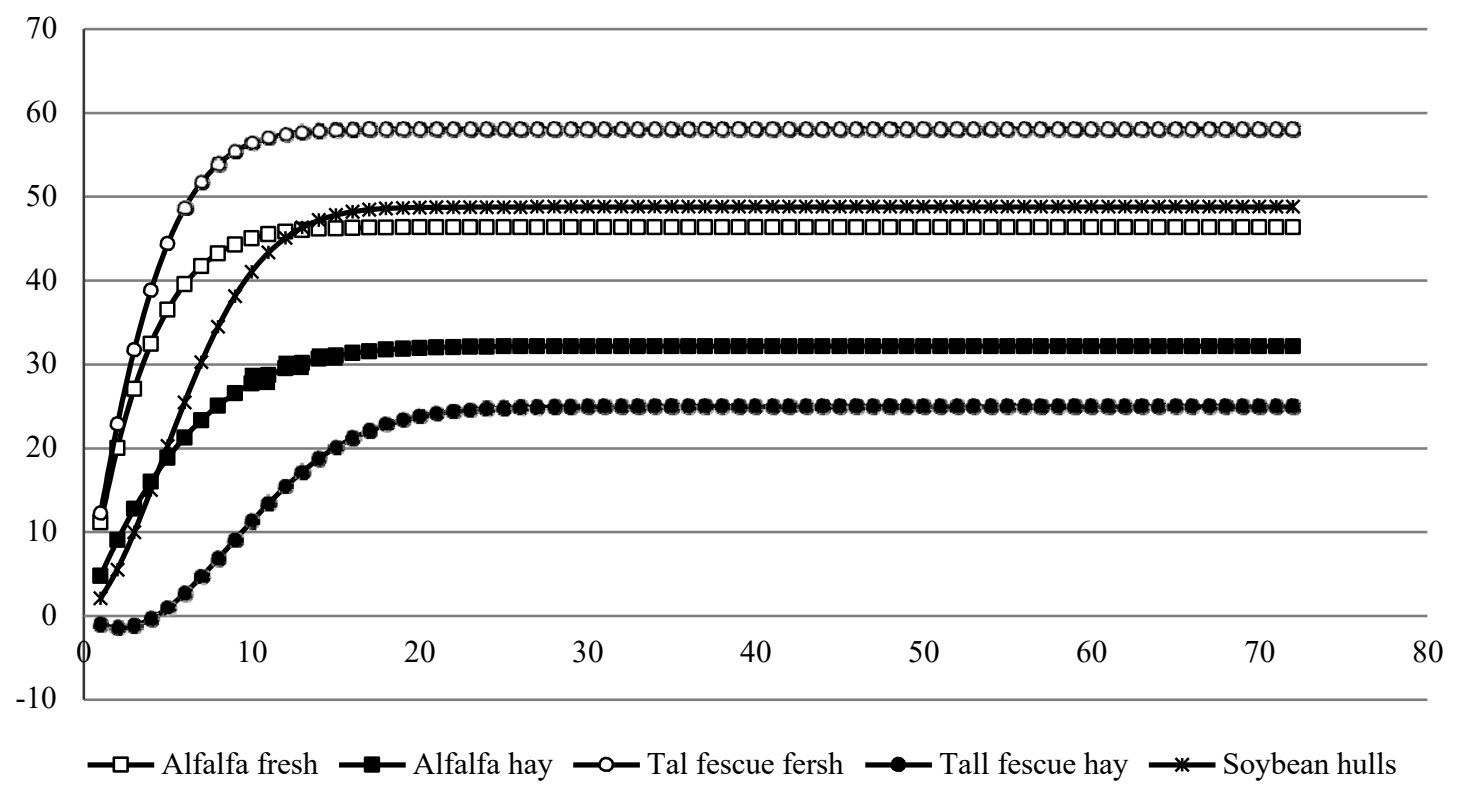

Figure 2.5. NDF ruminal degradation assuming $4 \% \cdot \mathrm{h}^{-1} \mathrm{Kp}$ using a batch culture system. 


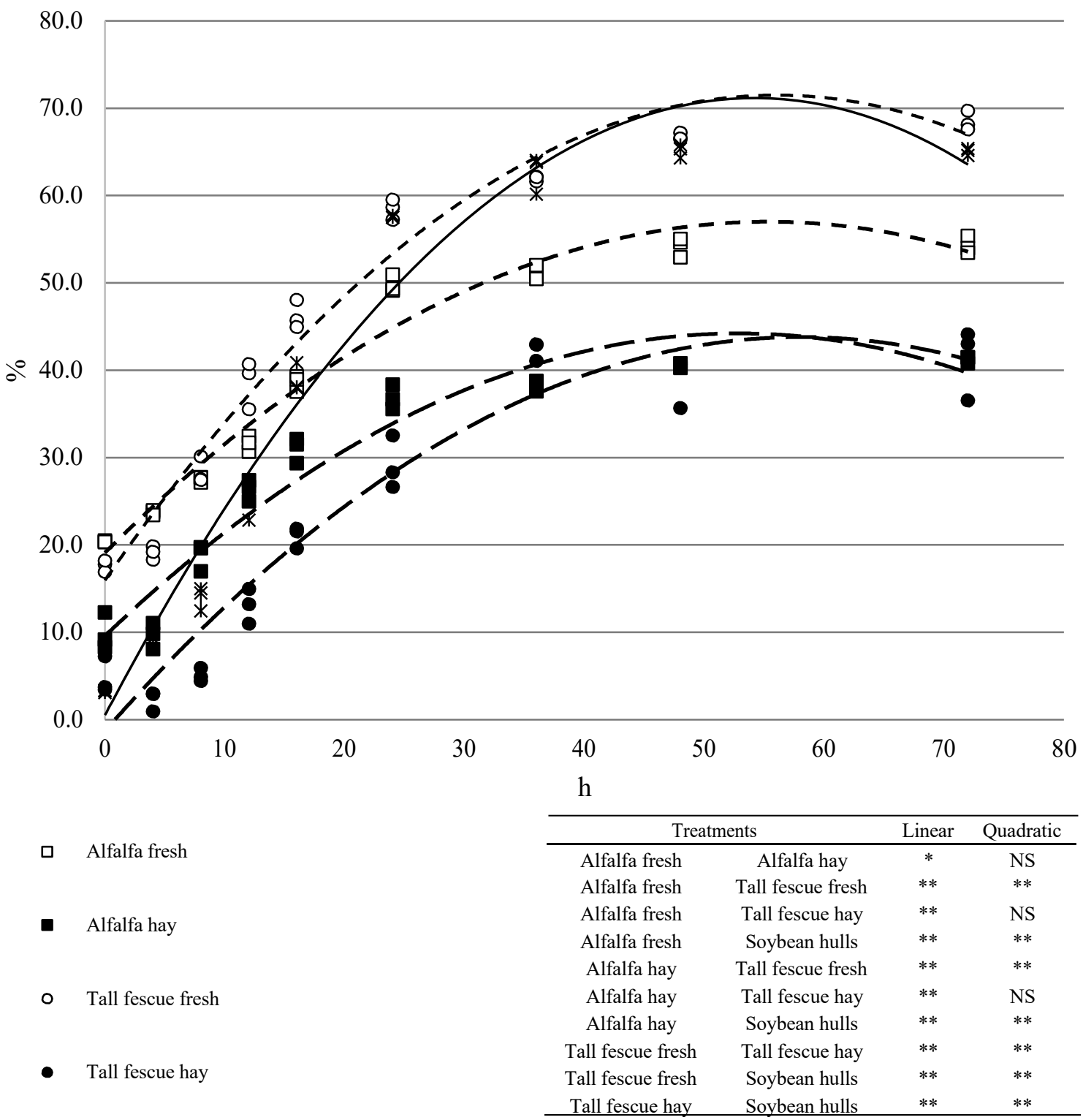

* Soybean hulls

$$
\begin{aligned}
& \text { - - Poly. (Alfalfa fresh) } \quad y=-0.0177 x^{2}+1.9832 x+15.944 \\
& \mathrm{R}^{2}=0.9697 \\
& \text { - Poly. (Alfalfa hay) } \\
& y=-0.0241 x^{2}+2.6081 x+0.4974 \\
& \mathrm{R}^{2}=0.9674 \\
& y=-0.0124 x^{2}+1.3697 x+19.099 \\
& \mathrm{R}^{2}=0.9702 \\
& \text { - Poly. (Tall fescue hay) } \quad \mathrm{y}=-0.0134 \mathrm{x}^{2}+1.5521 \mathrm{x}-1.2829 \\
& \mathrm{R}^{2}=0.9305 \\
& \text { Poly. (Soybean hulls) } \\
& y=-0.0124 x^{2}+1.3097 x+9.581 \\
& \mathrm{R}^{2}=0.9335
\end{aligned}
$$

\begin{tabular}{lcc}
\hline Treatments & Linear & Quadratic \\
\hline Alfalfa fresh & $* *$ & $* *$ \\
Alfalfa hay & $* *$ & $* *$ \\
Tall fescue fresh & $* *$ & $* *$ \\
Tall fescue hay & $* *$ & $* *$ \\
Soybean hulls & $* *$ & $* *$ \\
\hline
\end{tabular}

Figure 2.6. NDF ruminal degradation assuming $4 \% \cdot \mathrm{h}^{-1} \mathrm{Kp}$ using a batch culture system. 
Table 2.5. Degradation rate percent of variance source from different feedstuff using a batch culture system.

Variance source, \%

\begin{tabular}{|c|c|c|c|c|}
\hline Feedstuff & Experiment & Treatment & Hour & Error \\
\hline \multicolumn{5}{|l|}{ Nitrogen source } \\
\hline Soybean meal & 0.00 & - & 97.11 & 2.89 \\
\hline AminoPlus ${ }^{1}$ & 0.00 & - & 95.06 & 4.94 \\
\hline Cottonseed meal & 0.00 & - & 96.01 & 3.99 \\
\hline Dry distiller's grain solubles & 0.00 & - & 90.74 & 9.26 \\
\hline Porcine blood meal & 21.88 & - & 74.55 & 3.57 \\
\hline Fish meal & 0.00 & - & 98.31 & 1.69 \\
\hline Total & 3.41 & 0.00 & 93.30 & 3.28 \\
\hline \multicolumn{5}{|l|}{ Starch source } \\
\hline Ground corn & 0.00 & - & 99.72 & 0.28 \\
\hline Steam flaked corn & 0.00 & - & 99.58 & 0.42 \\
\hline Wheat middlings & 0.00 & - & 99.56 & 0.44 \\
\hline Barley grain & 0.00 & - & 99.30 & 0.70 \\
\hline Total & 0.00 & 0.00 & 99.55 & 0.45 \\
\hline \multicolumn{5}{|l|}{ NDF source } \\
\hline Alfalfa fresh & 0.00 & - & 99.03 & 0.97 \\
\hline Alfalfa hay & 20.19 & - & 78.47 & 1.34 \\
\hline Tall fescue fresh & 0.00 & - & 99.28 & 0.72 \\
\hline Tall fescue hay & 0.00 & - & 96.40 & 3.60 \\
\hline Soybean hulls & 0.00 & - & 99.70 & 0.30 \\
\hline Total & 9.90 & 0.00 & 89.17 & 0.93 \\
\hline
\end{tabular}

${ }^{1}$ AminoPlus (Ag Processing Inc, Omaha, NE) 


\title{
CHAPTER III
}

\author{
EFFECTS OF ROUGHAGE REMOVAL, RUMINAL \\ MODIFIER INCLUSION AND POST-RUMINAL AMINO ACID \\ SUPPLY ON GROWTH PERFORMANCE AND CARCASS \\ CHARACTERISTICS IN BEEF STEERS.
}

\begin{abstract}
The objective of this study was to determine the effects of roughage removal, ruminal modifiers, and diets balanced to meet effective energy and predicted AA requirement on beef steer growth performance. We hypothesized that growth performance of steers fed different ruminal modifiers, monensin (Rumensin 90, Elanco Animal Health, Greenfield, IN) vs. essential oils (Xtract X60-7065, Pancosma, Geneva, Switzerland), would not differ; that diets balanced to meet effective energy and predicted AA requirement would improve growth performance; and roughage removal would improve feed efficiency while maintaining growth performance. Crossbred steers $(\mathrm{n}=$ $150 ; 284 \pm 23 \mathrm{~kg} \mathrm{BW})$ were randomly assigned to 1 of 5 diets. Four diets were balanced to meet effective energy and predicted AA requirement with a traditional feedlot diet used as Control (DM basis; 15\% CP, 22\% NDF, 12\% fescue hay, 58\% corn, $27 \%$ wet distillers grains solubles; $250 \mathrm{mg} \cdot \mathrm{steer}^{-1} \cdot \mathrm{d}^{-1}$ monensin). Two diets contained roughage, with monensin (R-MO) or essential oils (R-EO) (DM basis; 17\% CP, 17\% NDF, 9.4\%
\end{abstract}


fescue hay, 70\% corn, 9.4\% AminoPlus, 9\% WDGS, 0.05\% AjiPro [Ajinomoto, Chicago, IL]; and $250 \mathrm{mg} \cdot \mathrm{steer}^{-1} \cdot \mathrm{d}^{-1}$ of monensin or $800 \mathrm{mg} \cdot \mathrm{steer}^{-1} \cdot \mathrm{d}^{-1}$ of Xtract X60-7065). Two diets replaced roughage with corn; no-roughage with monensin (NR-MO) or essential oil (NR-EO). Data were analyzed as a two-factor factorial arrangement plus control, with roughage and ruminal modifiers as main effects and steer as experimental unit. Main effects were only considered when interaction was not significant $(P>0.05)$. Control was compared only to R-MO. Steers fed roughage diets had greater BW $(P<0.01)$ compared no-roughage, and final BW was greater $(P=0.004)$ for R-MO than Control. Average daily gain was greater $(P<0.01)$ for steers fed roughage diets compared to noroughage. Steers fed balanced diet (R-MO) had greater ADG $(P<0.01)$ than Control. Dry matter intake was greater $(P<0.01)$ for steers fed roughage compared to no-

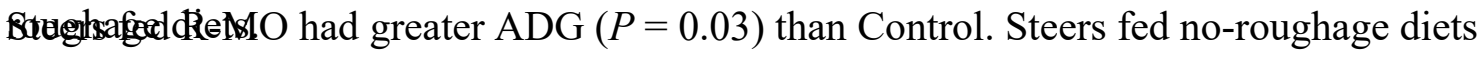
were more feed efficient $(P<0.01)$ compared to roughage diets. Hot carcass weight and marbling score were greater $(P<0.01)$ for steers fed roughage compared to no-roughage, and HCW was greater $(P=0.017)$ for R-MO than Control. Ribeye area was greater $(P=$ 0.02 ) for steers fed R-EO and other treatments did not differ among each other. Steers fed $\mathrm{R}-\mathrm{MO}$ had lesser ribeye area $\cdot \mathrm{cwt}^{-1}$ compared to all other diets $(P<0.05)$. Steers fed $\mathrm{R}-$ MO had greater yield grade $(P=0.03)$ compared to all other diets. In conclusion, roughage removal improved feed efficiency but gain and carcass weight were not optimized. Balancing diets to meet effective energy and predicted AA requirement increased ADG for overall period, and increased carcass weight. Overall steers performance was not affected by ruminal modifiers, monensin or essential oils. 


\section{INTRODUCTION}

Improving feed efficiency in beef production systems is a constant challenge. Among the available technologies, antibiotic ionophores have been successful in improving feed efficiency (Goodrich et al., 1984; Russell and Strobel, 1989) but their use has been banned in several countries such as the European Union.

Essential oils are alternatives to be used as a ruminal modifier feed additive due to their antimicrobial activities (Cardozo et al., 2005; Calsamiglia et al., 2007; Cobellis et al., 2016). Essential oils are generally recognized as safe for human and animal consumption, and have been tested in vitro and in vivo. Two other nutritional management approaches that have been evaluated are feeding no-roughage diets to feedlot cattle and balancing diets to meet effective energy and predicted AA requirement. Ionophores were consistently included on these approaches (Mueller, 2004; Davis, 2009; Minton, 2015).

In order to find alternatives to ionophores, several studies have been conducted to evaluate the effects of essential oils when fed to ruminants, especially dairy cows, but no studies have been performed using no-roughage diets. Because the effects of these feed additives are diet and $\mathrm{pH}$ dependent, essential oils needed to be tested on no-roughage diets.

We hypothesized that growth performance of steers fed different ruminal modifiers, monensin (Rumensin 90, Elanco Animal Health, Greenfield, IN) vs. essential oils (Xtract X60-7065, Pancosma, Geneva, Switzerland), would not differ; that diets balanced to meet effective energy and predicted AA requirement would improve growth 
performance; and roughage removal would improve feed efficiency while maintaining growth performance.

Therefore, the objective of this study was to determine the effects of roughage removal, ruminal modifiers and diets balanced to meet effective energy and predicted AA requirement on beef steer growth performance.

\section{MATERIAL AND METHODS}

\section{Animal Management}

The use of animals in this experiment was approved by the University of Missouri Animal Care and Use Committee. One hundred and forty mixed-breed steer calves (average $\mathrm{BW}=284 \pm 23 \mathrm{~kg}$ ) were purchased from a regional Missouri auction market and within 32-h of arrival at the Beef Research and Teaching Farm (Columbia, MO), steers were processed.

On initial processing, BW and hair color were recorded and bulls were castrated $(\mathrm{n}=7)$. Steers were identified with visual and electronic tags (High performance HDX Ultra EID tag; Allflex USA Inc., DFW Airport, TX). Steers were vaccinated with BoviShield GOLD BVD (Zoetis INC., Kalamazoo, MI); Endovac-Beef (IMMVAC, Columbia, MO); INFORCE 3 (Zoetis INC., Kalamazoo, MI) and ULTRACHOICE 8 (Zoetis INC., Kalamazoo, MI). Steers received an antiparasitic dose of Safe-Guard (Merck Animal Health, Summit, NJ) and were biopsied to test for persistent infection with bovine viral diarrhea. Metaphylactic dose $\left(1.1-\mathrm{mL} \cdot 45.45 \mathrm{~kg}^{-1} \mathrm{BW}\right)$ was administered using Draxxin (Zoetis INC., Kalamazoo, MI). 
Steers were placed in groups of 14 in 1 of 10 concrete pens and offered ad libitum access to water and received a corn based receiving diet for 14-d and a transitioning diet ( 3.1) for the following 7-d prior to feeding trial initiation.

On the first day of the trial (d 0), steers were implanted (Component with Tylan TE-IS, Elanco Animal Health, Indianapolis, IL; re-implant occurred on d 105) and consecutive 2-d weights were taken to determine initial BW. Treatments were randomly assigned to 2 of 10 pens. Steers were stratified by BW within color, ordered from lightest to heaviest weight and randomly assigned to 1 of 10 pens, producing similar average initial BW, and color across treatments and pens, resulting in 5 treatments with 2 pens per treatment and fourteen animals per pen.

Feed was delivered once daily from 0800 to $1000 \mathrm{~h}$ and individual feed intake was electronically measured using GrowSafe Systems Ltd., (Airdrie, AB, Canada). Pens were cleaned and re-bedded weekly with sawdust. Body weight was recorded in the morning $(0700 \mathrm{~h})$ prior to feeding, every $21 \mathrm{~d}$ for 162-d. Two consecutive BW were taken on $\mathrm{d} 0,1,63,64,161$ and 162 to determine initial and final BW, ADG, DMI \% BW, and G:F. Steers were slaughtered in a commercial plant (JBS, Grand Island, NE) when $70 \%$ appeared to grade Choice based upon subjective body composition evaluation. Carcass data were obtained by GeneNet (Hays, KS).

\section{Diet formulation}

Steers received the dietary treatment assigned on $\mathrm{d} 0$ throughout the experiment. Five dietary treatments ( 3.2 ) were composed of whole shell corn, wet distiller's grain solubles, fescue hay, AminoPlus (Ag Processing Inc, Omaha, NE), Ajipro-L (Ajinomoto, Chicago, IL), vitamin and mineral premix, urea, and either Rumensin 90 (Elanco Animal 
Health, Greenfield, IN) or Xtract X60-7065 (Pancosma, Geneva, Switzerland). Control diets (DM basis; $15 \% \mathrm{CP}, 22 \% \mathrm{NDF}, 12 \%$ fescue hay, $58 \%$ corn, $27 \%$ wet distiller's grain solubles; $250 \mathrm{mg} \cdot \mathrm{steer}^{-1} \cdot \mathrm{d}^{-1}$ monensin) were formulated to meet nutrient requirements to achieve $\mathrm{ADG}$ of $1.82 \mathrm{~kg}$ and $\mathrm{DMI}$ of $1.8 \%$ average $\mathrm{BW}$, with the inclusion of roughage in the diet. Ingredients and inclusion levels of Control diet were based upon the feedlot survey by Samuelson et al. (2016). Roughage diets were formulated to meet effective energy (Emmans, 1994) and predicted absorbable AA requirement for similar ADG and DMI $\left(1.82 \mathrm{~kg} \cdot \mathrm{d}^{-1} ; 1.8 \%\right.$ average BW) as Control diet. No-roughage diets had fescue hay replaced with whole corn. To meet nutrient requirements, no-roughage diets had ingredient levels adjusted with DMI predicted at $1.7 \%$ BW. Two diets contained roughage with monensin (R-MO) or essential oils (R-EO) (DM basis; 15\% CP, 17\% NDF, 9.4\% fescue hay, 70\% corn, 9.4\% AminoPlus, 9\% WDGS, $0.05 \%$ AjiPro [Ajinomoto, Chicago, IL]; and $250 \mathrm{mg} \cdot \mathrm{steer}^{-1} \cdot \mathrm{d}^{-1}$ of monensin or $800 \mathrm{mg} \cdot \mathrm{steer}^{-1} \cdot \mathrm{d}^{-1}$ of Xtract X60-7065) and 2 diets had no-roughage with monensin (NRMO) or essential oil (NR-EO) (DM basis; 14\% CP, 13\% NDF, 80\% corn, $8.7 \%$ AminoPlus, 9\% WDGS, 0.05\% AjiPro [Ajinomoto, Chicago, IL]; and $250 \mathrm{mg} \cdot \mathrm{steer}^{-1} \cdot \mathrm{d}^{-}$ ${ }^{1}$ of monensin or $800 \mathrm{mg} \cdot \mathrm{steer}^{-1} \cdot \mathrm{d}^{-1}$ of Xtract X60-7065).

Dietary samples were collected weekly, dried in forced air oven at $55^{\circ} \mathrm{C}$ for $72-\mathrm{h}$, and ground initially to pass through a 5-mm screen (Wiley Mill; Arthur H. Thomas Company, Philadelphia, PA). Subsamples were composited bi-monthly and ground again to pass through a 1-mm screen (Cyclotech grinder; Foss Tecator Cyclotec 1093 sample mill). Composited and ground samples were analyzed for DM, ash (AOAC, 2006), 
nitrogen content (vario Macro Cube, Elementar Americas, Mt. Laurel, NJ), NDF and ADF (ANKOM Technology, Macedon, NY) (Goering and Van Soest, 1970).

\section{Statistical analysis}

Data analyses were performed by analysis of variance (ANOVA) using SAS (SAS 9.4 Institute Inc., Cary, NC). When F-test was significant $(P<0.05)$, means separation was performed using LSMEANS statement. Monthly nutrient composition was analyzed using GLM procedure. Performance and carcass data were analyzed using GLIMMIX procedure. Control diet was only compared to R-MO as a complete randomized design. The other 4 treatments were compared as a two-factor factorial arrangement. Steer was considered as experimental unit. Carcass comparison model included 2 main factors and interaction between it as independent variables. Performance data were analyzed as repeated measure. The model included 2 main factors (roughage, ruminal modifier), time, and all possible interaction combinations among independent variables.

\section{RESULTS}

Dry matter $(\%)$ was greater $(P<0.001)$ for no-roughage diets compared to roughage which was greater than Control. Crude protein $(\% \mathrm{DM})$ was $8.15 \%$ greater $(P=$ 0.014) for Control (15.45) compared to NR-MO (14.24) and other diets did not differ. Neutral detergent fiber and ADF decreased between Control, roughage, and no-roughage diets for each respective diet. $(P<0.001)$. 
Growth performance and feed efficiency are summarized on 3.3. By design, initial BW did not differ $(P>0.79)$ among treatments. Calves fed roughage diets had greater BW compared to no-roughage at the end of period 1 and $2(21 \mathrm{~kg}$ and $34.5 \mathrm{~kg}$ differences respectively). Body weight did not differ at the end of period 1 between Control and R-MO however at the end of period two, BW was greater $(P=0.001)$ for RMO by $32 \mathrm{~kg}$. There were no interactions and no additive effect on BW $(P>0.15)$.

From total period, there was a roughage effect on ADG, where calves fed roughage, had $10.74 \%$ greater $(P=0.001)$ ADG than no-roughage. When data were separated into 2 periods, period 1 had similar results as overall period, however, during period two, there was an interaction effect $(P<0.001)$, in which calves feed R-MO had greater ADG than R-EO and this response was inverted for no-roughage diets, where NREO had greater ADG than NR-MO. For all periods, steers fed a balanced diet R-MO were growing faster $(P<0.02)$ than Control.

Dry matter intake from total period followed the same pattern as ADG, steers fed roughage had $21.3 \%$ greater $(P<0.001)$ DMI than no-roughage. Period 1 had similar results for DMI than total period. However, during period two, due to a roughage and additive interaction $(P<0.001)$, steers feed roughage diets, had greater DMI than noroughage diets, and steers consuming NR-EO had greater DMI than those consuming NR-MO. Steers fed a balanced diet of R-MO had $11 \%$ greater $(P<0.02)$ DMI than Control. However, this difference was not observed for period 2 and total period $(P>$ $0.08)$. 
When DMI was expressed as a percent of BW, dietary treatments had the same response as DMI $(\mathrm{kg})$ except for effect of balancing during period two, in which Control steers had $4.2 \%$ greater $(P<0.001)$ DMI than R-MO.

For total period, steers fed no-roughage diets were $12 \%$ more feed efficient than steers fed roughage diets. Period 1 had similar results for G:F compared to total period. However, during period two, due to a roughage by additive interaction $(P<0.001)$, G:F decreased among steers fed NR-MO, NR-EO, R-MO, R-EO for each respective diet. Period 2 was the only period when steers fed R-MO, were $11.8 \%$ more feed efficient $(P<$ 0.001) than Control.

Hot carcass weight was greater $(P<0.001)$ for steers fed roughage than noroughage (31.5 $\mathrm{kg}$ difference), and R-MO was greater $(P=0.17)$ than Control $(17 \mathrm{~kg}$ difference). Ribeye area was $8.2 \%$ greater $(P=0.02)$ for steers fed R-EO and did not differ for other diets. Ribeye area in relation to $\mathrm{HCW}$ was $8.2 \%$ less $(P<0.05)$ for R-MO compared to all other diets, including the Control. Marbling score was $10.4 \%$ less $(P<$ 0.05) for NR-MO compared to all other diets, except NR-EO, which did not differ from any diet. Yield grade was $18.9 \%$ greater $(P<0.03)$ compared to all diets, as well as Control.

\section{DISCUSSION}

Dietary treatments were formulated using a predictive model developed in our laboratory. Predicted versus observed data (intake and performance) were incorporated into the model generating 2 predictions of nutrient requirements. Predicted nutrient 
requirements were compared to estimate how similar dietary treatments were compared to the proposed experimental design. Dry matter intake on average was $25.4 \%(26 \%$ Control; 38\% R-EO; 36\% R-MO; 17\% NR-EO; 9\% NR-MO) greater than predicted, which caused an increase of energy and AA intake over what was expected. Effective energy was about 18.5\% (23\% Control; 24\% R-EO; 19\% R-MO; 15\% NR-EO; 12\% NRMO) greater than estimated with predicted intake. The predicted most limiting AA were lysine followed by arginine. Arginine and lysine were predicted to be 89 and $80 \%$ of the requirements respectively for Control, and 100\% for R-EO, R-MO, NR-EO and NR-MO. Due to the greater intake, new predictions were 103, 114, 110, 105 and 102\% for arginine and 92, 115, 111, 107 and 102\% for lysine in Control, R-EO, R-MO, NR-EO and NR$\mathrm{MO}$, respectively. Based on the model predictions, arginine was not limiting steer performance wheras lysine was limiting for the Control treatment.

\section{Roughage effects}

We hypothesized that feeding no-roughage diets would improve feed efficiency while maintaining growth performance. The removal of roughage in the diets caused a decrease in DMI, leading to a decrease in ADG, however, ADG was not decreased in the same degree as DMI, which resulted in greater feed efficiency for no-roughage fed steers. This decreased growth performance for no-roughage fed steers also impacted HCW, and most likely due to the lighter carcass, steers had a decrease in marbling score.

In comparison with findings of previous research, Kreikemeier et al. (1990) observed a linear increase in DMI with increasing dietary roughage while ADG, G:F and HCW responded quadratically. When roughage was included at 5 or $10 \%$, steers tended to gain faster, were more efficient and had heavier carcasses than steers fed no-roughage 
or those fed $15 \%$ roughage. There was a high incidence of condemned livers, 55 to $71 \%$, across treatments with no effect of roughage level. Authors reported this high percentage was expected because tylosin was not provided on the diets (Kreikemeier et al., 1990). Traxler et al. (1995) investigated the influence of roughage on performance of long-fed Holstein steers. They observed that, steers fed diets composed of whole shell corn and pelleted supplement had lesser DMI, ADG did not differ and G:F was greater compared to diets containing roughage. Diets containing $100 \%$ concentrate $(87 \%$ high moisture corn; $6.3 \%$ soybean meal) versus $85 \%$ concentrate with $15 \%$ corn silage were used to test the effects of timing and level of roughage inclusion on performance of feedlot steers by Loerch and Fluharty (1998). They reported no difference in ADG and DMI, but a 10\% improvement in G:F when steers where fed $100 \%$ concentrate compared to $85 \%$.

Concentrate level regime did not affect carcass characteristics. Even though steers were not fed antibiotics to control liver abscesses, concentrate level fed during growing phase had no effect on condemned livers incidence. However, condemned livers significantly increased, doubling the amount, when $100 \%$ concentrate was fed during the finishing phase compared to $85 \%$ concentrate (Loerch and Fluharty, 1998). Based on data from 6 large-pen feedlot trials, using a total of 6,895 steers, Turgeon et al. (2010), concluded that feeding no-roughage diets containing whole shell corn (processed corn was also included) reduced final BW, ADG and DMI by 1.5, 3.7 and 5.7\%, respectively, and improved G:F by $3.5 \%$ compared to diets containing roughage (6.6 to $10 \%$ roughage inclusion). Diets containing processed corn (high-moisture and dry-rolled) and wet distiller's grain solubles without roughage were fed to steers and caused a decrease in 
DMI, final BW, $\mathrm{ADG}, \mathrm{HCW}$ and 12th rib fat without a difference in G:F compared to steers fed the same diets containing different roughage sources (Benton et al., 2015).

To reduce the incidence and severity of digestive problems, most finishing diets generally contain 6 to $12 \%$ roughage (Samuelson et al., 2016) even though roughage is poorly digested in high concentrate finishing diets. Roughage level has been shown to influence DMI, (Defoor et al., 2002) leading to effects on feedlot performance and carcass characteristics. However, effects of roughage inclusion on feed intake are not well understood. The effect of roughage level on DMI in feedlot cattle was described by (Galyean and Defoor, 2003) in a review which compiled data from 7 studies involving 11 trials, in which 2 of them evaluated no-roughage diets. The authors reported, based on linear regression models, that the increase in DMI with increased roughage inclusion in high concentrate diets is a function of changes in dietary NDF $\left(r^{2}=0.920\right)$ rather than only roughage level $\left(r^{2}=0.699\right)$ in the diet. Galyean and Defoor (2003) noted that changes in roughage inclusion greater than 5\% (\% DM), affect DMI as a reflection of energy dilution; in other words, cattle decrease DMI to maintain energy intake.

\section{Balancing for AA:EE effects}

We hypothesized that feeding balanced diets to meet effective energy and predicted AA requirement would improve growth performance. Confirming our hypothesis, steers fed R-MO diets had 9.4\% greater ADG for total period compared to Control diets, resulting in $4.7 \%$ heavier $\mathrm{HCW}, 4.8 \%$ smaller ribeye area $\cdot \mathrm{cwt}^{-1}$, and $20.7 \%$ greater yield grade. When analyzed by period, steers did not have the same response. Steers fed a balanced diet had greater ADG, DMI and no difference in G:F was observed during period 1, while for period two, ADG continued to be greater with no 
difference in DMI leading to a $12.5 \%$ greater G:F compared to Control diets. It is important to point out that Control and R-MO diets were different in DM (60.37 vs. 74.84), NDF (22.11 vs. 17.22$)$, ADF (8.13 vs. 6.34$)$, and that CP was $15.2 \%$ for both diets.

There is an extensive amount of published research on effects of RUP in feedlot steer growth performance, which could increase post-ruminal AA supply if balanced to meet microbial requirements. However, limited research was selected for comparison. Selection criteria included roughage levels, species, trial period, and feed sources. Zinn and Owens (1993) fed increasing RUP levels $(0,2,4$ and 6\%) in a diet using a blend of equal amounts of blood meal, meat and bone meal, and feather meal to lightweight steers $(\mathrm{BW}=198 \mathrm{~kg}$ ) for an 84-d period. When 2\% RUP was added, ADG, DMI and G:F had a quadratic, cubic and quadratic improvement by $13.4,4.4$ and $8.6 \%$, respectively, and diets containing additional RUP amounts resulted in performance similar to the zero percent treatment. Legleiter et al. (2005) supplemented increasing amounts of blood meal, $0.5,1,1.5$ and 2 times amounts to meet arginine requirements for growing beef cattle, and did not observed an increase in lean tissue accretion. Authors noted the lack of response was most likely due to greater energy used to metabolize excess $\mathrm{N}$ to urea. Using the same diet balancing program as in the current study, Minton (2015) compared different feeding systems used to feed feedlot cattle. Compared with the current study, heifers with similar initial BW were fed for a similar time period. Diets contained similar ingredients and inclusions, except for Traditional (equivalent to our Control) diet in Exp. 2 , which included processed corn (15\% high moisture corn, $10 \%$ ground corn in the supplement, and $43 \%$ whole shell corn) and corn silage. For both experiments, authors 
reported that when heifers were fed traditional diets, DMI was greater and ADG did not differ, which resulted in less feed conversion compared to no-roughage diets balanced to meet effective energy and predicted AA requirement.

It is well known that monogastric animals have satiety controlled by energy and AA requirements, and that feed efficiency is optimized when energy and limiting AA requirements are met (NRC, 2012). Effective energy (Emmans, 1994) has been shown to predict energy requirement more accurately than NE, which over predicts the energy requirement by $20 \%$ (Liang, 2013). Absorbable AA requirements are met by postruminal AA supplied from microbial protein and RUP. To maximize the supply, microbial requirements ( $\mathrm{N}$ and peptides) should be met (Mueller, 2004; Brooks et al., 2012; Liang, 2013). Therefore, to maximize animal growth potential and feed efficiency, AA available for growth need to be proportional to energy available for growth (AA:EE). Therefore, improvement in feed efficiency is achieved when nutrients are supplied to match growth potential supported by energy density of the diet consumed.

\section{Roughage $X$ ruminal modifiers effects}

We hypothesized that growth performance of steers fed different ruminal modifiers would not differ. Overall and during period 1 , steer performance did not differ between 2 ruminal modifiers. However, during period 2 we observed a roughage inclusion by ruminal modifier interaction for ADG, DMI and G:F, leading to differences in ribeye area $\cdot \mathrm{cwt}^{-1}$. When roughage was present, monensin fed steers consumed the same amount of feed, gained more weight and where more efficient than those fed essential oils. However, when roughage was removed, essential oil fed steers consumed more feed, gained more weight and were less efficient than monensin fed steers. Steers 
fed R-MO had smaller ribeye area $\mathrm{cwt}^{-1}$ than all other treatments. Differences between growth and finishing phase might be due to different microbial adaptations to essential oils and monensin (Calsamiglia et al., 2007).

Essential oils have been shown to alter ruminal fermentation, feed digestibility and animal performance from on in vitro (Cardozo et al., 2005; Busquet et al., 2006; Cardozo et al., 2006) and in vivo studies (Geraci et al., 2012; Cobellis et al., 2016; Oh et al., 2017). Although essential oils have been extensively researched, most studies evaluated dairy cows with high roughage inclusion, and with different essential oil compounds or combinations, which makes direct comparisons with previous research difficult.

Geraci et al. (2012) fed 2 similar basal diets for $44-d$ containing about $72 \%$ dry rolled corn, $24 \%$ pelleted sunflower meal, $2.5 \%$ alfalfa hay, and $2.3 \%$ mineral vitamin premix. They compared growth performance and feed intake patterns of lightweight steers (initial BW $=141 \mathrm{~kg}$ ) fed monensin $\left(46.7 \mathrm{mg} \cdot \mathrm{kg}^{-1} \mathrm{DM}\right)$ vs. a blend containing eugenol, cinnamaldehyde and capsicum oleoresin $\left(400 \mathrm{mg} \cdot \mathrm{steer}^{-1} \cdot \mathrm{day}^{-1}\right)$ for $84-\mathrm{d}$. Authors reported ADG was $16 \%$ greater for essential oils fed steers than monensin, and no difference was observed for other performance parameters: body composition (ultrasound on back fat and longissimus muscle area) and feed intake pattern. Meyer et al. (2009) compared growth performance and carcass characteristics of steers fed a high concentrate ( $7.5 \%$ alfalfa hay) basal diet containing either no ruminal modifier, monensin with tylosin, essential oil blend with tylosin or essential oil blend, which contained thymol, eugenol, vanillin, guaiacol, and limonene. They observed a 5\% decrease in DMI for monensin with tylosin fed steers compared to other treatments, $4.2 \%$ greater G:F for 
treatments containing tylosin, and $17.3 \%$ greater yield grade for steers fed essential oils with tylosin.

In vivo studies evaluating essential oils on feedlot growth performance and further effects on carcass characteristics are needed. Results from in vitro research provides important information, however, they provide relative values rather than absolute. For example, because rumen fluid is filtered prior to use in vitro, most microbes present are those associated with the liquid phase, which is only 20 to $30 \%$ of the total population (Miron et al., 2001). Findings from research using cannulated animals are closer to ruminal fermentation absolute values, but provide no information regarding growth performance and carcass characteristics.

\section{CONCLUSION}

In conclusion, roughage removal improved feed efficiency but gain and final product carcass weight were not optimized. Balancing diets to meet effective energy and predicted $\mathrm{AA}$ requirement increased $\mathrm{ADG}$ for the total period, resulting in a heavier carcass, increased gain and feed intake. There was no difference in feed efficiency during period 1, whereas for period two, gain continued to be greater with no difference in feed intake leading to improved feed efficiency. Steer performance did not differ when fed ruminal modifiers, monensin and essential oils including eugenol, cinnamaldehyde and capsicum oleoresin, providing evidence for the use of essential oils as ruminal modifiers to feedlot steers fed high concentrate and no-roughage diets. 
Table 3.1. Dietary ingredients and composition for receiving and transitioning diets.

\begin{tabular}{|c|c|c|}
\hline Ingredient, $\% D M$ & Receiving & Transition \\
\hline Whole corn & 66.84 & 51.61 \\
\hline Dry distiller's grain solubles & 7.60 & 21.78 \\
\hline AminoPlus ${ }^{1}$ & - & 13.07 \\
\hline Oatlage & - & 10.81 \\
\hline Soybean meal & 8.03 & 2.76 \\
\hline Rye baleage & 8.11 & - \\
\hline Porcine blood meal & 4.81 & - \\
\hline Limestone & 1.08 & 1.66 \\
\hline Salt & 0.48 & 0.46 \\
\hline Magnesium oxide & 0.20 & 0.21 \\
\hline Trace mineral premix ${ }^{2}$ & 0.21 & 0.20 \\
\hline Vitamin premix ${ }^{3}$ & 0.29 & 0.20 \\
\hline Rumensin $90^{4}$ & - & 0.03 \\
\hline Dyna- $\mathrm{K}^{5}$ & 0.99 & - \\
\hline Choice white grease & 0.50 & - \\
\hline Cocci Curb $10 X^{6}$ & 0.68 & - \\
\hline Aureomycin $50^{7}$ & 0.11 & - \\
\hline Urea & 0.10 & - \\
\hline \multicolumn{3}{|l|}{ Calculated nutrient composition } \\
\hline $\mathrm{DM}, \%$ & 79.95 & 73.00 \\
\hline $\mathrm{CP}, \% D M$ & 18.55 & 19.50 \\
\hline
\end{tabular}

\footnotetext{
${ }^{1}$ AminoPlus; Ag Processing Inc, Omaha, NE.

${ }^{2}$ Trace mineral premix contained $24 \% \mathrm{Ca}, 2.5 \% \mathrm{Fe}, 2 \% \mathrm{Mn}, 3 \% \mathrm{Zn}, 1 \% \mathrm{Cu}, 100 \mathrm{ppm} \mathrm{Se}, 500$ ppm I, 100 ppm Co; Nutra Blend, Neosho, MO.

${ }^{3}$ Vitamin premix contained 8.818.490,487 IU/ $\mathrm{kg}$ of vitamin A; $1.763 .698 .097 \mathrm{IU} / \mathrm{kg}$ of vitamin D; 1.102,311 IU/kg of vitamin E; Nutra Blend, Neosho, MO.

${ }^{4}$ Rumensin 90; Elanco Animal Health, Greenfield, IN.

${ }^{5}$ Dyna-K; The Mosaic Company, Plymouth, MN.

${ }^{6}$ Cocci Curb 10X, Nutra Blend, Neosho, MO.

${ }^{7}$ Aureomycin 50; Zoetis INC., Kalamazoo, MI.
} 
Table 3.2. Dietary ingredient composition and nutrient analysis of treatments.

\begin{tabular}{|c|c|c|c|c|c|c|c|}
\hline \multirow[b]{3}{*}{ Item } & \multicolumn{5}{|c|}{ Treatments } & \multirow[b]{3}{*}{ SEM } & \multirow[b]{3}{*}{$P$-value } \\
\hline & \multicolumn{2}{|c|}{ No-roughage } & \multicolumn{2}{|c|}{ Roughage } & \multirow[b]{2}{*}{ Control } & & \\
\hline & Essential Oil & Monensin & Essential Oil & Monensin & & & \\
\hline \multicolumn{8}{|l|}{ Ingredient, $\% D M$} \\
\hline Whole corn & 79.58 & 79.58 & 69.74 & 69.63 & 57.59 & & \\
\hline Wet distiller's grain solubles & 8.98 & 8.98 & 8.96 & 8.96 & 27.19 & & \\
\hline AminoPlus $^{1}$ & 8.78 & 8.66 & 9.34 & 9.46 & - & & \\
\hline Tall fescue hay & - & - & 9.43 & 9.43 & 12.06 & & \\
\hline \multicolumn{8}{|l|}{ Supplement $\% D M$} \\
\hline Premix $^{2}$ & 2.2 & 2.32 & 2.32 & 2.32 & 2.81 & & \\
\hline Urea & 0.39 & 0.39 & 0.13 & 0.13 & 0.34 & & \\
\hline Ajipro- $\mathrm{L}^{3}$ & 0.06 & 0.05 & 0.06 & 0.05 & - & & \\
\hline Rumensin $90^{4}$ & - & 0.01 & - & 0.01 & 0.02 & & \\
\hline Xtract, X60-7065 & 0.01 & - & 0.01 & - & - & & \\
\hline \multicolumn{8}{|l|}{ Dietary nutrient analysis } \\
\hline $\mathrm{DM}, \%$ & $76.21^{\mathrm{ab}}$ & $76.68^{\mathrm{a}}$ & $74.32^{b}$ & $74.84^{\mathrm{ab}}$ & $60.37^{\mathrm{c}}$ & 0.49 & $<0.001$ \\
\hline $\mathrm{CP}, \% D M$ & $14.43^{\mathrm{ab}}$ & $14.24^{b}$ & $15.07^{\mathrm{ab}}$ & $14.96^{\mathrm{ab}}$ & $15.45^{\mathrm{a}}$ & 0.25 & 0.014 \\
\hline $\mathrm{NDF}, \% D M$ & $13.15^{\mathrm{c}}$ & $13.27^{\mathrm{c}}$ & $17.27^{\mathrm{b}}$ & $17.12^{b}$ & $22.11^{\mathrm{a}}$ & 0.72 & $<0.001$ \\
\hline $\mathrm{ADF}, \% D M$ & $3.88^{\mathrm{c}}$ & $3.70^{\mathrm{c}}$ & $6.18^{b}$ & $6.34^{\mathrm{b}}$ & $8.13^{\mathrm{a}}$ & 0.23 & $<0.001$ \\
\hline
\end{tabular}

\footnotetext{
${ }^{1}$ AminoPlus; Ag Processing Inc, Omaha, NE.

${ }^{2}$ Premix contained: salt, limestone, vitamins ADE, magnesium oxide and trace minerals.

${ }^{3}$ AjiPro-L; Ajinomoto, Chicago, IL.

${ }^{4}$ Rumensin 90; Elanco Animal Health, Greenfield, IN.

${ }^{5}$ Xtract 7065, contained 9.5\% eugenol, 5.5\% cinnamaldehyde and 3.5\% capsicum oleoresin; Pancosma, Geneva, Switzerland.
} 
Table 3.3. Effects of roughage removal, ruminal modifier inclusion and post ruminal amino acid supply on growth performance and feed efficiency during period one.

\begin{tabular}{|c|c|c|c|c|c|c|c|c|c|c|}
\hline \multirow[b]{3}{*}{ Item } & \multicolumn{5}{|c|}{ Treatment } & \multirow[b]{3}{*}{ SEM } & \multirow[b]{3}{*}{ Roughage } & \multirow{2}{*}{\multicolumn{2}{|c|}{$P$-value }} & \multirow[b]{3}{*}{ Balancing } \\
\hline & \multicolumn{2}{|c|}{ No-roughage } & \multicolumn{2}{|c|}{ Roughage } & \multirow[b]{2}{*}{ Control } & & & & & \\
\hline & $\begin{array}{c}\text { Essential } \\
\text { oil }\end{array}$ & Monensin & $\begin{array}{c}\text { Essential } \\
\text { oil } \\
\end{array}$ & Monensin & & & & Additive & $\begin{array}{c}\text { Rough. X } \\
\text { Addit. }\end{array}$ & \\
\hline \multicolumn{11}{|l|}{ Period 1} \\
\hline \multicolumn{11}{|l|}{ Body weight, $\mathrm{kg}$} \\
\hline Initial & 284 & 285 & 285 & 286 & 283 & 1.87 & 0.897 & 0.936 & 0.982 & 0.789 \\
\hline Final & $409^{b}$ & $411^{b}$ & $433^{\mathrm{a}}$ & $429^{\mathrm{aA}}$ & $415^{\mathrm{A}}$ & 2.40 & 0.004 & 0.927 & 0.718 & 0.145 \\
\hline $\mathrm{ADG}, \mathrm{kg} / \mathrm{d}$ & $1.95^{\mathrm{b}}$ & $1.97^{\mathrm{b}}$ & $2.31^{\mathrm{a}}$ & $2.25^{\mathrm{aA}}$ & $2.07^{\mathrm{B}}$ & 0.024 & $<0.001$ & 0.741 & 0.579 & 0.018 \\
\hline DMI, $\mathrm{kg} / \mathrm{d}$ & $7.32^{b}$ & $7.41^{\mathrm{b}}$ & $9.71^{\mathrm{a}}$ & $9.40^{\mathrm{aA}}$ & $8.42^{\mathrm{B}}$ & 0.095 & $<0.001$ & 0.595 & 0.370 & $<0.001$ \\
\hline DMI, $\% B W$ & $2.11^{\mathrm{b}}$ & $2.13^{\mathrm{b}}$ & $2.70^{\mathrm{a}}$ & $2.62^{\mathrm{aA}}$ & $2.42^{\mathrm{B}}$ & 0.020 & $<0.001$ & 0.411 & 0.269 & $<0.001$ \\
\hline $\mathrm{G}: \mathrm{F}$ & $0.27^{\mathrm{a}}$ & $0.27^{\mathrm{a}}$ & $0.24^{\mathrm{b}}$ & $0.24^{\mathrm{bA}}$ & $0.25^{\mathrm{A}}$ & 0.002 & $<0.001$ & 0.989 & 0.634 & 0.563 \\
\hline \multicolumn{11}{|l|}{ Period 2} \\
\hline Body weight, $\mathrm{kg}$ & $590^{\mathrm{b}}$ & $578^{b}$ & $611^{\mathrm{a}}$ & $626^{\mathrm{aA}}$ & $594^{\mathrm{B}}$ & 2.62 & $<0.001$ & 0.911 & 0.145 & 0.001 \\
\hline $\mathrm{ADG}, \mathrm{kg} / \mathrm{d}$ & $1.85^{\mathrm{b}}$ & $1.70^{\mathrm{c}}$ & $1.83^{b c}$ & $2.00^{\mathrm{aA}}$ & $1.83^{\mathrm{B}}$ & 0.010 & $<0.001$ & 0.371 & $<0.001$ & $<0.001$ \\
\hline DMI, $k g / d$ & $9.65^{b}$ & $8.69^{\mathrm{c}}$ & $11.06^{\mathrm{a}}$ & $11.16^{\mathrm{aA}}$ & $11.16^{\mathrm{A}}$ & 0.066 & $<0.001$ & $<0.001$ & $<0.001$ & 0.949 \\
\hline DMI, $\% B W$ & $1.93^{\mathrm{b}}$ & $1.76^{\mathrm{c}}$ & $2.12^{\mathrm{a}}$ & $2.12^{\mathrm{aB}}$ & $2.21^{\mathrm{A}}$ & 0.009 & $<0.001$ & $<0.001$ & $<0.001$ & $<0.001$ \\
\hline $\mathrm{G}: \mathrm{F}$ & $0.19^{b}$ & $0.20^{\mathrm{a}}$ & $0.17^{\mathrm{d}}$ & $0.18^{\mathrm{cA}}$ & $0.16^{\mathrm{B}}$ & 0.001 & $<0.001$ & $<0.001$ & $<0.001$ & $<0.001$ \\
\hline \multicolumn{11}{|l|}{ Overall } \\
\hline $\mathrm{ADG}, \mathrm{kg} / \mathrm{d}$ & $1.89^{\mathrm{b}}$ & $1.81^{\mathrm{b}}$ & $2.02^{\mathrm{a}}$ & $2.10^{\mathrm{aA}}$ & $1.92^{\mathrm{B}}$ & 0.012 & 0.001 & 0.975 & 0.060 & 0.018 \\
\hline DMI, $\mathrm{kg} / \mathrm{d}$ & $8.79^{b}$ & $8.24^{\mathrm{b}}$ & $10.55^{\mathrm{a}}$ & $10.53^{\mathrm{aA}}$ & $10.03^{\mathrm{A}}$ & 0.095 & $<0.001$ & 0.182 & 0.191 & 0.082 \\
\hline DMI, $\% B W$ & $2.01^{\mathrm{b}}$ & $1.91^{\mathrm{b}}$ & $2.35^{\mathrm{a}}$ & $2.31^{\mathrm{aA}}$ & $2.29^{\mathrm{A}}$ & 0.011 & $<0.001$ & 0.102 & 0.422 & 0.777 \\
\hline $\mathrm{G}: \mathrm{F}$ & $0.22^{\mathrm{a}}$ & $0.22^{\mathrm{a}}$ & $0.19^{b}$ & $0.20^{\mathrm{bA}}$ & $0.19^{\mathrm{A}}$ & 0.001 & 0.002 & 0.342 & 0.591 & 0.305 \\
\hline
\end{tabular}

$\mathrm{a}, \mathrm{b}, \mathrm{c}, \mathrm{d}$ least square means within a row with different superscript differ $(P<0.05)$.

${ }^{\mathrm{A}, \mathrm{B}}$ least square means within a row with different superscript differ $(P<0.05)$. 
Table 3.4. Effects of roughage removal, ruminal modifier inclusion and post ruminal amino acid supply on carcass characteristics.

\begin{tabular}{|c|c|c|c|c|c|c|c|c|c|c|}
\hline \multirow[b]{3}{*}{ Item } & \multicolumn{5}{|c|}{ Treatment } & \multirow[b]{3}{*}{ SEM } & \multirow{2}{*}{\multicolumn{4}{|c|}{$P$-value }} \\
\hline & \multicolumn{2}{|c|}{ No-roughage } & \multicolumn{2}{|c|}{ Roughage } & \multirow[b]{2}{*}{ Control } & & & & & \\
\hline & $\begin{array}{c}\text { Essential } \\
\text { oil } \\
\end{array}$ & Monensin & $\begin{array}{c}\text { Essential } \\
\text { oil } \\
\end{array}$ & Monensin & & & Roughage & \multicolumn{2}{|c|}{$\begin{array}{cc}\text { Rough. X } \\
\text { ve } \quad \text { Addit. }\end{array}$} & Balancing \\
\hline $\mathrm{HCW}, \mathrm{kg}$ & $351^{\mathrm{b}}$ & $342^{\mathrm{b}}$ & $379^{a}$ & $377^{\mathrm{aA}}$ & $360^{\mathrm{B}}$ & 5.35 & $<0.001$ & 0.408 & 0.555 & 0.017 \\
\hline Ribeye area, $\mathrm{cm}^{2}$ & $81.22^{b}$ & $82.88^{\mathrm{b}}$ & $89.33^{\mathrm{a}}$ & $82.63^{\mathrm{bA}}$ & $83.20^{\mathrm{A}}$ & 1.762 & 0.028 & 0.156 & 0.020 & 0.798 \\
\hline Ribeye area/cwt, $\mathrm{cm}^{2}$ & $23.22^{\mathrm{a}}$ & $24.24^{\mathrm{a}}$ & $23.65^{\mathrm{a}}$ & $21.98^{\mathrm{bB}}$ & $23.10^{\mathrm{A}}$ & 0.446 & 0.040 & 0.457 & 0.003 & 0.051 \\
\hline Marbling score & $4.29^{\mathrm{ab}}$ & $4.10^{\mathrm{b}}$ & $4.63^{\mathrm{a}}$ & $4.56^{\mathrm{aA}}$ & $4.46^{\mathrm{A}}$ & 0.151 & 0.005 & 0.334 & 0.666 & 0.646 \\
\hline Yield grade & $2.32^{b}$ & $2.36^{\mathrm{b}}$ & $2.39^{b}$ & $2.85^{\mathrm{aA}}$ & $2.36^{\mathrm{B}}$ & 0.128 & 0.032 & 0.061 & 0.108 & 0.004 \\
\hline
\end{tabular}

${ }^{\mathrm{a}, \mathrm{b}}$ least square means within a row with different superscript $\operatorname{differ}(P<0.05)$.

${ }^{\mathrm{A}, \mathrm{B}}$ least square means within a row with different superscript differ $(P<0.05)$. 


\title{
CHAPTER IV
}

\section{EFFECT OF ROUGHAGE REMOVAL AND RUMINAL MODIFIERS ON RUMINAL FERMENTATION IN BEEF STEERS.}

\begin{abstract}
The objective of this study was to determine the effect of roughage removal and ruminal modifiers on ruminal fermentation characteristics in beef steers fed no-roughage diets. We hypothesized that ruminal characteristics ( $\mathrm{pH}$, ammonia and VFA) of steers fed no-roughage diets with different ruminal modifiers, monensin (Rumensin 90, Elanco Animal Health, Greenfield, IN) or essential oils (Xtract X60-7065, Pancosma, Geneva, Switzerland), would not differ, and that roughage inclusion, when monensin is fed, would increase ruminal $\mathrm{pH}$, change VFA profile and decrease ammonia concentration. Three Simmental x Black Angus steers (initial BW $977 \pm 24.5 \mathrm{~kg}$ ) were used in a 3 x 3 Latin square. Roughage diet was formulated to meet effective energy and predicted absorbable AA requirement with monensin (R-MO; $\left.100 \mathrm{mg} \cdot \mathrm{kg}^{-1} \mathrm{DM}\right)$ to achieve an ADG $1.82 \mathrm{~kg} \cdot \mathrm{d}^{-}$

${ }^{1}$ for growing steers (BW $272 \mathrm{~kg}$ ). No-roughage diets had fescue hay replaced with whole corn. Some ingredient levels in No-roughage diets were adjusted to meet nutrient requirements, and contained monensin (NR-MO; $\left.100 \mathrm{mg} \cdot \mathrm{kg}^{-1} \mathrm{DM}\right)$ or essential oils (NREO; $\mathrm{mg} \cdot \mathrm{kg}^{-1} \mathrm{DM}$ of Xtract X60-7065). Dry matter intake was controlled at 1.87, 1.48,
\end{abstract}


and $1.52 \%$ BW for R-MO, NR-MO and NR-EO, respectively. Data were analyzed using repeated measures. Daily DMI and OM decreased between R-MO, NR-EO and NR-MO for each respective diet $(P=0.002)$. Intake of $\mathrm{CP}, \mathrm{NDF}$ and ADF was greater $(P<0.02)$ for R-MO compared to NR diets. Daily average ruminal $\mathrm{pH}$ (mean, minimum and maximum), ammonia $\mathrm{N}$ and VFA did not differ among diets. Ruminal $\mathrm{pH}$ was greater $(P$ $<0.04$ ) for R-MO and lesser for NR-MO in the initial hours after feeding and did not differ among diets between 8 and 10-h $(P>0.05)$. Average hourly $\mathrm{pH}$ across diets ranged from 6.37 to 5.74. Ammonia $\mathrm{N}$ was greater for NR-MO and NR-EO than R-MO during 2 and $10-\mathrm{h}$ after feeding. In conclusion, roughage removal and replacement of monensin by essential oils had no effect on VFA profile, daily average ammonia $\mathrm{N}$ concentration and $\mathrm{pH}$ (daily average, minimum and maximum).

\section{INTRODUCTION}

Efficiency of energy and protein utilization in the rumen are 1 of the most important factors impacting cattle production performance. Nutritional management approaches such as optimization of diet formulations and utilization of feed additives are used to modify ruminal environment and optimize ruminal fermentation. Among the available technologies, antibiotic ionophores have been successful in improving feed efficiency by altering ruminal fermentation (Goodrich et al., 1984; Russell and Strobel, 1989) but its use has been facing reduced social acceptance, and was banned in the European Union in January 2006 (Directive 1831/2003/CEE, European Commission, 2003). Essential oils are alternative feed additives that can be used as ruminal modifiers 
due to their antimicrobial activities (Cardozo et al., 2005; Calsamiglia et al., 2007; Cobellis et al., 2016). They are generally recognized as safe for human and animal consumption, and have been tested in vitro and in vivo (Meyer et al., 2009; Geraci et al., 2012). Another nutritional management approach to improve feed efficiency is feeding no-roughage diets containing ionophores to feedlot cattle (Mueller, 2004; Davis, 2009; Minton, 2015). In order to find alternatives to ionophores, the effects of feeding essential oils to ruminants, especially dairy cows, have been evaluated. However, no studies have been performed using no-roughage diets. Because the effects of these feed additives are diet and $\mathrm{pH}$ dependent, essential oils needed to be evaluated with no-roughage diets. We hypothesized that ruminal characteristics ( $\mathrm{pH}$, ammonia and VFA) of steers fed noroughage diets with different ruminal modifiers, monensin (Rumensin 90, Elanco Animal Health, Greenfield, IN) or essential oils (Xtract X60-7065, Pancosma, Geneva, Switzerland), would not differ, and that roughage inclusion containing monensin, would increase ruminal $\mathrm{pH}$, change VFA profile and decrease ammonia concentration. The objective of this study was to determine the effects of roughage removal and ruminal modifiers on ruminal fermentation characteristics in beef steers fed no-roughage diets.

\section{MATERIAL AND METHODS}

Three Simmental x Black Angus steers (initial BW $977 \pm 24.5 \mathrm{~kg}$ ) were used in a $3 \times 3$ Latin square design experiment previously fitted with ruminal fistulas. Dietary treatments used in this experiment were the same as used in a previous feedlot study to characterize rumen fermentation (4.1). Three dietary treatments (3.1) were composited 
of whole corn, wet distiller's grains solubles, fescue hay, AminoPlus (Ag Processing Inc, Omaha, NE), Ajipro-L (Ajinomoto, Chicago, IL), vitamin and mineral premix urea and either Rumensin 90 (Elanco Animal Health, Greenfield, IN) or Xtract X60-7065 (Pancosma, Geneva, Switzerland). Roughage diet was formulated to meet effective energy (Emmans, 1994) and predicted absorbable AA requirement with monensin (R$\mathrm{MO} ; \mathrm{mg} \cdot \mathrm{kg}^{-1} \mathrm{DM}$ ) to achieve an ADG $1.82 \mathrm{~kg} \cdot \mathrm{d}^{1}$ for growing steers (BW $272 \mathrm{~kg}$ ). Noroughage diets were the same as roughage diets except that tall fescue hay was replaced with whole shell corn. To meet nutrient requirements, no-roughage diets had some ingredients levels adjusted and contained monensin (NR-MO; $100 \mathrm{mg} \cdot \mathrm{kg}^{-1} \mathrm{DM}$ ) or essential oils (NR-EO; $100 \mathrm{mg} \cdot \mathrm{kg}^{-1} \mathrm{DM}$ of Xtract X60-7065). Dry matter intake was controlled at 1.87, 1.48, and 1.52\% BW for R-MO, NR-MO and NR-EO respectively.

\section{Animal Management and Feeding}

The use of animals in this experiment was approved by the University of Missouri Animal Care and Use Committee. Steers were adapted to a high concentrate diet using a 4 step up method, 5-d for each step and 20-d total period. Steps consisted of 25:75, 50:50, $75: 50,100: 0 \%$ dietary treatment to grass hay. Each steer was adapted to its respective diet from period one. During adaptation period feed was provided at the same level as trial periods (1.87, 1.48, and 1.52\% BW for R-MO, NR-MO and NR-EO respectively). One hour was allotted for steers to feed at the morning $(0730 \mathrm{~h})$ and evening $(1930 \mathrm{~h})$ feeding. After each feeding, orts were measured, sampled during data collection days, and stored at $-20^{\circ} \mathrm{C}$ for further analysis.

Periods consisted of 13-d, with 10-d acclimations and 3-d sampling. Steers were housed in tie stanchions equipped with rubber mats, with ad libitum access to water 
during collection d. During acclimation periods, steers were maintained together in a limestone packed dry lot without access to feed and ad libitum access to water, and were taken to tie stanchions at feeding hours. Body weight was recorded before first acclimation period and at the end of each period to adjust feed provided.

\section{Sampling and Laboratory Analysis}

Dietary samples were collected every feeding, during data collection d, dried in a forced air oven at $55^{\circ} \mathrm{C}$ for $72-\mathrm{h}$, and ground initially to pass through a 5 -mm screen (Wiley Mill; Arthur H. Thomas Company, Phyladelphia, PA). Subsamples were ground again to pass through a 1-mm screen (Cyclotech grinder; Foss Tecator Cyclotec 1093 sample mill). Samples were analyzed for DM, ash (AOAC, 2006), nitrogen content (vario Macro Cube, Elementar Americas, Mt. Laurel, NJ), NDF and ADF (ANKOM Technology, Macedon, NY, (Goering and Van Soest, 1970)).

Ruminal fluid was collected to measure $\mathrm{pH}$, ammonia $\mathrm{N}$ and VFA every 2-h over a 12-h period for 3-d. First sample was collected at 0-h prior to morning feeding. Samples were collected using a suction strainer modified from Raun and Burroughs (1962). The instrument was inserted in the ruminal fistula and samples were collected from the mid portion of the rumen. Approximately $300-\mathrm{mL}$ of rumen fluid were collected, and $\mathrm{pH}$ was recorded immediately. Samples were then filtered through 4 layers of cheese cloth and subsamples $(10-\mathrm{mL})$ were transferred to $15-\mathrm{mL}$ centrifuge tubes. Subsample of filtered rumen fluid, used for ammonia $\mathrm{N}$ analysis, were acidified with $300 \mu \mathrm{L}$ of $6.0 \mathrm{M} \mathrm{HCl}$, and subsamples used for VFA analysis were acidified and dosed with $32 \mu \mathrm{L}$ of 2-ethylbutyric acid as an internal marker. Each $15-\mathrm{mL}$ centrifuge tube was agitated and approximately $1.5-\mathrm{mL}$ were transferred to 4 microcentrifuge tubes $(2-\mathrm{mL})$, and stored at $-20^{\circ} \mathrm{C}$ for 
further analysis. Ammonia N samples were rapidly thawed using hot water, analyzed using the phenol-hypochlorite assay as described by Broderick and Kang (1980) and measured on a spectrophotometer (Evolution 201, Thermo Scientific, Waltham, MA). Volatile fatty acid samples were also rapidly thawed, and VFA were determined using gas chromatography as described by Salanitro and Muirhead (1975).

\section{Statistical Analysis}

Data analyses were performed by analysis of variance (ANOVA) using SAS (SAS 9.4 Institute Inc., Cary, NC). When F-test was significant $(P \leq 0.05)$, means separation was performed using LSMEANS statement. The procedure GLIMMIX was used to analyze all variables, except for nutrient composition, which was analyzed using MIXED procedure. Data were analyzed as 3 x 3 Latin square design. Feed, and nutrient daily intake model included period, steer, and treatment as independent variables. Daily mean, minimum and maximum $\mathrm{pH}$ included period, steer, and the interaction of treatment and day in the model. Ammonia, pH, and VFA were analyzed as repeated measures with period, steer, and treatment by hour interaction in the model.

\section{RESULTS}

Differences in dietary nutrient analysis are described in 4.1. Dry matter (\%) did not differ $(P=0.99)$ among diets. Organic matter was $0.7 \%$ greater $(P=0.002)$ for $\mathrm{R}$ MO than NR-MO, and NR-EO did not differ. Crude protein (\% DM) increased between R-MO, NR-EO and NR-MO for each respective diet $(P<0.001)$. Neutral detergent fiber and ADF was greater $(P<0.001)$ for R-MO compared to the other 2 diets. 
Because intake was controlled at different levels (\% BW) for each steer, results of daily feed and nutrient intake were expected by design ( 4.2). Daily DMI, DMI \% BW, and OM intake increased between NR-MO, NR-EO and R-MO for each respective diet $(P=0.002)$. Intake of $\mathrm{CP}$ was $8.6 \%$ greater $(P<0.01)$ for $\mathrm{R}-\mathrm{MO}$ compared to other 2 diets. Neutral detergent fiber and ADF intake were greater $(P<0.029)$ for R-MO than no-roughage diets (61.6\% difference for NDF daily intake among diets and $83.6 \%$ for ADF).

Data from ruminal fermentation characteristics were reported as daily and hourly means. Daily $\mathrm{pH}$, ammonia, and VFA did not differ $(P>0.064)$ among diets ( 4.3). When expressed as a repeated measure (Figure 4.1), ruminal $\mathrm{pH}$ differed $(P<0.04)$ among diets at all times except at 8 and $10-\mathrm{h}$ after feeding. The greatest differences in $\mathrm{pH}$ occurred at 0 and 2-h. Prior to feeding (0-h) and 2-h after, $\mathrm{pH}$ increased for NR-MO, NR-EO and RMO for each respective diet. At 4, 6 and 12-h, $\mathrm{pH}$ was greater for R-MO and NR-EO compared to NR-MO. When ruminal ammonia $\mathrm{N}$ concentration was expressed by hour (Figure 4.2), there were differences among diets at all times $(P<0.04)$. At 0 -h, ammonia was greater for R-MO than NR-MO, and NR-EO did not differ from other diets. At 2, 4, 6, 8 and 10-h after feeding, ammonia was greater for no-roughage diets compared to RMO. At 12-h after feeding, ammonia was greater for NR-EO compared to other diets. 


\section{DISCUSSION}

\section{Roughage effects}

We hypothesized that steers fed high concentrate diets containing roughage and monensin would increase ruminal $\mathrm{pH}$, change VFA profile and decrease ammonia concentration compared to no-roughage diets with monensin. Feed intake was controlled based on a previous study, in which the same diets were fed to feedlot steers. Dry matter intake was greater for R-MO, resulting in greater ingestion of OM, CP, NDF and ADF compared to NR-MO. On average, daily $\mathrm{pH}$, VFA and ammonia $\mathrm{N}$ did not differ. However, when observed by hour, $\mathrm{pH}$ was greater when roughage was fed at almost all sampling times except at 8 and 10-h after feeding. Ammonia $\mathrm{N}$ was lesser for R-MO at almost all hours, greater at 0 -h and did not differ at $12-\mathrm{h}$ after feeding compared to NRMO.

Decreased ammonia $\mathrm{N}$ concentration for R-MO diets might be due to greater assimilation by fibrolytic bacteria, which likely had a greater population when roughage was included, and are known to prefer ammonia as the primary $\mathrm{N}$ source (Hungate, 1966). Even with a $27 \%$ greater organic matter consumption when roughage was included, there was no difference in VFA production, possibly due to an increased liquid passage rate (Galyean and Defoor, 2003). Roughage inclusion in high concentrate diets is shown to increase DMI, which is positively correlated to water intake, as well as rumination and salivation, leading to increased liquid volume in the rumen and further increased grain passage rate (Galyean and Defoor, 2003; National Academies of Sciences and Medicine, 2016). Even though saliva secretion was not measured in this experiment, 
we speculate that decreased $\mathrm{pH}$ from NR-MO was caused by less salivation and rumination. Ruminal $\mathrm{pH}$ is primarily determined by a balance between fermentation acid production and secretion of salivary buffers (Allen, 1997).

Roughage is typically included at 6 to $12 \%$ in feedlot finishing diets, with the goal to reduce incidence and severity of digestive problems such as acidosis, optimize feed intake and maximize gain (Galyean and Defoor, 2003; Samuelson et al., 2016). However, roughages are poorly digested in high concentrate finishing diets, and expensive due to high cost per unit of energy (Stock, 2000). Subacute ruminal acidosis is characterized as ruminal $\mathrm{pH}$ less than 5.5 for 12-h or more (Reinhardt et al., 1997) and acute ruminal acidosis is defined as less than 5.2 for a 6 -h or more period (Owens et al., 1998). Neither acute nor subacute ruminal acidosis was observed in this experiment on no-roughage diets. Ruminal daily minimum $\mathrm{pH}$ for treatment NR-MO was 5.45 and an average of 5.9. Benton et al. (2015) observed subacute acidosis on ruminally cannulated steers fed noroughage (processed corn with wet distiller's grains solubles) diets over $19 \mathrm{~h} \cdot \mathrm{d}^{-1}$ and about $12 \mathrm{~h} \cdot \mathrm{d}^{-1}$ were spent at a $\mathrm{pH}$ of less than 5.3 . The slower rate of ruminal fermentation of whole shell corn from our diets is likely the main reason for no observed subacute acidosis based on $\mathrm{pH}$.

\section{Monensin vs. essential oils effects}

Monensin was compared to essential oils because research has found similar effects of both feed additives on ruminal fermentation (Cardozo et al., 2005, 2006), and monensin was chosen among commercial available ionophores because it is the most used in feedlot finishing diets (Samuelson et al., 2016). 
We hypothesized that ruminal fermentation characteristics $(\mathrm{pH}$, ammonia and VFA) of steers fed no-roughage diets with different ruminal modifiers, monensin or an essential oil blend containing eugenol, cinnamaldehyde and capsicum oleoresin would not differ. On average, $\mathrm{pH}, \mathrm{VFA}$ and ammonia $\mathrm{N}$ did not differ with either essential oil or monensin. However, when expressed by hour, $\mathrm{pH}$ was greater when essential oils were fed at almost all sampling times, except at 8 and 10 -h after feeding. Ammonia $\mathrm{N}$ was less for monensin treatment only at 12 -h after feeding.

Effects of monensin on ruminal fermentation and its mode of action have been extensively researched and reviewed (Bergen and Bates, 1984; Goodrich et al., 1984; Duffield et al., 2012), therefore this discussion is not going to cover this topic. Essential oils have been tested individually and in combinations at high doses using in vitro studies and demonstrated effects on microbial fermentation such as changing VFA profile and protein degradation. However, results from in vivo studies are conflicting, most likely due to different doses and active components present in commercial products, type of basal diet as well as ruminal microbial population.

Cinnamaldehyde was tested with diets containing 50:50 forage to concentrate and were used in 2 different in vitro systems (Busquet et al., 2005a; Busquet et al., 2006). When increasing levels of cinnamaldehyde were evaluated in a batch culture system for 24-h, high doses (300 to 3,000 $\mathrm{mg} \cdot \mathrm{L}^{-1}$ ) decreased total VFA production, increased propionate without affecting acetate and butyrate proportions, and decreased ammonia $\mathrm{N}$ concentrations (Busquet et al., 2006). 2 levels of cinnamaldehyde and monensin, as well as a control without rumen modifiers, were tested using longer incubation times and a dual flow continuous culture by Busquet et al. (2005a). Compared to control treatment, 
higher inclusions of monensin $\left(12.5 \mathrm{mg} \cdot \mathrm{L}^{-1}\right)$ increased VFA concentrations and proportion of propionate while decreasing molar proportions of acetate, butyrate, branched chain VFA and acetate:propionate ratio. Low inclusion of cinnamaldehyde $\left(31.2 \mathrm{mg} \cdot \mathrm{L}^{-1}\right)$ also decreased acetate:propionate ratio while high inclusion $\left(312 \mathrm{mg} \cdot \mathrm{L}^{-1}\right)$ increased proportions of propionate and butyrate, and decreased acetate. Cinnamaldehyde was also tested using rumen fluid from cattle fed a high concentrate diet (10:90 forage to concentrate). When fermentation was maintained at $\mathrm{pH} 7$, cinnamaldehyde increased acetate:propionate ratio and decreased total VFA production, while at $\mathrm{pH} 5.5$, total VFA increased, and ammonia $\mathrm{N}$ as well as acetate to propionate ratio decreased (Cardozo et al., 2005). Suggesting that essential oil effects are $\mathrm{pH}$ dependent, and cinnamaldehyde may have more relevant effects on feedlot cattle fed high concentrate diets. These changes in ruminal fermentation were hypothesized by Cardozo et al. (2005) as a combination of microbial population susceptibility and greater hydrophobicity of the essential oil active molecules caused by increased proportion of undissociated molecules due to the lower $\mathrm{pH}$.

Cardozo et al. (2005) teste eugenol $\left(0\right.$ to $\left.30 \mathrm{mg} \cdot \mathrm{L}^{-1}\right)$ and reported that at $\mathrm{pH} 5.5$, total VFA and butyrate proportion increased, propionate and branced chain VFA concentration decreased, and there was no change in acetate proportion and acetate:propionate ratio. In contrast, using high doses of eugenol (300 to $\left.3,000 \mathrm{mg} \cdot \mathrm{L}^{-1}\right)$ in a short-term batch culture system, authors reported an increase on propionate and butyrate proportions and a decrease in branched chain VFA and ammonia $\mathrm{N}$ concentration (Busquet et al., 2006). 
Capsicum inclusion using a short-term in vitro system at $\mathrm{pH} 5.5$ resulted in favorable ruminal fermentation for feedlot cattle (Cardozo et al., 2005), reducing ammonia $\mathrm{N}$ concentration, acetate proportion and acetate:propionate ratio, and increasing total VFA production and propionate proportions. When cannulated animals were fed a high concentrate diet, $1 \mathrm{~g}$ of capsicum extract, containing $15 \%$ the active ingredient capsaicin, did not change VFA production, decreased acetate proportion and concentration of large peptides, while increasing small peptides and AA without affecting ammonia N (Cardozo et al., 2006). The same experiment used a combination of cinnamaldehyde with eugenol, and results were favorable to ruminal fermentation for feedlot cattle similar to in vitro.

Feeding a high concentrate dry rolled corn basal diet, Geraci et al. (2012) observed a decrease in ammonia $\mathrm{N}$ concentration on cannulated steers supplemented with a blend containing eugenol, cinnamaldehyde and capsicum oleoresin $\left(400 \mathrm{mg} \cdot \mathrm{steer}^{-1} \cdot \mathrm{d}^{-1}\right)$ compared to monensin supplementation $\left(46.7 \mathrm{mg} \cdot \mathrm{kg}^{-1} \mathrm{DM}\right)$. Using an essential oil blend containing thymol, eugenol, vanillin, guaiacol, and limonene and also comparing it to monensin, Meyer et al. (2009) observed no difference on $\mathrm{pH}$ and VFA proportions. Differences in $\mathrm{pH}$ cannot be explained by patterns in VFA and ammonia $\mathrm{N}$ concentration because VFA did not differ and ammonia $\mathrm{N}$ concentration was only different at 12-h. The greater $\mathrm{pH}$ for most of the time could be due to increases in salivation and water intake. Although water intake and salivation secretion were not measured in this experiment, capsicum has been proven to increase salivation due to the pungent effect (Dunér-Engström et al., 1986; Nasrawi and Pangborn, 1990) and water intake (Cardozo et al., 2006), which would increase buffer capacity and ruminal pH. 


\section{CONCLUSION}

In conclusion, ruminal average daily $\mathrm{pH}, \mathrm{VFA}$ and ammonia $\mathrm{N}$ concentration was not different between R-MO and NR-MO, however, when observed by hours, $\mathrm{pH}$ was greater and ammonia $\mathrm{N}$ concentration was lesser for $\mathrm{R}-\mathrm{MO}$ at almost all sampling times compared to NR-MO. average daily $\mathrm{pH}, \mathrm{VFA}$ and ammonia $\mathrm{N}$ did not differ in steers fed no-roughage diets with different ruminal modifiers, monensin or an essential oil blend containing eugenol, cinnamaldehyde and capsicum oleoresin. However, when expressed by hour, monensin fed steers demonstrated decreased ruminal $\mathrm{pH}$ at almost all sampling times, and ammonia $\mathrm{N}$ was less only at 12 -h after feeding compared to essential oils. 
Table 4.1. Dietary ingredient composition and nutrient analysis.

\begin{tabular}{|c|c|c|c|c|c|}
\hline \multirow[b]{2}{*}{ Item } & \multicolumn{3}{|c|}{ Treatments $^{1}$} & \multirow[b]{2}{*}{ SEM } & \multirow[b]{2}{*}{$P$-value } \\
\hline & $\mathrm{R}-\mathrm{MO}$ & NR-MO & NR-EO & & \\
\hline \multicolumn{6}{|l|}{ Ingredient, $\% D M$} \\
\hline Whole corn & 69.63 & 79.58 & 79.58 & & \\
\hline Wet distiller's grain solubles & 8.96 & 8.98 & 8.98 & & \\
\hline AminoPlus $^{2}$ & 9.46 & 8.66 & 8.78 & & \\
\hline Tall fescue hay & 9.43 & - & - & & \\
\hline \multicolumn{6}{|l|}{ Supplement, \% DM } \\
\hline Premix $^{3}$ & 2.32 & 2.32 & 2.20 & & \\
\hline Urea & 0.13 & 0.39 & 0.39 & & \\
\hline Ajipro- $\mathrm{L}^{4}$ & 0.05 & 0.05 & 0.06 & & \\
\hline Rumensin $90^{5}$ & 0.01 & 0.01 & - & & \\
\hline Xtract, X60-7065 & - & - & 0.01 & & \\
\hline \multicolumn{6}{|l|}{ Dietary nutrient analysis } \\
\hline $\mathrm{DM}, \%$ & 71.57 & 71.62 & 71.65 & 0.68 & 0.990 \\
\hline OM, $\% D M$ & $95.25^{\mathrm{a}}$ & $94.57^{\mathrm{b}}$ & $94.96^{\mathrm{ab}}$ & 0.15 & 0.001 \\
\hline $\mathrm{CP}, \% D M$ & $15.91^{\mathrm{c}}$ & $18.24^{\mathrm{a}}$ & $17.59^{\mathrm{b}}$ & 0.55 & $<0.001$ \\
\hline $\mathrm{NDF}, \% D M$ & $19.08^{\mathrm{a}}$ & $12.67^{\mathrm{b}}$ & $12.27^{\mathrm{b}}$ & 0.41 & $<0.001$ \\
\hline $\mathrm{ADF}, \% D M$ & $7.74^{\mathrm{a}}$ & $4.04^{b}$ & $3.82^{b}$ & 0.26 & $<0.001$ \\
\hline \multicolumn{6}{|c|}{$\begin{array}{l}1{ }^{1} \text { R-MO: roughage with monensin; NR-MO: no-roughage with monensin; NR-EO: no-roughage } \\
\text { with essential oils. } \\
{ }^{2} \text { AminoPlus; Ag Processing Inc, Omaha, NE. } \\
{ }^{3} \text { Premix contained: salt, limestone, vitamins ADE, magnesium oxide and trace minerals. } \\
{ }^{4} \text { AjiPro-L; Ajinomoto, Chicago, IL. } \\
{ }^{5} \text { Rumensin 90; Elanco Animal Health, Greenfield, IN. } \\
\text { Pancosma, Geneva, Switzerland. }\end{array}$} \\
\hline
\end{tabular}


Table 4.2. Effect of roughage removal and ruminal modifier inclusion on daily intake.

\begin{tabular}{lccccc} 
& \multicolumn{4}{c}{ Treatments $^{1}$} & \\
\cline { 2 - 4 } Item & R-MO & NR-MO & NR-EO & SEM & $P$-value \\
\hline Daily intake & & & & & \\
DM, $k g$ & $18.65^{\mathrm{a}}$ & $14.79^{\mathrm{c}}$ & $15.39^{\mathrm{b}}$ & 0.36 & 0.002 \\
$\mathrm{DM}, \% B W$ & $1.87^{\mathrm{a}}$ & $1.48^{\mathrm{c}}$ & $1.52^{\mathrm{b}}$ & 0.04 & $<0.001$ \\
$\mathrm{OM}, \mathrm{kg}$ & $17.77^{\mathrm{a}}$ & $14.00^{\mathrm{c}}$ & $14.61^{\mathrm{b}}$ & 0.35 & 0.003 \\
$\mathrm{CP}, g$ & $2980^{\mathrm{a}}$ & $2757^{\mathrm{b}}$ & $2709^{\mathrm{b}}$ & 44.1 & 0.011 \\
$\mathrm{NDF}, g$ & $3554^{\mathrm{a}}$ & $1873^{\mathrm{b}}$ & $1886^{\mathrm{b}}$ & 159.4 & 0.029 \\
$\mathrm{ADF}, g$ & $1442^{\mathrm{a}}$ & $596^{\mathrm{b}}$ & $587^{\mathrm{b}}$ & 80.0 & 0.013 \\
\hline
\end{tabular}

a, b, c least square means within a row with different superscript differ $(P<0.05)$.

${ }^{1} \mathrm{R}-\mathrm{MO}$ : roughage with monensin; NR-MO: no-roughage with monensin; NR-EO: no-roughage with essential oils. 
Table 4.3. Effect of roughage removal and ruminal modifier inclusion on daily ruminal fermentation.

\begin{tabular}{|c|c|c|c|c|c|}
\hline \multirow[b]{2}{*}{ Item } & \multicolumn{3}{|c|}{ Treatments $^{1}$} & \multirow[b]{2}{*}{ SEM } & \multirow[b]{2}{*}{$P$-value } \\
\hline & $\mathrm{R}-\mathrm{MO}$ & NR-MO & NR-EO & & \\
\hline \multicolumn{6}{|l|}{ Ruminal pH } \\
\hline Average & 6.22 & 5.90 & 6.10 & 0.09 & 0.077 \\
\hline Minimum & 5.42 & 5.45 & 5.69 & 0.11 & 0.236 \\
\hline Maximum & 6.82 & 6.47 & 6.53 & 0.09 & 0.106 \\
\hline Ammonia $\mathrm{N}, m g \cdot d L^{-1}$ & 10.14 & 13.52 & 14.86 & 0.67 & 0.064 \\
\hline Total VFA, $m M$ & 93.36 & 92.50 & 90.18 & 1.56 & 0.618 \\
\hline \multicolumn{6}{|l|}{$\mathrm{VFA}, \mathrm{mol} \cdot 100 \mathrm{~mol}^{-1}$} \\
\hline Acetate & 48.11 & 44.67 & 49.14 & 0.47 & 0.332 \\
\hline Propionate & 23.24 & 27.72 & 22.17 & 1.11 & 0.715 \\
\hline Butyrate & 16.90 & 13.24 & 16.06 & 0.94 & 0.634 \\
\hline Valerate & 2.97 & 5.25 & 3.45 & 0.25 & 0.449 \\
\hline Isovalerate & 6.29 & 6.98 & 6.53 & 0.34 & 0.933 \\
\hline Isobutyrate & 2.49 & 2.15 & 2.66 & 0.06 & 0.216 \\
\hline Ace:Pro & 2.31 & 1.80 & 2.27 & 0.10 & 0.746 \\
\hline
\end{tabular}

${ }^{1} \mathrm{R}-\mathrm{MO}$ : roughage with monensin; NR-MO: no-roughage with monensin; NR-EO: no-roughage with essential oils. 


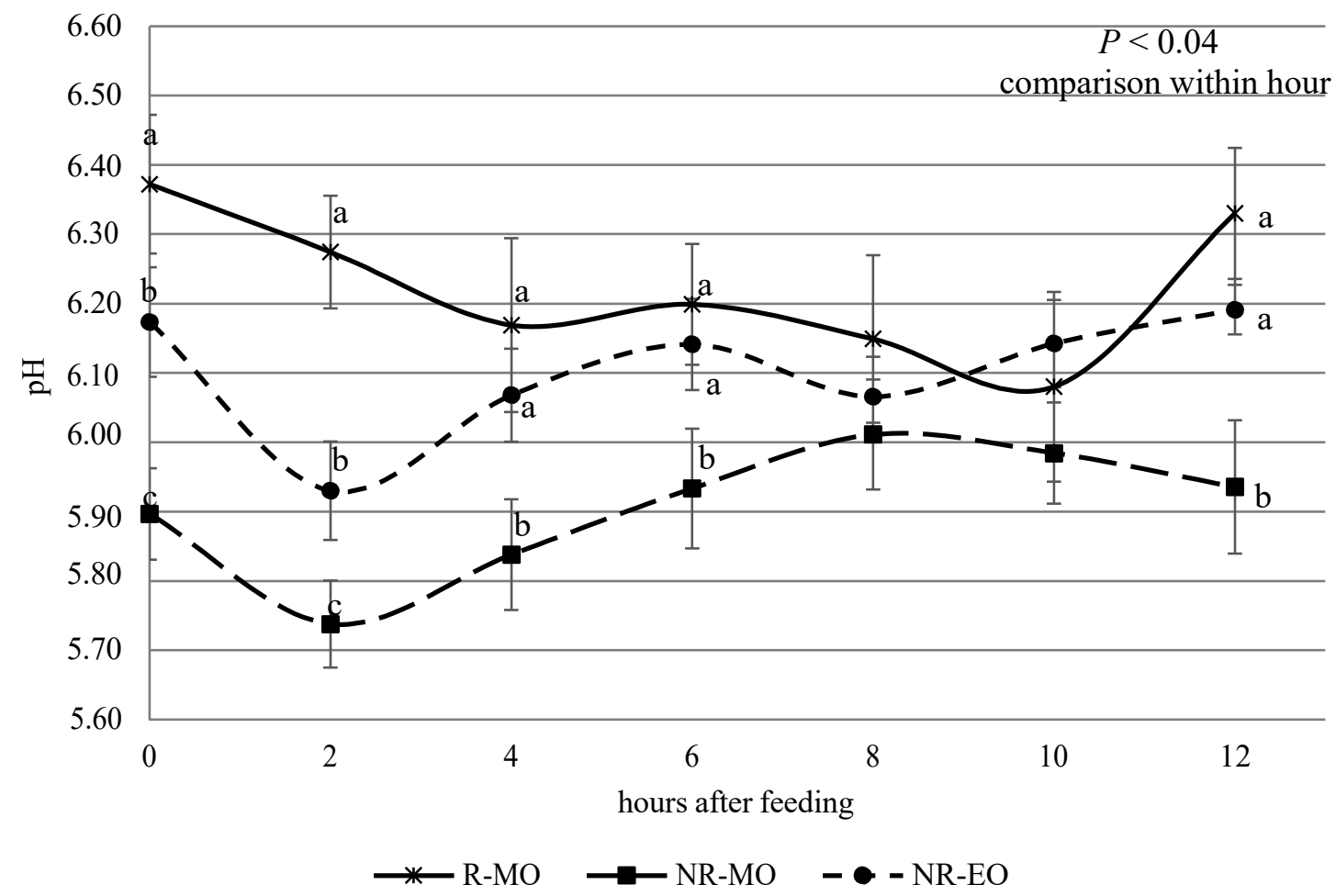

R-MO: roughage with monensin; NR-MO: no-roughage with monensin; NR-EO: no-roughage with essential oils

Figure 4.1. Effect of roughage removal and ruminal modifier inclusion on ruminal $\mathrm{pH}$ after feeding. 


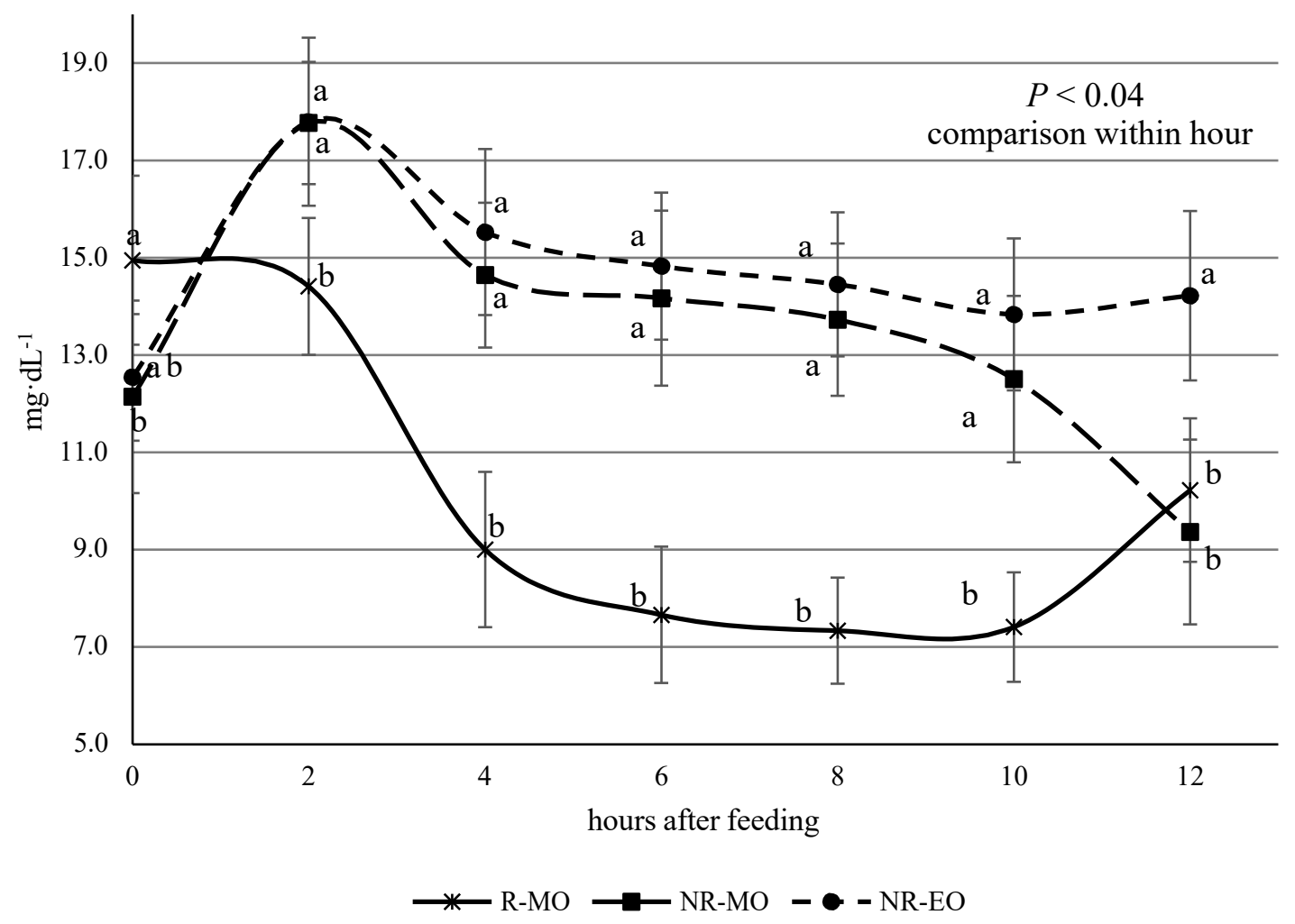

R-MO: roughage with monensin; NR-MO: no-roughage with monensin; NR-EO: no-roughage with essential oils

Figure 4.2. Effect of roughage removal and ruminal modifier inclusion on ruminal ammonia $\mathrm{N}$ concentration after feeding. 


\section{LITERATURE CITED}

Allen, M. S. 1997. Relationship between fermentation acid production in the rumen and the requirement for physically effective fiber. Journal of Dairy Science 80(7):1447-1462.

Archimède, H., M. Eugène, C. M. Magdeleine, M. Boval, C. Martin, D. Morgavi, P. Lecomte, and M. Doreau. 2011. Comparison of methane production between C3 and C4 grasses and legumes. Animal Feed Science and Technology 166:59-64.

Bach, A., M. Ruiz Moreno, M. Thrune, and M. Stern. 2008. Evaluation of the fermentation dynamics of soluble crude protein from three protein sources in continuous culture fermenters. Journal of animal science 86(6):1364-1371.

Bailey, C., and C. Balch. 1961. Saliva secretion and its relation to feeding in cattle. British Journal of Nutrition 15(03):383-402.

Bannink, A., J. Kogut, J. Dijkstra, J. France, E. Kebreab, A. Van Vuuren, and S. Tamminga. 2006. Estimation of the stoichiometry of volatile fatty acid production in the rumen of lactating cows. Journal of Theoretical Biology 238(1):36-51.

Batajoo, K. K., and R. D. Shaver. 1998. In situ dry matter, crude protein, and starch degradabilities of selected grains and by-product feeds. Animal Feed Science and Technology 71(1):165-176.

Beauchemin, K., L. Eriksen, P. Nørgaard, and L. Rode. 2008. Short communication: Salivary secretion during meals in lactating dairy cattle. Journal of Dairy Science 91(5):2077-2081.

Beauchemin, K., T. McAllister, Y. Dong, B. Farr, and K. Cheng. 1994. Effects of mastication on digestion of whole cereal grains by cattle. Journal of animal science 72(1):236-246.

Beauchemin, K. A. 1991. Ingestion and mastication of feed by dairy cattle. Veterinary Clinics of North America: Food Animal Practice 7(2):439-463.

Beever, D. 1993. Rumen Function. Digestion. Ch 9. Quantitative Aspects of Rumiant Digestion and Metabolism. Edited by: JM Forbes and F. France

Benchaar, C., and H. Greathead. 2011. Essential oils and opportunities to mitigate enteric methane emissions from ruminants. Animal Feed Science and Technology 166:338-355. 
Benton, J., A. Watson, G. Erickson, T. Klopfenstein, K. Vander Pol, N. Meyer, and M. Greenquist. 2015. Effects of roughage source and inclusion in beef finishing diets containing corn wet distillers' grains plus solubles. Journal of animal science 93(9):4358-4367.

Bergen, W. G., and D. B. Bates. 1984. Ionophores: their effect on production efficiency and mode of action. Journal of animal science 58(6):1465-1483.

Blaxter, K., and J. Clapperton. 1965. Prediction of the amount of methane produced by ruminants. British Journal of nutrition 19(01):511-522.

Boadi, D., C. Benchaar, J. Chiquette, and D. Massé. 2004. Mitigation strategies to reduce enteric methane emissions from dairy cows: update review. Canadian Journal of Animal Science 84(3):319-335.

Boadi, D., and K. Wittenberg. 2002. Methane production from dairy and beef heifers fed forages differing in nutrient density using the sulphur hexafluoride (SF6) tracer gas technique. Canadian Journal of Animal Science 82(2):201-206.

Broderick, G., and J. Kang. 1980. Automated simultaneous determination of ammonia and total amino acids in ruminal fluid and in vitro media. Journal of dairy science 63(1):64-75.

Brooks, M. A. 2010. Ruminal degradation of protein and carbohydrate in the domestic and wild ruminant. University of Missouri-Columbia.

Brooks, M. A., R. M. Harvey, N. F. Johnson, and M. S. Kerley. 2012. Rumen degradable protein supply affects microbial efficiency in continuous culture and growth in steers. Journal of animal science 90(13):4985-4994.

Busquet, M., S. Calsamiglia, A. Ferret, P. Cardozo, and C. Kamel. 2005a. Effects of cinnamaldehyde and garlic oil on rumen microbial fermentation in a dual flow continuous culture. Journal of Dairy Science 88(7):2508-2516.

Busquet, M., S. Calsamiglia, A. Ferret, and C. Kamel. 2005b. Screening for the effects of natural plant extracts and secondary plant metabolites on rumen microbial fermentation in continuous culture. Anim. Feed Sci. Technol 123(124):597-613.

Busquet, M., S. Calsamiglia, A. Ferret, and C. Kamel. 2006. Plant extracts affect in vitro rumen microbial fermentation. Journal of dairy science 89(2):761-771.

Callaway, E., and S. Martin. 1997. Effects of a Saccharomyces cerevisiae culture on ruminal bacteria that utilize lactate and digest cellulose. Journal of Dairy Science 80(9):2035-2044.

Calsamiglia, S., M. Busquet, P. Cardozo, L. Castillejos, and A. Ferret. 2007. Invited review: essential oils as modifiers of rumen microbial fermentation. Journal of dairy science 90(6):2580-2595. 
Calsamiglia, S., P. Cardozo, A. Ferret, and A. Bach. 2008. Changes in rumen microbial fermentation are due to a combined effect of type of diet and $\mathrm{pH}$. Journal of animal science 86(3):702-711.

Cardozo, P., S. Calsamiglia, A. Ferret, and C. Kamel. 2005. Screening for the effects of natural plant extracts at different $\mathrm{pH}$ on in vitro rumen microbial fermentation of a high-concentrate diet for beef cattle. Journal of animal science 83(11):2572-2579.

Cardozo, P., S. Calsamiglia, A. Ferret, and C. Kamel. 2006. Effects of alfalfa extract, anise, capsicum, and a mixture of cinnamaldehyde and eugenol on ruminal fermentation and protein degradation in beef heifers fed a high-concentrate diet. Journal of animal science 84(10):2801-2808.

Cassida, K., and M. Stokes. 1986. Eating and resting salivation in early lactation dairy cows. Journal of dairy science 69(5):1282-1292.

Chaucheyras-Durand, F., N. Walker, and A. Bach. 2008. Effects of active dry yeasts on the rumen microbial ecosystem: Past, present and future. Animal Feed Science and Technology 145(1):5-26.

Church, D. 1988. Salivary function and production. The Ruminant Animal. Digestive physiology and nutrition. DC Church (Ed). Prentice Hall, Englewood Cliffs, NewJersey:117-124.

Cobellis, G., M. Trabalza-Marinucci, and Z. Yu. 2016. Critical evaluation of essential oils as rumen modifiers in ruminant nutrition: A review. Science of the Total Environment 545:556-568.

Cook, D., W. v. Engelhardt, S. Leonhard-Marek, G. Breves, and D. Giesecke. 1995. Salivary secretion in ruminants. In: Ruminant physiology: digestion, metabolism, growth and reproduction. Proceedings 8th International Symposium on Ruminant Physiology. p 153-170.

Davis, M. P. 2009. Influence of diet, production traits, blood hormones and metabolites, and mitochondrial complex protein concentrations on residual feed intake in beef cattle, University of Missouri--Columbia.

Defoor, P., M. Galyean, G. Salyer, G. Nunnery, and C. Parsons. 2002. Effects of roughage source and concentration on intake and performance by finishing heifers. Journal of animal science 80(6):1395-1404.

Dehority, B. A. 2003. Rumen microbiology.

Dorman, H., and S. Deans. 2000. Antimicrobial agents from plants: antibacterial activity of plant volatile oils. Journal of applied microbiology 88(2):308-316. 
Duffield, T., J. Merrill, and R. Bagg. 2012. Meta-analysis of the effects of monensin in beef cattle on feed efficiency, body weight gain, and dry matter intake. Journal of animal science 90(12):4583-4592.

Dunér-Engström, M., B. Fredholm, O. Larsson, J. Lundberg, and A. Saria. 1986. Autonomic mechanisms underlying capsaicin induced oral sensations and salivation in man. The Journal of physiology 373(1):87-96.

Ellis, J., J. Dijkstra, A. Bannink, E. Kebreab, S. Hook, S. Archibeque, and J. France. 2012. Quantifying the effect of monensin dose on the rumen volatile fatty acid profile in high-grain-fed beef cattle. Journal of animal science 90(8):2717-2726.

Ellis, J., J. Dijkstra, E. Kebreab, A. Bannink, N. Odongo, B. McBride, and J. France. 2008. Aspects of rumen microbiology central to mechanistic modelling of methane production in cattle. The Journal of Agricultural Science 146(02):213233.

Emmans, G. 1994. Effective energy: a concept of energy utilization applied across species. British Journal of Nutrition 71(06):801-821.

Eugène, M., H. Archimede, and D. Sauvant. 2004. Quantitative meta-analysis on the effects of defaunation of the rumen on growth, intake and digestion in ruminants. Livestock Production Science 85(1):81-97.

Fahey, G., and L. Berger. 1988. Carbohydrate nutrition of ruminants. The ruminant animal: digestive physiology and nutrition:269-297.

Faichney, G. 1986. The kinetics of particulate matter in the rumen. In: Proceedings of 6th International Symposium on Ruminant Physiology, Banff (Canada), 10-14 Sep 1984

Faichney, G. J. 1993. Digesta flow. Cab International.

Firkins, J., M. Eastridge, N. St-Pierre, and S. Noftsger. 2001. Effects of grain variability and processing on starch utilization by lactating dairy cattle. Journal of animal science 79(E-Suppl):E218-E238.

Galyean, M., and P. Defoor. 2003. Effects of roughage source and level on intake by feedlot cattle. Journal of animal science 81(14_suppl_2):E8-E16.

Geraci, J. I., A. D. Garciarena, G. A. Gagliostro, K. A. Beauchemin, and D. Colombatto. 2012. Plant extracts containing cinnamaldehyde, eugenol and capsicum oleoresin added to feedlot cattle diets: Ruminal environment, short term intake pattern and animal performance. Animal feed science and technology 176(1):123-130.

Goering, H. K., and P. J. Van Soest. 1970. Forage Fiber Analyses (apparatus, Reagents, Procedures, and Some Applications). U.S. Agricultural Research Service. 
Goodrich, R., J. Garrett, D. Gast, M. Kirick, D. Larson, and J. Meiske. 1984. Influence of monensin on the performance of cattle. Journal of animal science 58(6):14841498.

Griffin, S. G., S. G. Wyllie, J. L. Markham, and D. N. Leach. 1999. The role of structure and molecular properties of terpenoids in determining their antimicrobial activity. Flavour and Fragrance Journal 14(5):322-332.

Groot, J. C., B. A. Williams, A. J. Oostdam, H. Boer, and S. Tamminga. 1998. The use of cumulative gas and volatile fatty acid production to predict in vitro fermentation kinetics of Italian ryegrass leaf cell walls and contents at various time intervals. British Journal of Nutrition 79(06):519-525.

Guan, H., K. Wittenberg, K. Ominski, and D. Krause. 2006. Efficacy of ionophores in cattle diets for mitigation of enteric methane. Journal of animal science 84(7):1896-1906.

Hammond, K., S. Muetzel, G. Waghorn, C. Pinares-Patino, J. Burke, and S. Hoskin. 2009. The variation in methane emissions from sheep and cattle is not explained by the chemical composition of ryegrass. In: Proceedings of the New Zealand Society of Animal Production. p 174-178.

Hart, K., D. Yanez-Ruiz, S. Duval, N. McEwan, and C. Newbold. 2008. Plant extracts to manipulate rumen fermentation. Animal Feed Science and Technology 147(1):835.

Holzer, P. 2011. Transient receptor potential (TRP) channels as drug targets for diseases of the digestive system. Pharmacology \& therapeutics 131(1):142-170.

Huhtanen, P., M. Rinne, and J. Nousiainen. 2009. A meta-analysis of feed digestion in dairy cows. 2 . The effects of feeding level and diet composition on digestibility. Journal of dairy science 92(10):5031-5042.

Hungate, R. 1966. The rumen and its microbes Academic Press New York and London.

Johnson, K. A., and D. E. Johnson. 1995. Methane emissions from cattle. Journal of animal science 73(8):2483-2492.

Kahn, C. M. 2010. Merck Veterinary Manual. 20th ed. Merck \& Co., Whitehouse Station, NJ.

Knapp, J., G. Laur, P. Vadas, W. Weiss, and J. Tricarico. 2014. Invited review: Enteric methane in dairy cattle production: Quantifying the opportunities and impact of reducing emissions. Journal of Dairy Science 97(6):3231-3261.

Krehbiel, C., S. Rust, G. Zhang, and S. Gilliland. 2003. Bacterial direct-fed microbials in ruminant diets: Performance response and mode of action. Journal of animal science 81(14_suppl_2):E120-E132. 
Kreikemeier, K., D. Harmon, R. Brandt, T. Nagaraja, and R. Cochran. 1990. Steam-rolled wheat diets for finishing cattle: effects of dietary roughage and feed intake on finishing steer performance and ruminal metabolism. Journal of animal science 68(7):2130-2141.

Kristensen, N. B., and D. Harmon. 2004. Splanchnic metabolism of volatile fatty acids absorbed from the washed reticulorumen of steers. Journal of animal science 82(7):2033-2042.

Lana, R. P., J. B. Russell, and M. E. Van Amburgh. 1998. The role of $\mathrm{pH}$ in regulating ruminal methane and ammonia production. Journal of animal science 76(8):21902196.

Legleiter, L., A. Mueller, and M. Kerley. 2005. Level of supplemental protein does not influence the ruminally undegradable protein value. Journal of animal science 83(4):863-870.

Liang, Y. 2013. Applying effective energy concept for intake prediction and balancing ruminal nitrogen and post-ruminal amino acid requirements for beef cattle, University of Missouri--Columbia.

Lindsay, D. 1970. Carbohydrate metabolism in ruminants. Physiology of Digestion and Metabolism in the Ruminant:438-451.

Llamas-Lamas, G., and D. Combs. 1990. Effect of alfalfa maturity on fiber utilization by high producing dairy cows. Journal of dairy science 73(4):1069-1080.

Loerch, S., and F. Fluharty. 1998. Effects of corn processing, dietary roughage level, and timing of roughage inclusion on performance of feedlot steers. Journal of animal science 76(3):681-685.

Maekawa, M., K. Beauchemin, and D. A. Christensen. 2002. Chewing activity, saliva production, and ruminal $\mathrm{pH}$ of primiparous and multiparous lactating dairy cows. Journal of dairy science 85(5):1176-1182.

Marden, J., C. Bayourthe, F. Enjalbert, and R. Moncoulon. 2005. A new device for measuring kinetics of ruminal $\mathrm{pH}$ and redox potential in dairy cattle. Journal of dairy science 88(1):277-281.

Martin, S. A., and D. J. Nisbet. 1992. Effect of direct-fed microbials on rumen microbial fermentation. Journal of Dairy Science 75(6):1736-1744.

McDonald, P., R. Edwards, J. Greenhalgh, C. Morgan, L. Sinclair, and R. Wilkinson. 2010. ANIMAL NUTRITION. Pearson Education.

McDougall, E. 1948. Studies on ruminant saliva. 1. The composition and output of sheep's saliva. Biochemical Journal 43(1):99. 
McLeod, M., and D. Minson. 1988. Breakdown of large particles in forage by simulated digestion and detrition. Journal of animal science 66(4):1000-1004.

Meyer, N., G. E. Erickson, T. J. Klopfenstein, M. A. Greenquist, M. K. Luebbe, P. Williams, and M. Engstrom. 2009. Effect of essential oils, tylosin, and monensin on finishing steer performance, carcass characteristics, liver abscesses, ruminal fermentation, and digestibility. Journal of animal science 87(7):2346-2354.

Miller, T. 1994. Ecology of methane production and hydrogen sinks in the rumen. In: Proceedings of the Society of Nutrition Physiology (Germany)

Minton, N. O. 2015. Methods to improve growth efficiency in beef cattle, University of Missouri, Columbia.

Miron, J., D. Ben-Ghedalia, and M. Morrison. 2001. Invited review: adhesion mechanisms of rumen cellulolytic bacteria. Journal of Dairy Science 84(6):12941309.

Moe, P., and H. Tyrrell. 1979. Methane production in dairy cows. Journal of Dairy Science 62(10):1583-1586.

Moss, A. R., D. Givens, and P. Garnsworthy. 1994. The effect of alkali treatment of cereal straws on digestibility and methane production by sheep. Animal Feed Science and Technology 49(3):245-259.

Moss, A. R., J.-P. Jouany, and J. Newbold. 2000. Methane production by ruminants: its contribution to global warming. In: Annales de zootechnie. p 231-253.

Mould, F., R. Morgan, K. Kliem, and E. Krystallidou. 2005. A review and simplification of the in vitro incubation medium. Animal Feed Science and Technology 123:155-172.

Mourino, F., R. Akkarawongsa, and P. Weimer. 2001. Initial pH as a determinant of cellulose digestion rate by mixed ruminal microorganisms in vitro. Journal of Dairy Science 84(4):848-859.

Mueller, A. L. 2004. The ability of empirical equations based on dilution rate to predict microbial efficiency and amino acid flow post ruminally, University of MissouriColumbia.

Nagaraja, T. 2012. A microbiologist's view on improving nutrient utilization in ruminants. In: 23rd Annual Ruminant Nutrition Symposium. p 149175.

Nasrawi, C. W., and R. M. Pangborn. 1990. Temporal gustatory and salivary responses to capsaicin upon repeated stimulation. Physiology \& behavior 47(4):611-615.

National Academies of Sciences, E., and Medicine. 2016. Nutrient Requirements of Beef Cattle: Eighth Revised Edition. The National Academies Press, Washington, DC. 
Nisbet, D., and S. Martin. 1991. Effect of a Saccharomyces cerevisiae culture on lactate utilization by the ruminal bacterium Selenomonas ruminantium. Journal of animal science 69(11):4628-4633.

Nocek, J., and W. Kautz. 2006. Direct-fed microbial supplementation on ruminal digestion, health, and performance of pre-and postpartum dairy cattle. Journal of dairy science 89(1):260-266.

Nocek, J., W. Kautz, J. Leedle, and J. Allman. 2002. Ruminal supplementation of directfed microbials on diurnal $\mathrm{pH}$ variation and in situ digestion in dairy cattle. Journal of dairy science $85(2): 429-433$.

NRC. 2000. Nutrient Requirements of Beef Cattle: Seventh Revised Edition: Update 2000. The National Academies Press.

NRC. 2012. Nutrient requirements of swine. National Academies Press.

Oetzel, G., K. Emery, W. Kautz, and J. Nocek. 2007. Direct-fed microbial supplementation and health and performance of pre-and postpartum dairy cattle: A field trial. Journal of dairy science 90(4):2058-2068.

Offner, A., A. Bach, and D. Sauvant. 2003. Quantitative review of in situ starch degradation in the rumen. Animal Feed Science and Technology 106(1):81-93.

Oh, J., A. Hristov, C. Lee, T. Cassidy, K. Heyler, G. Varga, J. Pate, S. Walusimbi, E. Brzezicka, and K. Toyokawa. 2013. Immune and production responses of dairy cows to postruminal supplementation with phytonutrients. Journal of dairy science 96(12):7830-7843.

Oh, J., E. Wall, D. Bravo, and A. Hristov. 2017. Host-mediated effects of phytonutrients in ruminants: A review. Journal of Dairy Science

Okoh, O., A. Sadimenko, and A. Afolayan. 2010. Comparative evaluation of the antibacterial activities of the essential oils of Rosmarinus officinalis L. obtained by hydrodistillation and solvent free microwave extraction methods. Food chemistry 120(1):308-312.

Owens, F., D. Secrist, W. Hill, and D. Gill. 1998. Acidosis in cattle: a review. Journal of animal science 76(1):275-286.

Pinares-Patiño, C., G. Waghorn, R. Hegarty, and S. Hoskin. 2009. Effects of intensification of pastoral farming on greenhouse gas emissions in New Zealand. New Zealand veterinary journal 57(5):252-261.

Pinares-Patiño, C., G. Waghorn, A. Machmüller, B. Vlaming, G. Molano, A. Cavanagh, and H. Clark. 2007. Methane emissions and digestive physiology of non-lactating dairy cows fed pasture forage. Canadian Journal of Animal Science 87(4):601613. 
Piveteau, P. 1999. Metabolism of lactate and sugars by dairy propionibacteria: a review. Le Lait 79(1):23-41.

Raun, N. S., and W. Burroughs. 1962. Suction strainer technique in obtaining rumen fluid samples from intact lambs. Journal of animal science 21(3):454-457.

Reinhardt, C., R. Brandt, K. Behnke, A. Freeman, and T. Eck. 1997. Effect of steamflaked sorghum grain density on performance, mill production rate, and subacute acidosis in feedlot steers. Journal of animal science 75(11):2852-2857.

Ruckebusch, Y. 1988. Motility of the gastro-intestinal tract, The Ruminant Animal: Digestive Physiology and Nutrition. Prentice-Hall, Englewood Cliffs, NJ. p. 64107.

Russell, J. 2002. Rumen microbiology and its role in rumen nutrition. Russell, Ithaca, New York.

Russell, J., R. Onodera, and T. Hino. 1991. Ruminal protein fermentation: new perspectives on previous contradictions. In: Y. S. a. R. K. T. Tsuda, editor, Physiological Aspects of Digestion and Metabolism in Ruminants. Academic Press, San Diego. p. 681-697.

Russell, J., and R. Wallace. 1997. Energy-yielding and energy-consuming reactions, The rumen microbial ecosystem. Springer. p. 246-282.

Russell, J. B., and H. Strobel. 1989. Effect of ionophores on ruminal fermentation. Applied and environmental microbiology 55(1):1.

Salanitro, J., and P. Muirhead. 1975. Quantitative method for the gas chromatographic analysis of short-chain monocarboxylic and dicarboxylic acids in fermentation media. Applied microbiology 29(3):374-381.

Samuelson, K., M. Hubbert, M. Galyean, and C. Löest. 2016. Nutritional recommendations of feedlot consulting nutritionists: The 2015 New Mexico State and Texas Tech University survey. Journal of animal science 94(6):2648-2663.

Sniffen, C., J. O'connor, P. Van Soest, D. Fox, and J. Russell. 1992. A net carbohydrate and protein system for evaluating cattle diets: II. Carbohydrate and protein availability. Journal of animal science 70(11):3562-3577.

Stefanon, B., A. Pell, and P. Schofield. 1996. Effect of maturity on digestion kinetics of water-soluble and water-insoluble fractions of alfalfa and brome hay. Journal of animal science 74(5):1104-1115.

Stock, R. 2000. Acidosis in cattle: an overview. Acidosis in cattle: an overview.:30-37.

Sutherland, T. 1987. Particle separation in the forestomachs of sheep, Aspects of Digestive Physiology in Ruminants. Cornell University Press. p. 63-73. 
Sutton, J. 1979. Carbohydrate fermentation in the rumen-variations on a theme. Proceedings of the Nutrition Society 38(03):275-281.

Sutton, J., M. Dhanoa, S. Morant, J. France, D. Napper, and E. Schuller. 2003. Rates of production of acetate, propionate, and butyrate in the rumen of lactating dairy cows given normal and low-roughage diets. Journal of dairy science 86(11):36203633 .

Tedeschi, L. O., T. R. Callaway, J. P. Muir, and R. C. Anderson. 2011. Potential environmental benefits of feed additives and other strategies for ruminant production. Revista Brasileira de Zootecnia 40:291-309.

Traxler, M., D. Fox, T. Perry, R. Dickerson, and D. Williams. 1995. Influence of roughage and grain processing in high-concentrate diets on the performance of long-fed Holstein steers. Journal of animal science 73(7):1888-1900.

Turgeon, O., J. Szasz, W. Koers, M. Davis, and K. Vander Pol. 2010. Manipulating grain processing method and roughage level to improve feed efficiency in feedlot cattle. Journal of animal science 88(1):284-295.

Ultee, A., M. Bennik, and R. Moezelaar. 2002. The phenolic hydroxyl group of carvacrol is essential for action against the food-borne pathogen Bacillus cereus. Applied and environmental microbiology 68(4):1561-1568.

Ushida, K., and J. Jouany. 1996. Methane production associated with rumen-ciliated protozoa and its effect on protozoan activity. Letters in Applied Microbiology 23(2):129-132.

Van Kessel, J. A. S., and J. B. Russell. 1996. The effect of $\mathrm{pH}$ on ruminal methanogenesis. FEMS Microbiology Ecology 20(4):205-210.

Van Nevel, C., and D. Demeyer. 1996. Control of rumen methanogenesis. Environmental Monitoring and assessment 42(1-2):73-97.

Van Soest, P. J. 1994. Nutritional ecology of the ruminant. Cornell University Press.

Vennekens, R., J. Vriens, and B. Nilius. 2008. Herbal compounds and toxins modulating TRP channels. Current neuropharmacology 6(1):79-96.

Vieira, R. A. M., L. O. Tedeschi, and A. Cannas. 2008. A generalized compartmental model to estimate the fibre mass in the ruminoreticulum: 2 . Integrating digestion and passage. Journal of Theoretical Biology 255(4):357-368.

Wallace, R. J., N. R. McEwan, F. M. McIntosh, B. Teferedegne, and C. J. Newbold. 2002. Natural products as manipulators of rumen fermentation. Asian Australasian Journal of Animal Sciences 15(10):1458-1468. 
Welch, J. 1982. Rumination, particle size and passage from the rumen. Journal of animal science 54(4):885-894.

Wolin, M. 1975. Interactions between the bacterial species of the rumen. Digestion and Metabolism in the Ruminant:134-148.

Yarns, D., P. Putnam, and E. Leffel. 1965. Daily salivary secretion by beef steers. Journal of animal science 24(1):173-176.

Zeng, Z., S. Zhang, H. Wang, and X. Piao. 2015. Essential oil and aromatic plants as feed additives in non-ruminant nutrition: a review. Journal of animal science and biotechnology 6(1):7.

Zinn, R., and F. Owens. 1993. Ruminal escape protein for lightweight feedlot calves. Journal of animal science 71(7):1677-1687.

Zinn, R., F. Owens, and R. Ware. 2002. Flaking corn: processing mechanics, quality standards, and impacts on energy availability and performance of feedlot cattle. Journal of animal science 80(5):1145-1156. 


\section{VITA}

Mariana M. Masiero was born in São José dos Campos, SP, Brazil and grew up in Jacareí, SP. She is the daughter of Paulo José Masiero and Tânia Mara M. Masiero. She has one sister, Ana Paula M. Masiero and one brother, Matheus M. Masiero.

Mariana earned her Bachelor's degree in Animal Sciences at Universidade de São Paulo, Pirassununga, SP, Brazil in September of 2010. During her Bachelor's program, she became interested in ruminant nutrition. In January of 2012, she was accepted as a Master student under the supervision of Dr. Monty S. Kerley at the University of Missouri, Columbia, USA, earning the Master of Science degree in Animal Science in December of 2014. She continued working under Dr. Monty S. Kerley supervision during her Ph.D. Mariana defended her dissertation in December of 2017, and was awarded her Ph.D. in Animal Sciences with emphasis in Ruminant Nutrition. 